SANDIA REPORT

SAND98-0319 • UC-906

Unlimited Release

Printed February 1998

\title{
Nondestructive Inspection Assessment of Eddy Current and Electrochemical Analysis to Separate Inconel and Stainless Steel Alloys
}

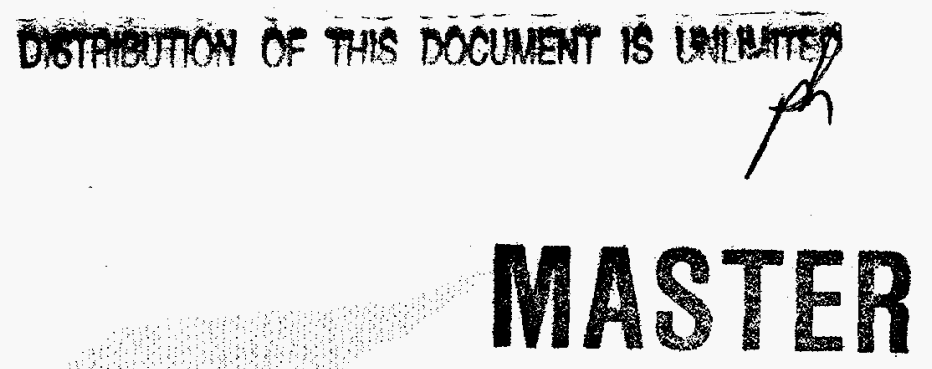

David G. Moore, N. Rob Sorensen

Prepared by

Sandia National Laboratories

Albuquerque, New Mexico 87185 and Livermore, California 94550

Sandia is a multiprogram laboratory, operated by Sandra corporation, a Lockheed Martin Company, for the United States Bepartment of

Energy under Contract DE-ACO4-94AL85000.

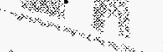

RECEIVED

MAR 091998

Q.

Approved for public release, further dissemination unilnited.

This work was supported by the Federal Aviation Administation Hughes

Technical Center, Atlantic City International Airport, NeW Jersey 08405.

?
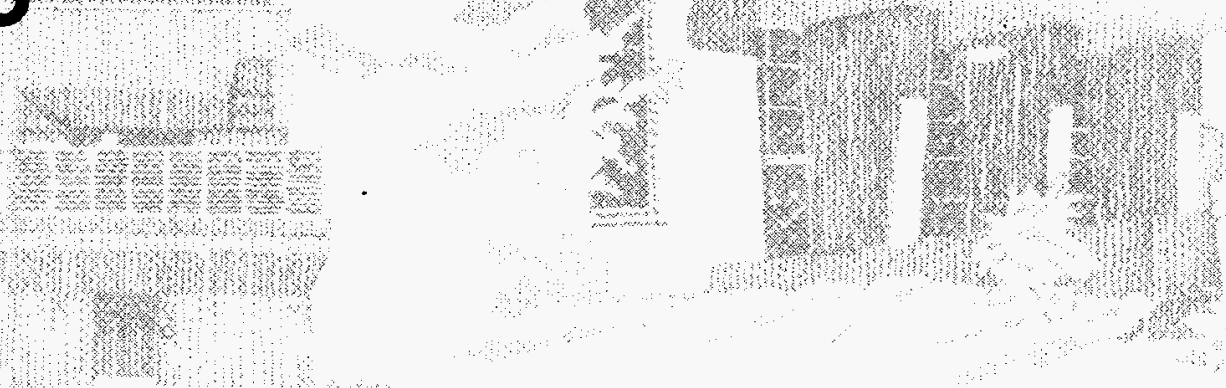
Issued by Sandia National Laboratories, operated for the United States Department of Energy by Sandia Corporation.

NOTICE: This report was prepared as an account of work sponsored by an agency of the United States Government. Neither the United States Government nor any agency thereof, nor any of their employees, nor any of their contractors, subcontractors, or their employees, makes any warranty, express or implied, or assumes any legal liability or responsibility for the accuracy, completeness, or usefulness of any information, apparatus, product, or process disclosed, or represents that its use would not infringe privately owned rights. Reference herein to any specific commercial product, process, or service by trade name, trademark, manufacturer, or otherwise, does not necessarily constitute or imply its endorsement, recommendation, or favoring by the United States Government, any agency thereof, or any of their contractors or subcontractors. The views and opinions expressed herein do not necessarily state or reflect those of the United States Government, any agency thereof, or any of their contractors.

Printed in the United States of America. This report has been reproduced directly from the best available copy.

Available to DOE and DOE contractors from

Office of Scientific and Technical Information

P.O. Box 62

Oak Ridge, TN 37831

Prices available from (615) 576-8401, FTS 626-8401

Available to the public from

National Technical Information Service

U.S. Department of Commerce

5285 Port Royal Rd

Springfield, VA 22161

NTIS price codes

Printed copy: A04

Microfiche copy: A01

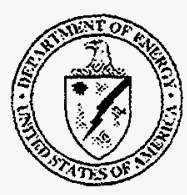




\section{DISCLAIMER}

Portions of this document may be illegible electronic image products. Images are produced from the best available original document. 
SAND98-0319

Distribution

Unlimited Release

Category UC-906

Printed February 1998

\title{
Nondestructive Inspection Assessment of Eddy Current and Electrochemical Analysis to Separate Inconel and Stainless Steel Alloys*
}

\author{
David G. Moore \\ Airworthiness Assurance Department \\ N. Rob Sorensen \\ Mechanical \& Corrosion Metallurgy Department \\ Sandia National Laboratories \\ P. O. Box 5800 \\ Albuquerque, NM 87185-0615
}

\begin{abstract}
This report presents a nondestructive inspection assessment of eddy current and electrochemical analysis to separate inconel alloys from stainless steel alloys as well as an evaluation of cleaning techniques to remove a thermal oxide layer on aircraft exhaust components. The results of this assessment are presented in terms of how effective each technique classifies a known exhaust material. Results indicate that either inspection technique can separate inconel and stainless steel alloys. Based on the experiments conducted, the electrochemical spot test is the optimum for use by airframe and powerplant mechanics. A spot test procedure is proposed for incorporation into the Federal Aviation Administration Advisory Circular 65-9A Airframe \& Powerplant Mechanic - General Handbook.
\end{abstract}

*This work was performed for the Federal Aviation Administration (FAA) Hughes Technical Center under US Department of Transportation Contract DTFA03-95-X-90002. 


\section{Preface}

In August 1991, a center was opened at Sandia National Laboratories by the Federal Aviation Administration Hughes Technical Center under a federal government interagency agreement. The center resides at the Albuquerque International Airport in a hangar leased from the City of Albuquerque, New Mexico. This center, the Airworthiness Assurance Nondestructive Inspection Validation Center (AANC) validates nondestructive inspection (NDI) technology, provides a quick response nondestructive evaluation capability, assesses the reliability of NDI applications and performs other projects to support the FAA and aviation industry. The work described in this report falls under the quick response program. 


\section{Acknowledgments}

Special thanks are due to Jim Gilleeny and Mike Fisher. Mr. Gilleeny is the President of System Scientific Laboratories, Incorporated in Walnut Creek, California. Mr. Gilleeny provided a demonstration electro-deposit spot test kit for the AANC to evaluate. This kit has the capability to distinguish between inconel and stainless steel alloys by detecting the presence of nickel content in the material. Mr Fisher operates and owns the Heliarc Welding Company in Denver, Colorado. Mr. Fisher provided the use of his facility to AANC and supplied several inconel exhaust components for field testing of both the eddy current and spot test inspections. 
Exhaust Samples Used to Evaluate the Eddy Current Conductivity

Inspection and Spot Test Procedure

Cleaning (oxide removal) 5

$\begin{array}{ll}\text { Chemical Cleaning } & 6\end{array}$

$\begin{array}{ll}\text { Mechanical Cleaning } & 8\end{array}$

Electrochemical Spot Test $\quad 10$

Alloy Separation Process (Test Coupons) 10

Alloy Separation Process (Exhaust Components) 14

Development of Eddy Current Procedure $\quad 16$

$\begin{array}{ll}\text { Eddy Current Conductivity Test Set-Up } & 17\end{array}$

Eddy Current Conductivity Inspection Results $\quad 21$

$1 \mathrm{MHz}$ Absolute Shielded Pencil Probe Compared to the Spot Test 21

Sample \#1 Cessna 400 Series Exhaust Component $\quad 21$

Sample \#2 Cessna 400 series Cross Over Pipe 28

Inspection Results Comparing the Spot Test and Eddy Current Instrument With $\mathrm{P} / 500 \mathrm{kHz}-1 \mathrm{MHz} / \mathrm{A}$ Absolute Shielded Pencil Probe 31

$2 \mathrm{MHz}$ absolute Bridge Unshielded Probe Compared to the Spot Test 32

Sample \#1 Cessna 400 Series Exhaust Component 32

Sample \#2 Cessna 400 Series Cross Over Pipe 37

Inspection Results Comparing the Spot Test and Eddy Current Instrument

With SP2000 Absolute Unshielded $2 \mathrm{MHz}$ Probe

Field Survey at Heliarc Welding 
$\begin{array}{lr}\text { Summary of Chemical Cleaning } & 48\end{array}$

$\begin{array}{ll}\text { Summary of Mechanical Cleaning } & 48\end{array}$

$\begin{array}{ll}\text { Summary of Spot Test } & 49\end{array}$

Summary of Eddy Current Conductivity Sorting 49

Comparison Between Spot Test and Eddy Current $\quad 50$

Summary of Field Survey at Heliarc Welding $\quad 50$

$\begin{array}{ll}\text { Conclusions } & 51\end{array}$

$\begin{array}{ll}\text { References } & 52\end{array}$

Appendix AC 65-9A Draft Revision $\quad 53$ 


\section{List of Figures}

Figure 1. Model 421 engine exhaust system components.

Figure 2. Model 400 series engine exhaust system components. Detail 12 is on of the exhaust section obtained for the experiments.

Figure 3. Test Sample \#2 exhaust section abraded with 320 grit aluminum oxide $\left(\mathrm{Al}_{2} \mathrm{O}_{3}\right)$.

Figure 4. Test Sample \#2 exhaust section abraded with 400 grit silicon carbide (SiC).

Figure 5. Test Sample \#2 exhaust section abraded with 600 grit silicon carbide (SiC). Surface appears burnished rather than abraded.

Figure 6. Test Sample \#2 exhaust section abraded with polymer pad (similar to Scotch Bright) designed for cleaning stainless steel surfaces.

Figure 7. Electrochemical spot test kit from Systems Scientific Laboratories, Inc.

Figure 8. Spot test run on stainless steel (a) and Inconel (b) coupons supplied with the test kit. The pink color indicates the presence of $\mathrm{Ni}$ and is used to distinguish between the two classes of metals.

Figure 9. Spot test results from clean, flat plates of stainless steel and Inconel alloys. The plates were purchased from a local steel supplier. The pink color indicates the presence of high $\mathrm{Ni}$ content in the alloys. The brown color indicates the presence of low Ni content in the stainless steel alloys.

Figure 10. Layout of exhaust components showing locations used for analysis. The upper exhaust component shown is Sample \#1 and the lower exhaust component is sample \#2. A third system was also inspected but is not shown in this figure.

Figure 11. Spot test results for selected locations on the test exhaust systems. Results indicated that the components are constructed from stainless steel. The results from an inconel 600 reference plate are included for comparison.

Figure 12. Staveley 19e II Eddy Current Instrument.

Figure 13. Zetec MIZ-22 Eddy Current Instrument.

Figure 14. Nortec $1 \mathrm{MHz}, 0.125$ inch diameter absolute shielded pencil probe (a) and 2 $\mathrm{MHz}, 0.750$ inch diameter absolute unshielded probe (b). 
Figure 15. Material Standards used to obtain conductivity readings.

Figure 16. Conductivity curve for stainless steel and inconel alloys using a $1 \mathrm{MHz}$ absolute shielded 0.125 inch diameter probe.

Figure 17. Conductivity curve for stainless steel and inconel alloys using a standard absolute bridge unshielded $2 \mathrm{MHz} 0.750$ inch diameter probe.

Figure 18. Inspection Site \#1 on Sample \#1 reveals differences between clean surface and thermal oxide. The site was cleaned with polymer abrasive pad. The material is classified as stainless steel with eddy current and the spot test.

Figure 19. Inspection Site \#12 on Sample \#1 was cleaned with polymer abrasive pad. The material is classified as stainless steel with eddy current and the spot test. A conductivity reading was also taken on the welded joint.

Figure 20. Inspection Site \#4 on Sample \#1 reveals differences between clean surface and thermal oxide. The site was cleaned with polymer abrasive pad. The material is classified as stainless steel with the spot test and fell in between stainless steel and inconel with eddy current.

Figure 21. Inspection Site $\# 4$ on Sample \#1 after cleaning with 320 grit aluminum oxide paper. The material is classified as stainless steel with eddy current.

Figure 22. Inspection Site \#7 on Sample \#1 reveals differences between clean surface and thermal oxide. The site was cleaned with polymer abrasive pad. The material is classified as stainless steel with the spot test and inconel with eddy current.

Figure 23. Inspection Site \#7 on Sample \#1 was cleaned with 320 grit aluminum oxide paper. The material is classified as inconel with eddy current.

Figure 24. Inspection Site \#7 on Sample \#1was filed and cleaned with 320 grit aluminum oxide paper. The material is classified as stainless steel with eddy current.

Figure 25. Inspection Site \#2 on Sample \#1 reveals differences between clean surface and thermal oxide. The site was cleaned with 600 grit silicon carbide paper. The material is classified as stainless steel with eddy current and the spot test.

Figure 26. Inspection Site \#3 on Sample \#1 reveals differences between clean surface and thermal oxide. The site was cleaned with 400 grit silicon carbide paper. The material is classified as stainless steel with eddy current and the spot test. 
Figure 27. Inspection Site \#5 on Sample \#1 reveals differences between clean surface and thermal oxide. The site was cleaned with 320 grit aluminum oxide cloth. The material is classified as stainless steel with the spot test and fell in between stainless steel and Inconel with eddy current.

Figure 28. Inspection Site $\# 5$ on Sample \#1 after cleaning with 320 grit aluminum oxide paper. The material is classified as stainless steel with the spot test and eddy current.

Figure 29. Inspection Site \#13 on Sample \#1 was cleaned with 320 grit aluminum oxide cloth. The material is classified as stainless steel with the spot test and eddy current.

Figure 30. Inspection Site \#14 on Sample \#1 was cleaned with 320 grit aluminum oxide paper. The material is classified as stainless steel with eddy current and the spot test.

Figure 31. Inspection Site \#6 on Sample \#1 reveals differences between clean surface and thermal oxide. The site was cleaned with 320 grit aluminum oxide paper. The material is classified as stainless steel with the spot test and inconel with eddy current.

Figure 32. Inspection Site \#6 on Sample \#1 was again cleaned extensively with 320 grit aluminum oxide paper. The material is classified as inconel with eddy current.

Figure 33. Inspection Site \#6 on Sample \#1 was again cleaned with 320 grit aluminum oxide paper. The stainless steel and inconel calibration curves are added to the impedance plane. This site is still classified as inconel with eddy current.

Figure 34. Inspection Site \#6 on Sample \#1 was filed and cleaned with 320 grit aluminum oxide paper. The material is classified as stainless steel with eddy current.

Figure 35. Inspection Site $\# 8$ on Sample $\# 2$ was cleaned with 320 grit aluminum oxide cloth. The material is classified as stainless steel with the spot test and eddy current. This sample has a strong magnetic oxide and could be called as inconel.

Figure 36. Inspection Site \#8 on Sample \#2 was cleaned was extensive cleaned with 320 grit aluminum oxide paper. The material is classified as stainless steel with the spot test and eddy current. 
Figure 37. Inspection Site \#9 on Sample \#2 reveals differences between clean surface and thermal oxide. The site was cleaned with polymer abrasive pad. The material is classified as stainless steel with the spot test and is between stainless steel and inconel with eddy current.

Figure 38. Inspection Site \#9 on Sample \#2 was cleaned with 320 grit aluminum oxide paper. The material is classified as inconel with eddy current.

Figure 39. Inspection Site \#10 on Sample \#2 reveals differences between clean surface and thermal oxide. The site was cleaned with 400 grit silicon carbide paper. The material is classified as stainless steel with the spot test and inconel with eddy current.

Figure 40. Inspection Site \#10 on Sample \#2 was cleaned with 320 grit aluminum oxide paper. The material is classified as inconel with eddy current.

Figure 41. Inspection Site \#11 on Sample \#2 reveals differences between clean surface and thermal oxide. The site was cleaned with 600 grit silicon carbide paper. The material is classified as stainless steel with the spot test and is in between inconel and stainless steel with eddy current.

Figure 42. Inspection Site \#11 on Sample \#2 was cleaned with 320 grit aluminum oxide paper. The material is classified as stainless steel with eddy current.

Figure 43. Inspection Site \#1 on Sample \#1 was cleaned with polymer abrasive pad. The material is classified as stainless steel with eddy current and the spot test.

Figure 44. Inspection Site \#4 on Sample \#1 was cleaned with polymer abrasive pad. The material is classified as stainless steel with eddy current and the spot test.

Figure 45. Inspection Site \#7 on Sample \#1 was cleaned with polymer abrasive pad then 320 grit aluminum oxide paper. The material is classified as stainless steel with eddy current and the spot test. Calibration standards are also present as a reference.

Figure 46. Inspection Site \#12 on Sample \#1 was cleaned with polymer abrasive pad. The material is classified as stainless steel with eddy current and the spot test. Calibration standards are also present as a reference. 
Figure 47. Inspection Site \#2 on Sample \#1 was cleaned with 600 grit silicon carbide paper. The material is classified as stainless steel with eddy current and the spot test.

Figure 48. Inspection Site \#3 on Sample \#1 was cleaned with 400 grit silicon carbide paper. The material is classified as stainless steel with eddy current and the spot test.

Figure 49. Inspection Site \#5 on Sample \#1 was cleaned with 320 grit aluminum oxide cloth then 320 aluminum oxide paper. The material is classified as stainless steel with eddy current and the spot test.

Figure 50. Inspection Site \#13 on Sample \#1 was cleaned with 320 grit aluminum oxide cloth. The material is classified as stainless steel with the spot test and eddy current.

Figure 51. Inspection Site \#14 on Sample \#1 was cleaned with 320 grit aluminum oxide paper. The material is classified as stainless steel with eddy current and the spot test.

Figure 52. Inspection Site \#6 on Sample \#1 was cleaned with 320 grit aluminum oxide paper. The material is classified as stainless steel with eddy current and the spot test.

Figure 53. Inspection Site \#8 on Sample $\# 2$ was cleaned with 320 grit aluminum oxide cloth. The material is classified as stainless steel with the spot test and eddy current. Calibration standards are also present as a reference. This site could be called inconel.

Figure 54. Inspection Site \#8-A on Sample \#2 was not cleaned and the probe was place at various points near the repair. Heat treatment occurred during the weld repair and has changed the material conductivity. Inspection points near the weld should not be considered.

Figure 55. Photo of inspection site \#8 on Sample \#2. As the probe enters the heat affective zone the conductivity moves toward inconel. Site A could be classified as inconel.

Figure 56. Inspection Site \#9 on Sample \#2 was cleaned with polymer abrasive pad the 320 grit aluminum oxide paper. The material is classified as stainless steel with the spot test and eddy current. 
Figure 57. Inspection Site \#10 on Sample \#2 was cleaned with 400 grit silicon carbide paper then with 320 grit aluminum oxide paper. The material is classified as stainless steel with the spot test and eddy current.

Figure 58. Inspection Site \#11 on Sample \#2 was cleaned with 600 Grit silicon carbide paper the 320 grit aluminum paper. The material is classified as stainless steel with the spot test and eddy current. Calibration standards are also present as a reference.

Figure 59. Spot test results on the two clean sample pieces from the kit. The pink color indicates the presence of high nickel content in the inconel and is used to distinguish between the two types of alloys..

Figure 60. Spot test results on a 421 front and aft riser. The pink color indicates the presence of high nickel content in the material. Both eddy current and the spot test classified this sample as inconel.

Figure 61. Spot test results on a sample provided from Heliarc Welding. The brown color indicates the presence of low nickel content in the material. Both eddy current and the spot test classified this sample as stainless steel.

Figure 62. Spot test results on an inconel exhaust component with a stain on the outside of the pipe. The faint pink color indicates a high nickel content in the material. Both eddy current and the spot test classified the sample as inconel.

Figure 63. Spot test results on a nickel coated stainless steel exhaust component. The light brown color (a) indicates the presence of low nickel in the material. Both eddy current and the spot test classified this "clean" location as stainless steel. The pink color (b) and (c) indicates the presence of high nickel content in the material. Both eddy current and the spot test classified these locations as inconel without prior mechanical cleaning. This false call is due to the spot test sampling only on the surface of the part.

Figure 64. Internal exhaust component taken from the pipe which feeds air into the turbo charger. The three locations (A, B, and C) were inspected with eddy current and the spot test.

Figure 65. Displays the eddy current and spot test results on the front surface at position "A".

Figure 66. Displays the eddy current and spot test results on the front surface at position "B". 
Figure 67. Displays the eddy current and spot test results on the front surface at position "C".

Figure 68. Displays the eddy current and spot test results on the back surface at position "A".

Figure 69. Displays the eddy current and spot test results on the back surface at position "B".

Figure 70. Displays the eddy current and spot test results on the back surface at position " $\mathrm{C}$ ". 


\section{List of Tables}

Table 1. ASTM standard cleaning solutions for removing corrosion products from $\mathrm{Ni}$ and $\mathrm{Fe}$ base alloys [1].

Table 2. Pickling schedule for stainless steels [2].

Table 3. Solutions used in chemical etching tests on exhaust piece parts.

Table 4. Mechanical cleaning results using five abrasives.

Table 5. Inspection location and type of mechanical cleaning.

Table 6. Test results for eddy current pencil probe and the spot test.

Table 7. Test results for eddy current $\mathrm{SP} 2000$ probe and the spot test. 
This Page Left Intentionally Blank 


\section{Executive Summary}

The Federal Aviation Administration's (FAA) Airworthiness Assurance NDI Validation Center at Sandia National Laboratories conducted a series of experiments to determine the required steps to appropriately remove a thermal oxide from three sample Cessna exhaust components. Chemical etching techniques similar to those recommended by American Society of Testing Materials (ASTM) for removal of corrosion products were tried and found to be ineffective. Mechanical cleaning with different grit size paper and polymer abrasive pads was also evaluated. The 320 grit aluminum oxide and the abrasive pads were both effective in providing a bare metal surface. After removal of the thermal oxide, both the electrochemical 'spot test' developed by Systems Scientific Laboratories Walnut Creek, California and eddy current technique 'conductivity sorting' were employed on each prepared site to determine if a rapid on-site inspection method could be used to separate stainless steel alloys from inconel alloys.

It was determined that for the spot test, cleaning the surface and removing all the oxide layer was less critical. An eddy current inspection procedure using an absolute unshielded probe is more effective than using a shielded probe. When using an absolute shielded eddy current pencil probe with a probe diameter of 0.125 inches, the thermal oxide produces a magnetic layer which will skew the conductivity curve away from stainless steel and toward inconel resulting in a false call. When using the absolute unshielded 0.750 inch diameter probe the conductivity test results did not vary on sample exhaust sections. Both the spot test and the eddy current procedures are less effective on or near the heat affected areas of weldments. Inspection points near the weld should not be considered.

AANC did not acquire an inconel exhaust system to evaluate in the laboratory setting. However, AANC traveled to Heliarc Welding Service, Denver Colorado to inspect inconel exhaust parts. Both the 'spot test' and eddy current tests were effective in indicating the presence of inconel. Five different exhaust components were provided by Heliarc Welding Service. Both eddy current and the spot test were able to classify the inconel exhaust samples without mechanical cleaning and with heavy stains on the outside surface.

Both eddy current and the spot test could not correctly classify stainless steel exhaust component coated with nickel. Each inspection technique classified the part as inconel. Since eddy current and the spot test rely on the material constituent close to the surface to make a measurement it is required to know the material history. Therefore, it is recommended that all field returns should be properly cleaned prior to conducting a sorting inspection. Only the spot test could inspect a exhaust component that had severe heat treatment on the metal surface if the surface is mechanically sand blasted. The eddy current test could not classify the part due to the magnetic properties on the surface caused from the exhaust temperature heat treating the metal. The magnetic properties on the metal surface skew the conductivity curve away from the stainless steel and inconel conductivity curves thus making it impossible to classify the part. 
Based on the results of these experiments, a spot test procedure for distinguishing between inconel and stainless was written and is appendixed to this report. This spot test procedure should be incorporated into the existing procedure specified in AC 65-9A Airframe \& Powerplant Mechanics - General Handbook. 


\section{Introduction}

The National Transportation Safety Board (NTSB) issued safety recommendations as a result of its investigation of an accident of September 2, 1995, involving a Cessna 421C aircraft. The NTSB recommended the replacement of the acid test currently specified within Advisory Circular 65-9A, Airframe \& Powerplant Mechanics General Handbook, used to distinguish inconel from stainless steel and replace it with a practical and effective test.

\section{Current AC Call-Out to Distinguish Inconel from Stainless Steel}

Stainless steel, a iron based corrosion resistant alloy and inconel, a nickel-chromium-iron alloy, resemble each other in appearance. Because these two alloys look very much alike a definitive test is needed to distinguish between these two alloys. The current method to distinguish inconel from stainless steel requires a solution of 10 grams of cupric chloride in 100 cubic centimeters of hydrochloric acid. A drop of this solution is applied on a sample. At the end of two minutes, the sample is rinsed with water and dried. If the spot on the sample looks like copper in color, the material is classified as stainless steel. Note: the copper in the cupric chloride will deposit on the stainless steel but not on the nickel base inconel. If the spot on the sample looks like the surrounding metal, the material is classified as inconel.

This report documents the work conducted at AANC under the quick response proposal under the current contract between Sandia National Laboratories and the Federal Aviation Administration. It includes experimental results and an assessment from AANC of two technologies. The first technology is eddy current conductivity sorting. The second technology is an electrochemical spot test designed to indicate the presence of nickel provided by Systems Scientific Laboratories.

\section{Exhaust Samples Used to Evaluate the Eddy Current Conductivity Inspection and Spot Test Procedure}

Three test samples acquired were non airworthy parts from an aircraft maintenance facility. The exhaust samples are from a Cessna 400 series aircraft. Each exhaust system exhibits thermal oxide layers on the pipes. Sample \#1 exhaust component attaches to the exhaust manifold. This sample has three inlets. The inlet inside diameter is 1.61 inches. The wall thickness is 0.070 inches, the maximum outside diameter is 3.060 inches and is approximately 25.5 inches long. Sample $\# 2$ is a cross over pipe between the exhaust manifolds. This sample has a wall thickness of 0.055 inches, maximum diameter of 2.35 inches and is approximately 14 inches long. It also has one weld repair near a flange fitting. Sample \#3 also attaches to the exhaust manifold. This sample has a wall thickness of 0.055 inches. The inlet inside diameter is 1.61 inches, the maximum diameter is 2.40 inches and is approximately 21 inches long. None of these test samples are past the aft slip joint. Figures 1 and 2 display the full exhaust systems for Model 421 and 400 series aircraft. 


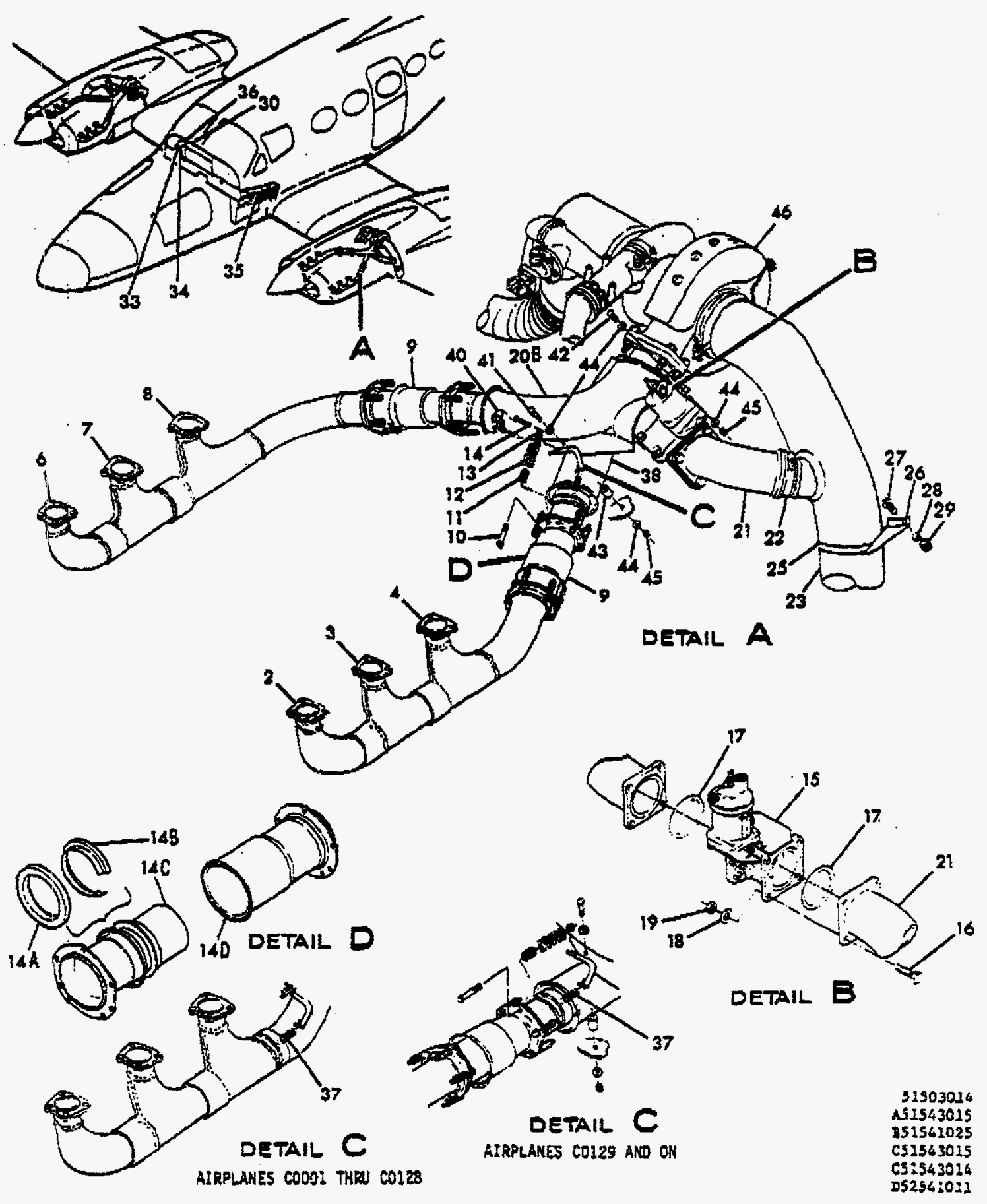

Figure 1. Model 421 engine exhaust system components. 

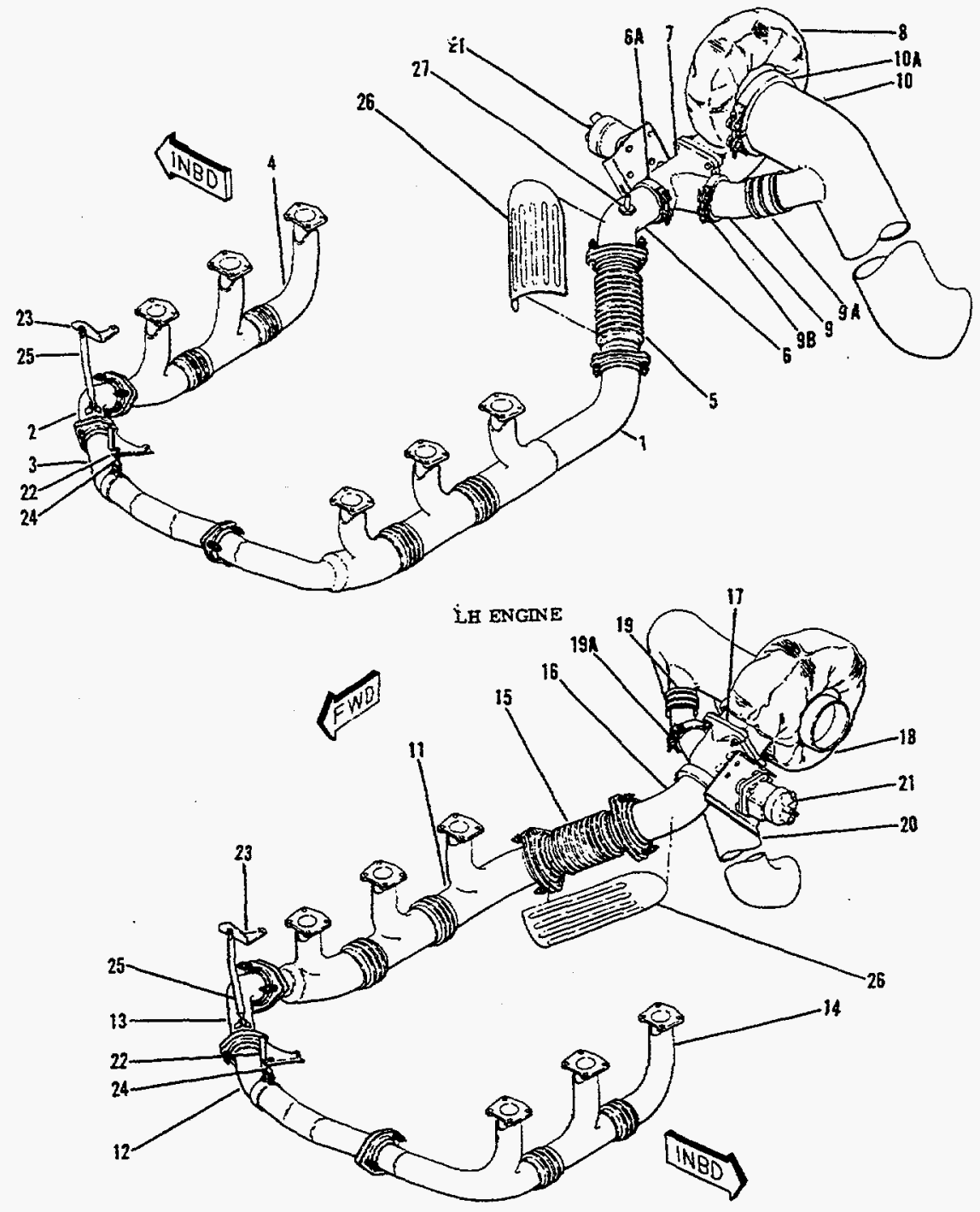

Figure 2. Model 400 series engine exhaust system components. Detail 12 is one of the exhaust sections obtained for the experiments.

\section{Cleaning (oxide removal)}

For maximum effectiveness of both eddy current and chemical spot test procedures, they should be performed on clean, scale free metal surfaces. Thermal oxides form on both inconel and stainless steel due to elevated temperatures experienced by the exhaust system. The oxide is a coherent, continuous film that ranges in color from light blue to brown or black. It is the natural product of the reaction between the metal and oxygen in the air at elevated temperatures. It is much thicker than the air-formed oxide normally present on these alloys. During operation, aircraft exhaust systems are exposed to very high temperatures and become covered with this tenacious high temperature oxide layer. Two processes (chemical and mechanical cleaning) were evaluated to determine their ability to produce a clean bare metal surface. 


\section{Chemical Cleaning}

There are several solutions that are recommended by the ASTM for removal of corrosion products from the surface of metal samples. Solutions used with stainless steel and nickel base alloys are presented in Table 1 . Table 2 presents processes suggested for the pickling of 300 and 400 series stainless steels [1]. Both processes are obviously intended for parts that can be immersed in a series of baths rather than parts to be pickled in-situ. Both tables call for aggressive chemicals, extended contact times and elevated temperatures. Therefore, none of these processes appear to be suitable for field cleaning of exhaust components still connected to the engine. Rather than attempt to use the processes suggested in these two tables, general exposure to hydrochloric, nitric, and sulfuric acids was performed in an attempt to chemically remove the oxide layer from used exhaust sections.

Table 1. ASTM standard cleaning solutions for removing corrosion products from $\mathrm{Ni}$ and $\mathrm{Fe}$ base alloys. [1]

\begin{tabular}{|c|c|c|c|}
\hline \multirow{4}{*}{$\begin{array}{l}\frac{\text { Material }}{\text { Nickel \& Nickel }} \\
\text { Alloys }\end{array}$} & Solution & Time & Temperature \\
\hline & $150 \mathrm{~mL} \mathrm{HCl}$ & 1 to 3 minutes & 20 to $25^{\circ} \mathrm{C}$ \\
\hline & Water to make $1000 \mathrm{~mL}$ & & \\
\hline & $\begin{array}{l}100 \mathrm{~mL} \text { sulfuric acid } \\
\text { Water to make } 1000 \mathrm{~mL}\end{array}$ & 1 to 3 minutes & 20 to $25^{\circ} \mathrm{C}$ \\
\hline \multirow[t]{6}{*}{ Stainless Steels } & $\begin{array}{l}100 \mathrm{~mL} \text { nitric acid } \\
\text { Water to make } 1000 \mathrm{~mL}\end{array}$ & 5 minutes & $60^{\circ} \mathrm{C}$ \\
\hline & $\begin{array}{l}100 \mathrm{~g} \text { citric acid } \\
50 \mathrm{~mL} \text { diammonium citrate } \\
\text { Water to make } 1000 \mathrm{~mL}\end{array}$ & $\begin{array}{l}10 \text { to } 60 \\
\text { minutes }\end{array}$ & $70^{\circ} \mathrm{C}$ \\
\hline & $\begin{array}{l}100 \mathrm{~g} \text { citric acid } \\
50 \mathrm{~mL} \text { sulfuric acid } \\
2 \mathrm{~g} \text { inhibitor } \\
\text { Water to make } 100 \mathrm{~mL}\end{array}$ & 5 minutes & $60^{\circ} \mathrm{C}$ \\
\hline & $\begin{array}{l}200 \mathrm{~g} \mathrm{NaOH} \\
30 \mathrm{~g} \mathrm{KMnO}_{4} \\
\text { Water to make } 1000 \mathrm{~mL} \\
\text { followed by } \\
100 \mathrm{~g} \text { diammonium citrate } \\
\text { Water to make } 1000 \mathrm{~mL}\end{array}$ & 5 minutes & boiling \\
\hline & $\begin{array}{l}100 \mathrm{~mL} \text { nitric acid } \\
20 \mathrm{~mL} \text { hydrofluoric acid } \\
\text { Water to make } 1000 \mathrm{~mL}\end{array}$ & $\begin{array}{l}5 \text { to } 20 \\
\text { minutes }\end{array}$ & 20 to $25^{\circ} \mathrm{C}$ \\
\hline & $\begin{array}{l}200 \mathrm{~g} \text { sodium hydroxide } \\
50 \mathrm{~g} \text { zinc powder } \\
\text { Water to make } 1000 \mathrm{~mL}\end{array}$ & 20 minutes & Boiling \\
\hline
\end{tabular}


Table 2. Pickling schedule for stainless steels [2].

Tuble 3 Sequence of procedures for piekling 300 series
staimless steels

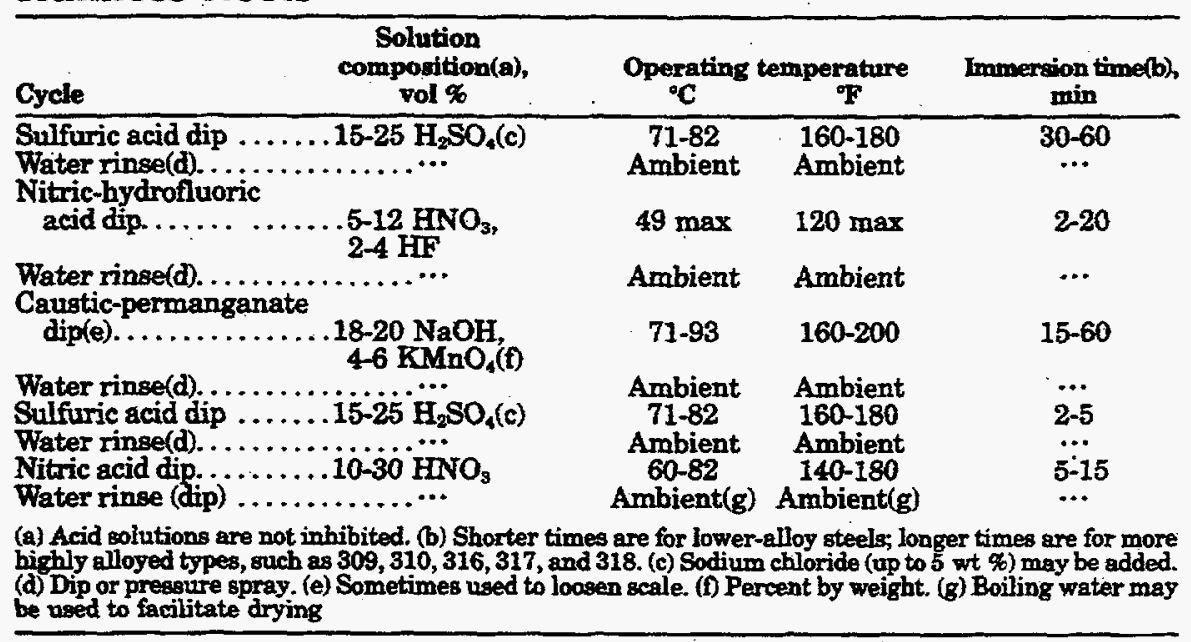

\section{Iuble 4 Sequence for pickling low-earbon 400 series} stainloss stools

\begin{tabular}{|c|c|c|c|}
\hline $\begin{array}{l}\text { Solution } \\
\text { composition(a), } \\
\text { vol } \%\end{array}$ & $\underset{{ }^{\circ} \mathrm{C}}{\text { Operating }}$ & $\begin{array}{l}\text { inperature } \\
\text { of }\end{array}$ & Immersion time \\
\hline $\begin{array}{l}\text { Sulfuric acid dip.......15-25 } \mathrm{H}_{2} \mathrm{SO}_{4}(\mathrm{~b}) \\
\text { Water rinse(c).................... } \\
\text { Caustic permanganate }\end{array}$ & $\begin{array}{c}71-82 \\
\text { Ambient }\end{array}$ & $\begin{array}{l}160-180 \\
\text { Ambient }\end{array}$ & $5-30 \min$ \\
\hline $\begin{array}{r}\text { dip }(d) \ldots \ldots \ldots \ldots \ldots .18-20 \mathrm{NaOH}_{4} \\
4-6 \mathrm{KMnO}_{4}(\mathrm{e})\end{array}$ & $71-93$ & $160-200$ & $20 \mathrm{~min}$ to $8 \mathrm{~h}(\mathrm{f})$ \\
\hline 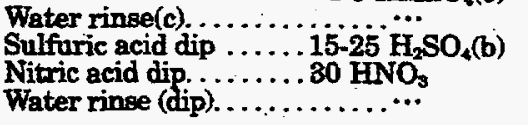 & $\begin{array}{l}\text { Ambient } \\
71-82 \\
\text { Ambient } \\
\text { Ambient(g) }\end{array}$ & $\begin{array}{l}\text { Ambient } \\
160-180 \\
\text { Ambient } \\
\text { Ambient(g) }\end{array}$ & $\begin{array}{c}2-3 \\
10-30 \min \\
\ldots\end{array}$ \\
\hline \multicolumn{4}{|c|}{$\begin{array}{l}\text { (a) Acid solutions are not inhibited. (b) Sodiun chloride (up to } 5 \text { wt } \text { g) may be added. (c) Dip, prossure } \\
\text { hose, or spray. High-preasure spray or jets are more effective for removing scale and smat. (d) Sometime } \\
\text { used to loosen scale. (e) Wt \%. (f) Immersion time may exceed this range. (g) Boiling water may be used } \\
\text { to facilitate drying }\end{array}$} \\
\hline
\end{tabular}

Several acid solutions were used in an attempt to remove the high temperature oxide from the exhaust system parts. The solutions and the results of their application are presented in Table 3. All solutions were applied with a cotton applicator to the metal surface. They were left on the surface for at least 10 minutes. The parts were then rinsed with water and visually examined under a low power microscope. In all instances, the high temperature oxides were essentially impervious to the acid solutions. Several mixtures of acid could be tested in an attempt to remove the oxide. In particular, a pickling agent (hydrofluoric / nitric - $\mathrm{HF} / \mathrm{HNO}_{3}$ ) may have some hope of attacking or removing the oxide, but because of extreme hazards associated with the use of hydrofluoric acid in the field. This test was not conducted. It is apparent that the high temperature oxide is difficult to remove. It is very hard and durable, and is chemically resistant to the range of acids applied in this test. 
Table 3. Solutions used in chemical etching tests on exhaust piece parts

Solution
\begin{tabular}{|l|l|}
\hline $10 \%$ nitric acid $\left(\mathrm{HNO}_{3}\right)$ & No effect \\
\hline $\begin{array}{l}10 \% \text { hydrochloric acid } \\
(\mathrm{HCl})\end{array}$ & No effect \\
\hline $10 \%$ sulfuric acid $\left(\mathrm{H}_{2} \mathrm{SO}_{4}\right)$ & No effect \\
\hline concentrated $\mathrm{HNO}_{3}$ & No effect \\
\hline concentrated $\mathrm{HCl}$ & No effect \\
\hline concentrated $\mathrm{H}_{2} \mathrm{SO}_{4}$ & No effect \\
\hline
\end{tabular}

\section{Mechanical Cleaning}

Because of the lack of response to the cleaning solutions, mechanical means were evaluated to remove the thermal oxide. Five abrasives were tested on the exhaust components. They were aluminum oxide cloth ( 320 grit), silicon carbide paper ( 400 \& 600 grit), aluminum oxide paper ( 320 grit), and a polymer abrasive pad designed specifically for stainless steel cleaning.

In all cases, wet manual abrasion was used. Water was applied while sanding the surface. At frequent intervals, the surface was rinsed and wiped with a paper towel to remove any loose debris. The sanding continued until a significant spot of bare metal was observed. The area was then rinsed a final time, wiped with a paper towel and allowed to dry thoroughly. All of the abrasives were at least partially effective in removing the oxide. During the process, the following points were noted:

- Alumina is readily available as fine as 320 grit. It was not available in 600 grit. It appears that it could be ordered in 500 grit.

- Oxide hardness varies from sample to sample and may be a function of oxide thickness. It is considerably more difficult to get down to bare metal in some cases.

- The aluminum oxide 320 grit cloth did remove the oxide, although significant effort was required. It did not appear to damage the metal, nor did it remove large amounts of material.

- The 400 and 600 silicon carbide grit material essentially burnished the surface. There is some indication that a portion of the oxide was removed, but it is not clear that bare metal was exposed.

- The polymer pad (similar to a Scotch Bright ${ }^{\mathrm{TM}}$ ) was somewhat effective in removing the surface oxide. Significant effort was required to expose bare metal. 
Photographs of the surface following mechanical cleaning are given in Figures 3-6. As can be seen, not all techniques were equally effective in exposing bare metal. In addition, the oxide varies from part to part (probably depending on the maximum temperature and time at temperature), resulting in differences in the amount of effort required to expose bare metal. Based on the results of the visual inspection of the surface after mechanical cleaning, wet sanding with 320 grit aluminum oxide is the most effective method of removing the high temperature oxide without damaging the underlying metal surface. Table 4 summarizes the findings during the mechanical cleaning process.

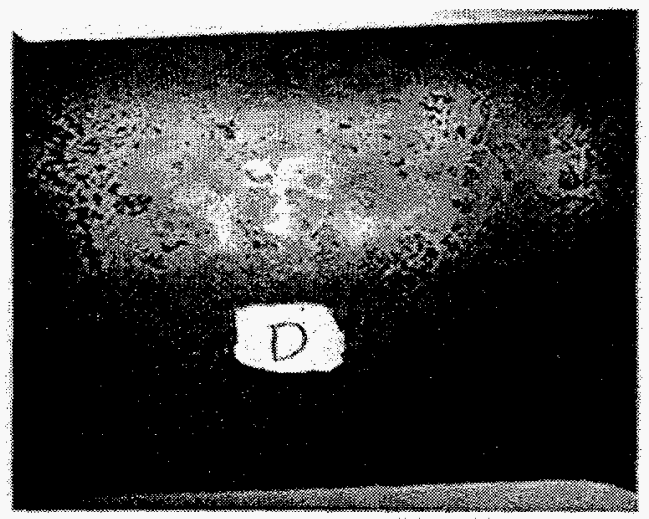

Figure 3. Test Sample \#2 exhaust section abraded with 320 grit aluminum oxide $\left(\mathrm{Al}_{2} \mathrm{O}_{3}\right)$.

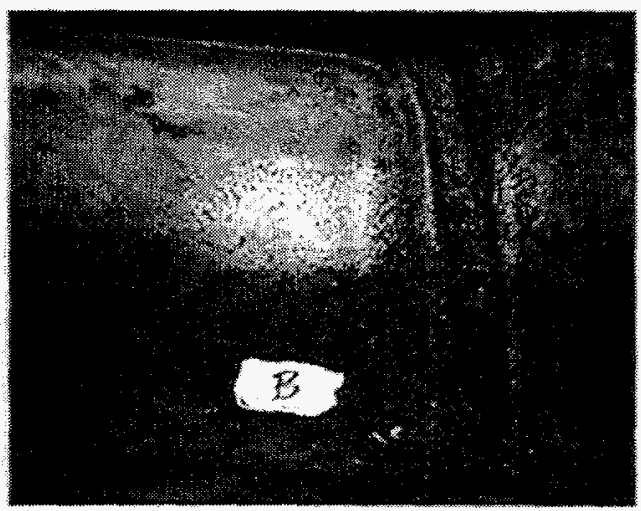

Figure 5. Test Sample \#2 exhaust section abraded with 600 grit silicon carbide (SiC). Surface appears burnished rather than abraded.

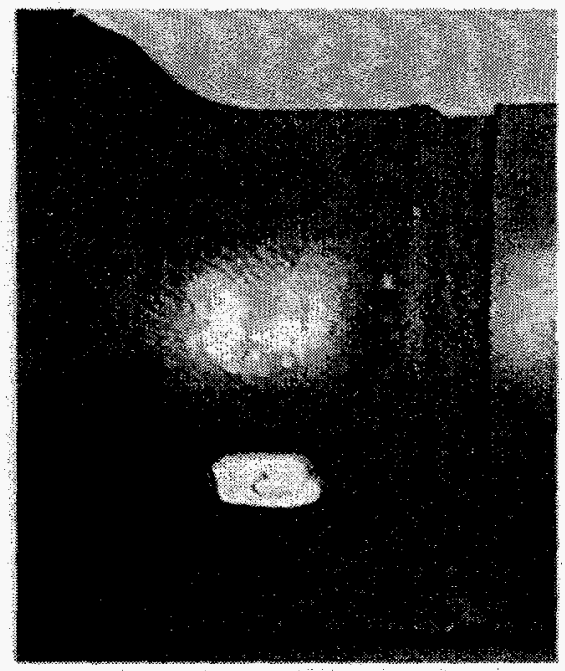

Figure 4. Test Sample \#2 exhaust section abraded with 400 grit silicon carbide $(\mathrm{SiC})$.

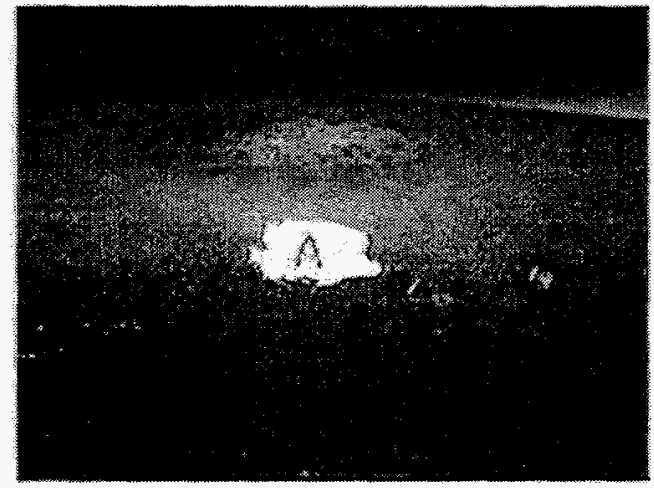

Figure 6. Test Sample \#2 exhaust section abraded with polymer pad (similar to Scotch Bright) designed for cleaning stainless steel surfaces. 
Table 4. Mechanical cleaning results using five abrasives.

\begin{tabular}{|l|l|}
\hline Cleaning Technique & Surface Results \\
\hline Polymer Pad & Removed oxide, requires significant effort \\
\hline 600 Grit Silicon Carbide & Burnished surface, did not remove oxide \\
\hline 400 Grit Silicon Carbide & Burnished surface, did not remove oxide \\
\hline 320 Aluminum Oxide Cloth & Removed oxide, requires significant effort \\
\hline 320 Aluminum Oxide Paper & Removes oxide, requires low effort \\
\hline
\end{tabular}

\section{Electrochemical Spot Test}

A commercially available electrochemical deposit 'spot test' was evaluated to see if it could distinguish between inconel alloys and stainless steels. The spot test was applied on test coupons and sections of three exhaust system components. The test is designed to indicate the presence of nickel (Ni). While nickel is present in stainless steels, the concentration is low enough that a distinction between iron ( $\mathrm{Fe}$ ) base alloys and Ni-base alloys is possible.

The spot test consists of: (1) a battery, (2) an electrical circuit with an alligator clip on one end, an aluminum electrode on the other and a light emitting diode LED connected to the battery, (3) pieces of filter paper, (4) two chemical solutions, and (5) coupons of stainless steel and inconel 718. Figure 7 displays the spot kit with all included items.

\section{Alloy Separation Process (Test Coupons)}

A drop of electrolyte from one bottle is applied to the filter paper. The paper is placed on a material coupon supplied with the kit. The alligator clip is attached to the metal test coupon at a convenient location. The aluminum electrode is placed against the filter paper and pressure is applied to the piece being tested. The LED will glow when proper polarity of the battery is employed and good electrical contact is made with the metal. The circuit is maintained for 30 seconds, during which nickel atoms are electrochemically removed from the metal test coupon and deposited on the filter paper. The filter paper is removed and a drop of developing solution is applied to the paper. A pink color on the filter paper indicates the presence of high nickel content found in inconel alloys. A brownish color on the filter paper indicates the presence of low nickel content found in stainless steel alloys. Results of the spot test on clean metal test coupon supplied with the kit are shown in Figure 8. The two different colors make it is easy to distinguish between stainless steel and inconel alloys. To determine the sensitivity of the spot test, six types of steel alloys and two types of inconel alloys were purchased. The stainless steels alloys were $304,316,410,17-7$ and inconel alloys were 600 and 718 . The spot test was performed on each test sample. Figure 9 displays the test results for the clean flat plates. The brown color indicates the presence of low nickel content found in stainless steel 
alloys. The pink color indicates the presence of high nickel content found in inconel alloys.

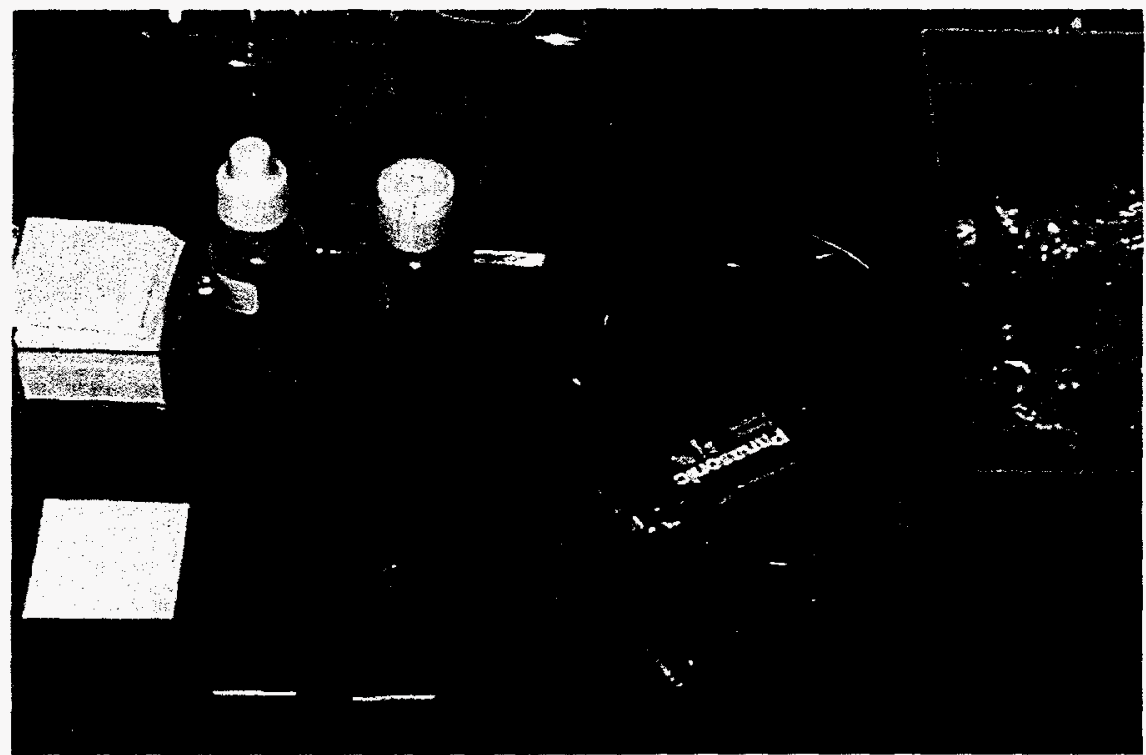

Figure 7. Electrochemical spot test kit from Systems Scientific Laboratories, Inc.

In both figures, the bright pink color is indicative of a $\mathrm{Ni}$-base alloy. The slight pink color that can be seen with the $\mathbf{3 0 0}$ series stainless steel samples is the result of a small ( $8 \%$ chemical composition) amount of $\mathrm{Ni}$ in the alloy. From these results, it demonstrates that the spot test will distinguish between corrosion resistant (CRES) stainless steel and inconel alloys.

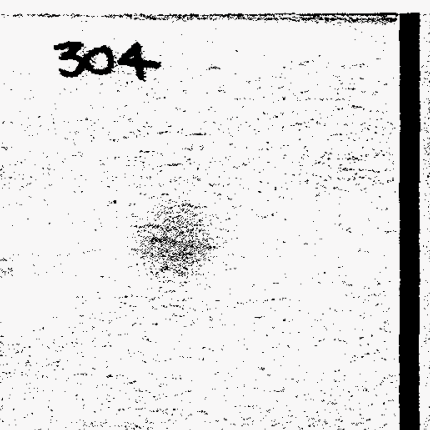

(a)

\section{In 718}

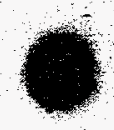

(b)

Figure 8. Spot test run on stainless steel (a) and Inconel (b) coupons supplied with the test kit. The pink color indicates the presence of high $\mathrm{Ni}$ content and is used to distinguish between the two classes of metals. 


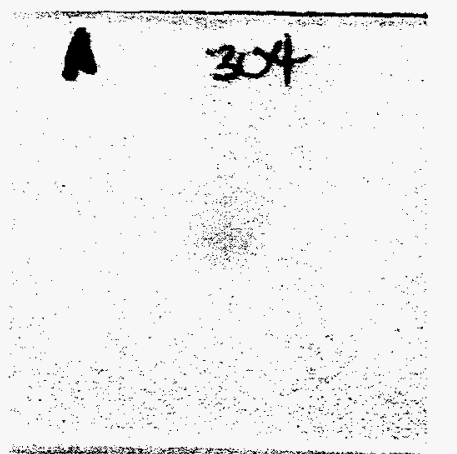

Type 304

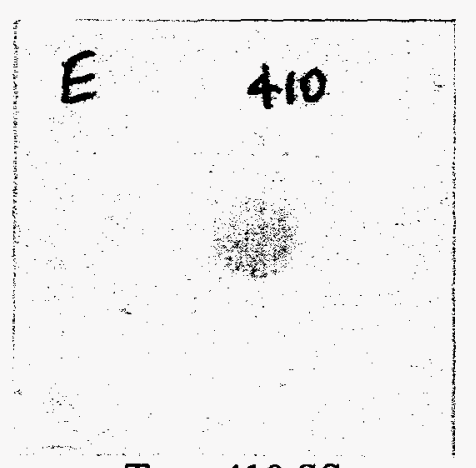

Type 410 SS

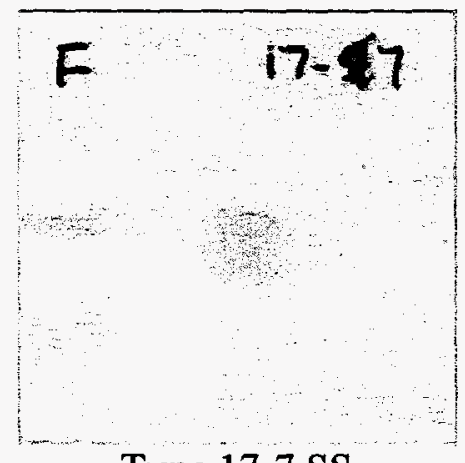

Type 17-7 SS

\section{$316 \quad B$}

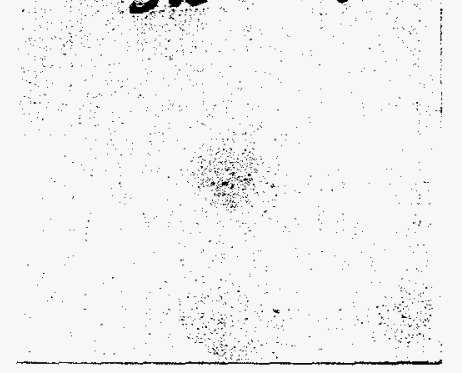

Type 316 SS

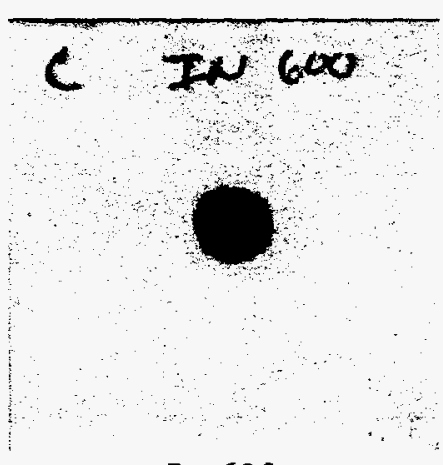

In-600
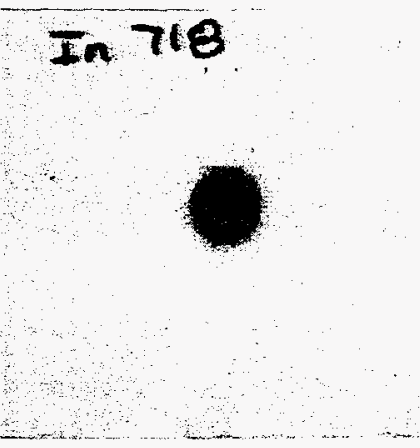

In-718

Figure 9. Spot test results from clean, flat plates of stainless steel and Inconel alloys. The plates were purchased from a local steel supplier. The pink color indicates the presence of high $\mathrm{Ni}$ content in the alloys. The brown color indicates the presence of low Ni content in the stainless steel alloys. 
In addition to the clean flat plates, spot tests were run on sections of the exhaust components. Figure 10 shows the locations that were tested. Each area was mechanically cleaned using one of the abrasives discussed previously and summarized in Table 5. As pointed out earlier, the two abrasives that gave the best results were the 320 grit $\mathrm{Al}_{2} \mathrm{O}_{3}$ and the polymer abrasive pad.

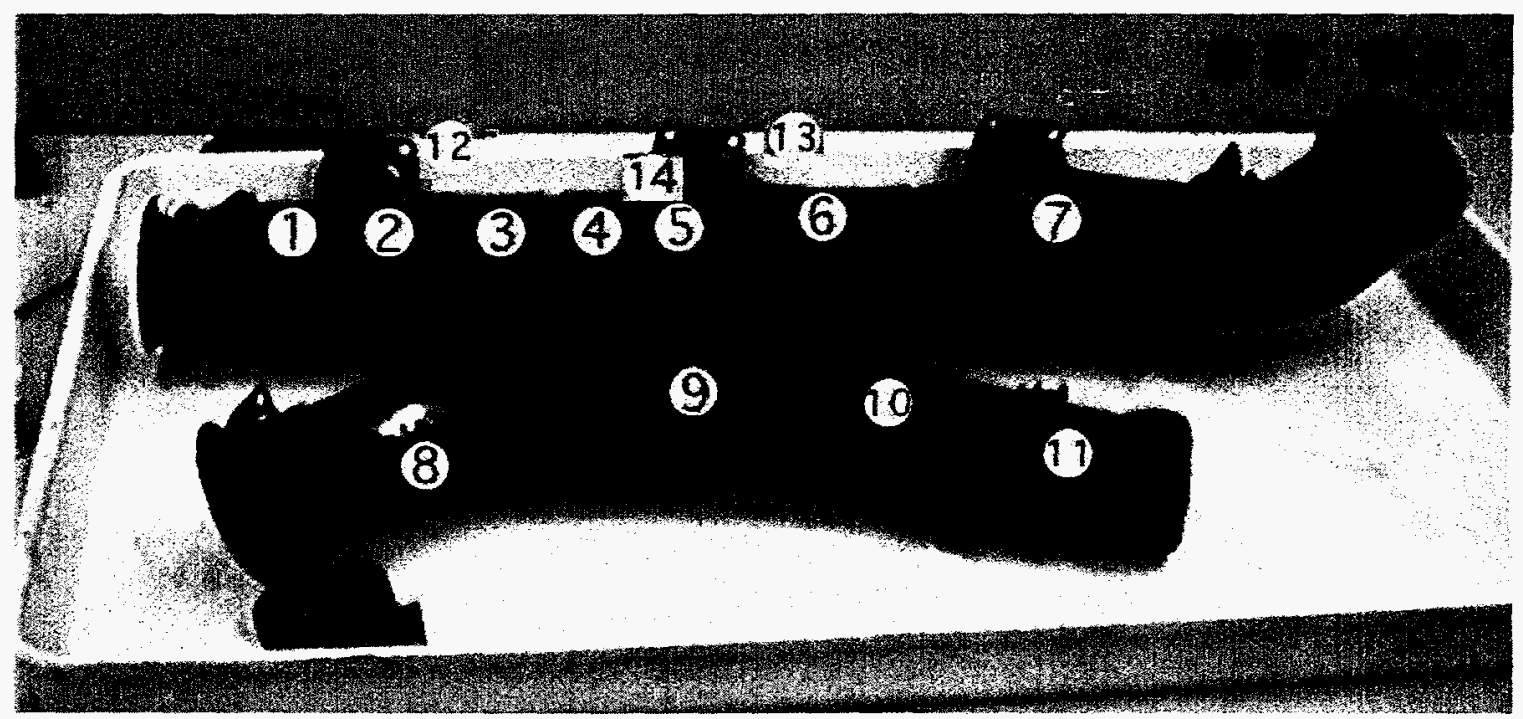

Figure 10. Layout of exhaust components showing locations used for analysis.

The upper exhaust component shown is Sample \#1 and the lower exhaust component is Sample \#2. A third system was also inspected but is not shown in this figure. Location \#8 is near a weld repair.

Table 5. Inspection location and type of mechanical cleaning.

\begin{tabular}{|c|l|}
\hline \multicolumn{1}{|c|}{ Inspection Site } & \multicolumn{1}{|c|}{ Cleaning Technique } \\
\hline 1 & Polymer Pad \\
\hline 2 & 600 Grit Silicon Carbide \\
\hline 3 & 400 Grit Silicon Carbide \\
\hline 4 & Polymer Pad \\
\hline 5 & 320 Aluminum Oxide Cloth \\
\hline 6 & 320 Aluminum Oxide Paper \\
\hline 7 & Polymer Pad \\
\hline 8 & 320 Aluminum Oxide Cloth \\
\hline 9 & Polymer Pad \\
\hline 10 & 400 Grit Silicon Carbide \\
\hline 11 & 600 Grit Silicon Carbide \\
\hline 12 & Polymer Pad \\
\hline 13 & 320 Aluminum Oxide Cloth \\
\hline 14 & 320 Aluminum Oxide Cloth \\
\hline
\end{tabular}




\section{Alloy Separation Process (Exhaust Components)}

A drop of electrolyte from one bottle is applied to the filter paper. The paper is placed on a "clean" area of the exhaust. The alligator clip is attached to the exhaust component at a convenient location. The aluminum electrode is placed against the filter paper and pressure is applied to the part being tested. The LED glows when proper polarity of the battery is employed and good electrical contact is made with the metal. The circuit is maintained for 30 seconds, during which nickel atoms are electrochemically removed from the exhaust component and deposited on the filter paper. The filter paper is removed and a drop of developing solution is applied to the paper. A brown color on the filter paper indicates the presence of low nickel content found in stainless steel alloys. A pink color on the filter paper indicates the presence of high nickel content found in inconel alloys.

All of the spot tests results conducted on the three exhaust components indicated Fe-base stainless steels. There was no indication of inconel material being used in any of the three exhaust component sections. There were slight differences in the results depending on the location and the amount of oxide removed. The spot technique definitely performs better when the oxide is removed to expose bare metal. Results of some of the spot tests are presented in Figure 11. In all cases, the spot test produced a yellow/brown/red spot. As a comparison, the In-600 results are included. Note the bright pink color associated with the Ni-base alloy. Location 11, which was cleaned with 600 grit SiC paper shows very little indication of electrochemical reaction. This is most likely because the oxide was not removed by the action of the 600 grit paper. To test this hypothesis, a test was run on the intact oxide near location 10. These results are also included in Figure 11, and indicate that very little material removal has occurred, even though a good electrical contact was established (the LED glowed brightly). This supports the requirement that the oxide be removed prior to running the spot test. According to the spot test results, all of the sections of all three exhaust components examined were constructed of stainless steel. 


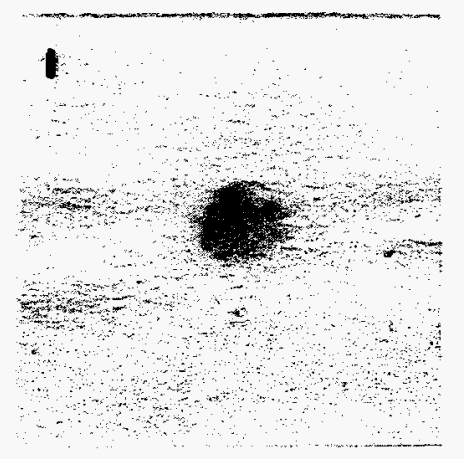

Location 1

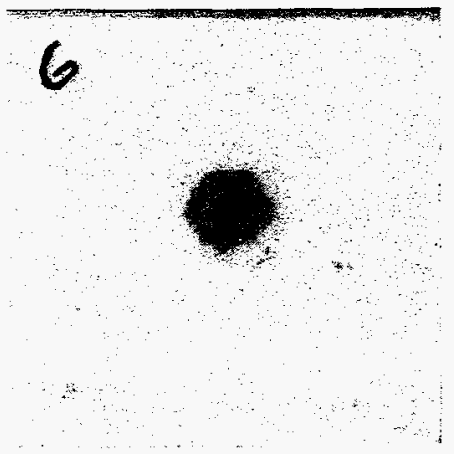

Location 6

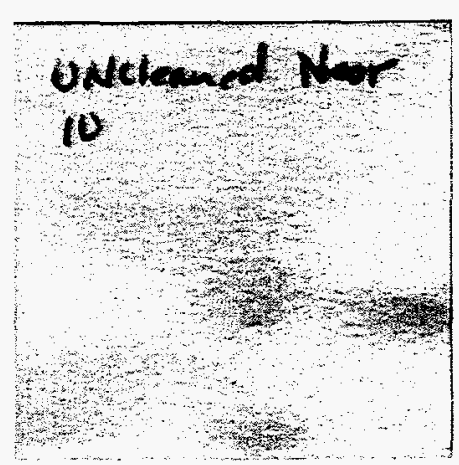

Near location 10 (no mechanical cleaning)

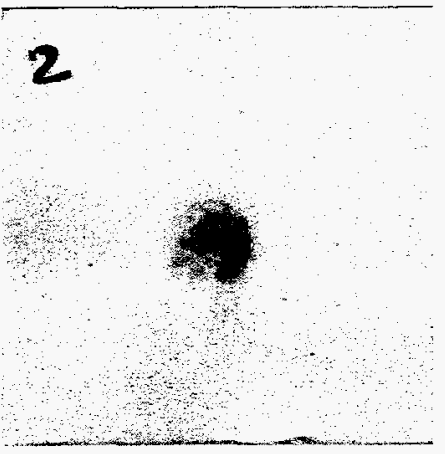

Location 2

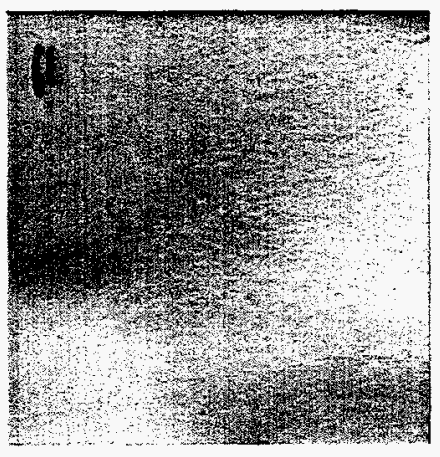

Location 11

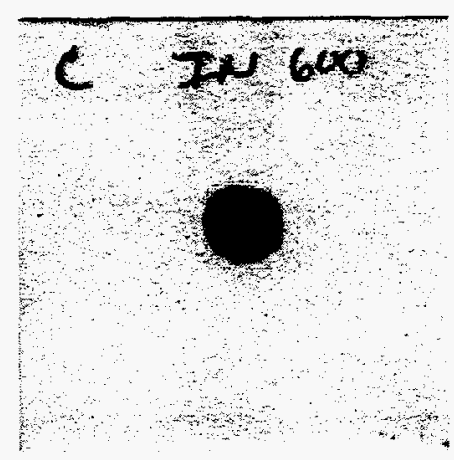

In-600 reference plate

Figure 11. Spot test results for selected locations on the test exhaust systems. Results indicated that the components are constructed from stainless steel. The results from an inconel 600 reference plate are included for comparison. 


\section{Development of Eddy Current Procedure}

AANC developed an eddy current procedure for rapid on-site field analysis to distinguish between Inconel and Stainless Steels. Eddy current has the capability to directly measure conductivity of materials in International Annealed Copper Standard (IACS) read-out or a conductivity curve on an impedance plane instrument. Most digital conductivity meters are limited in frequency selection. Three common operating frequencies for measuring conductivity are 60,120 , and $240 \mathrm{kHz}$. For most conductivity readings this frequency range is acceptable however, to inspect thin tubular parts higher operating frequencies are required. Since the conductivity difference between stainless steel (2.4\% IACS) and Inconel $600(1.7 \%$ IACS $)$ is small the phase difference between the two alloys make if difficult to distinguished between the alloys.

To better understand the conductivity sorting using eddy current the major factors which affect conductivity measurements and its accuracy are described below. Following is a partial list of things that can affect measurements:

- Effects of Heat Treatment and Mechanical Stress

The conductivity of the exhaust pipe is influenced by the heat treatment of the hot exhaust gases. Mechanical stresses introduced in the metal during initial fabrication process also influences the material conductivity.

- Effects of Curved Exhaust Surfaces

Conductivity readings will be altered if a probe is placed to close to an edge of a part surface or severely curved surfaces.

- Effect of Material Thickness

Material thickness will affect test results when the depth of eddy current penetration is greater than the material thickness. The depth of penetration $\delta$ is calculated from MIL-STD 15377 equation [2] :

$$
\delta=\frac{26}{\sqrt{f \sigma \mu}} \text { where: } \quad \begin{aligned}
\delta & =\text { depth of penetration in inches } \\
\mu & =1.0 \\
f & =\text { frequency in Hertz } \\
\sigma & =\text { conductivity in \% IACS }
\end{aligned}
$$

For a probe operating at $1 \mathrm{MHz}$ frequency the depth of penetration for inconel 600 is $0.020^{\prime \prime}$ and stainless steel 304 is $0.017^{\prime \prime}$. 
- Effects of Conductive Coatings (Oxide Layer)

Variation in conductivity will be observed in low iron content stainless steels if the surface exhibits conductive oxide layer.

- Effect of Test Material Temperature on Conductivity Measurements

Temperature of the exhaust pipe and the reference standards must be similar to obtain the best conductivity reading. The influence of temperature on the resistivity of a metal is well documented. Note: If the temperature is increased resistivity increases and conductivity decreases from their ambient temperature values.

- Operating Frequency of Eddy Current for Conductivity Tests

At low frequencies $(100 \mathrm{kHz})$ the separation angle between lift off and stainless steel is quite small. Therefore, it is difficult to obtain lift off suppression. By selecting a higher frequency $(1 \mathrm{MHz})$ the separation angle for stainless steel is quite large and allows lift-off suppression and good sensitivity to conductivity differences between stainless steel and inconel.

\section{Eddy Current Conductivity Test Set-Up}

The eddy current instruments used for this study were a Staveley Nortec $19 \mathrm{e}$ eII and Zetec MIZ-22. Figures 12 and 13 are photographs of the eddy current systems. The probes selected for this conductivity evaluation are Nortec $\mathrm{P} / 500 \mathrm{kHz}-1 \mathrm{MHz} / \mathrm{A}$, absolute shielded 0.125 inch diameter and a Nortec SP2000, absolute unshielded $2 \mathrm{MHz} 0.750$ inch diameter. Figure 14 are photographs of the eddy current probes used during the evaluation. The inspection frequency used for the absolute shielded probe is set at $1 \mathrm{MHz}$ for the $19 \mathrm{e}-\mathrm{II}$ instrument and $900 \mathrm{kHz}$ for the MIZ-22 instrument. The inspection frequency for the SP2000 probe is $2 \mathrm{MHz}$ with the $19 \mathrm{e}-\mathrm{II}$ instrument.

The standards used to create the conductivity curve on the eddy current instruments were purchased stainless steel and inconel 11 gage sheet stock. Note: 17-4PH was not available from the supplier at 0.125 inch thickness. The inconel alloys procured were 600 and 718. Standards traceable to National Institute of Standards \& Technology are available from suppliers at the cost of $\$ 225$ each. Figure 15 displays the reference standards used for the instrument set-up. 
The instrument is balanced in air (conductivity $=0$ ) and then the probe is placed on each standard. The instrument's phase angle and gain were adjusted to present the conductivity data on the screen. Figure 16 displays the conductivity curve for stainless steel and inconel alloys using the $1 \mathrm{MHz}$ absolute shielded 0.125 inch diameter probe. Figure 17 displays the conductivity curve for stainless steel and inconel alloys using the absolute bridge unshielded $2 \mathrm{MHz} 0.750$ inch diameter probe.

The fourteen inspection sites on the exhaust components were then inspected by placing the probe on the surface. A conductivity curve for each site was recorded. If the site had oxide layer present in the inspection area the probe was lifted off the initial site and placed on the oxide layer surface. Any variation in the metal surface and if this condition affected conductivity was documented. 


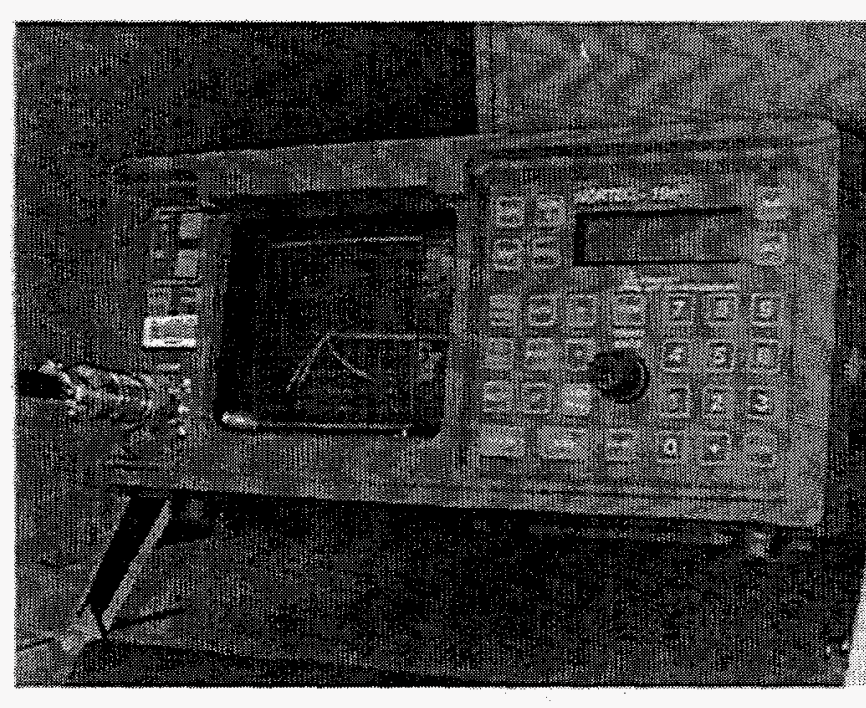

Figure 12. Staveley 19 e II eddy current instrument.

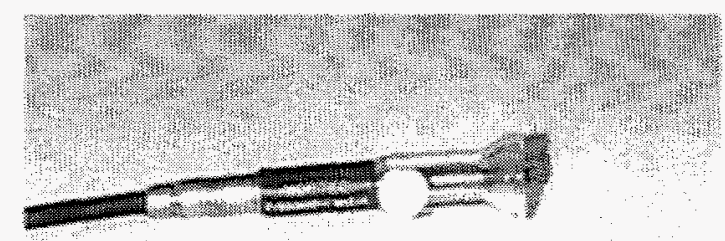

(a)

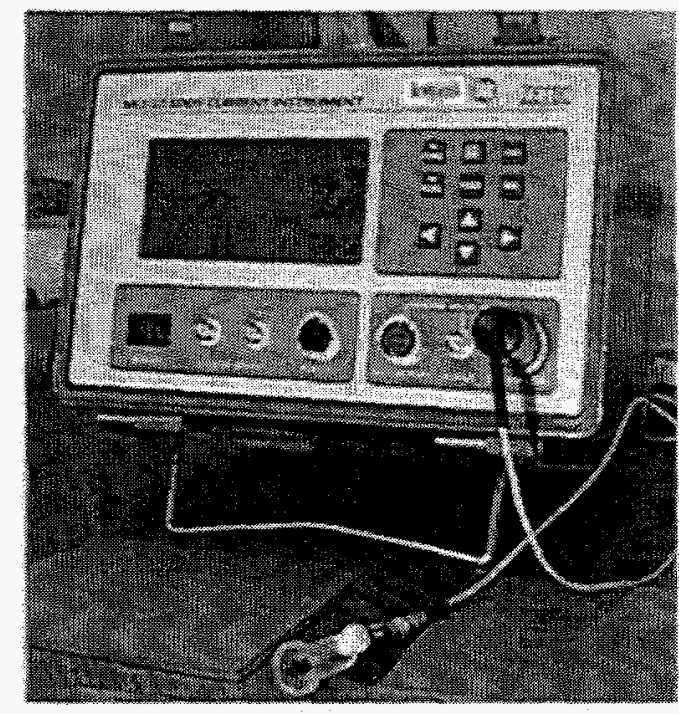

Figure 13. Zetec MIZ-22 eddy current instrument

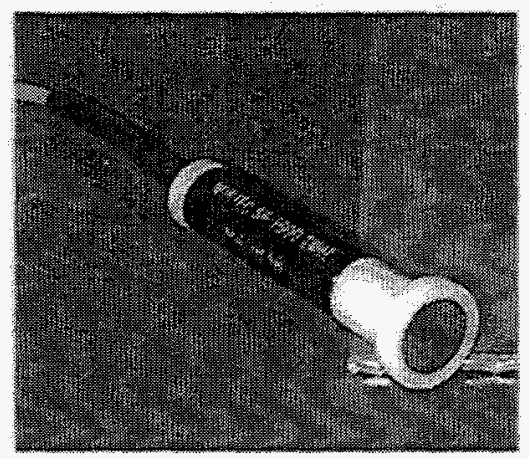

(b)

Figure 14. Nortec $1 \mathrm{MHz}, 0.125$ inch diameter absolute shielded pencil probe (a) and $2 \mathrm{MHz}, 0.750$ inch diameter absolute unshielded probe (b).

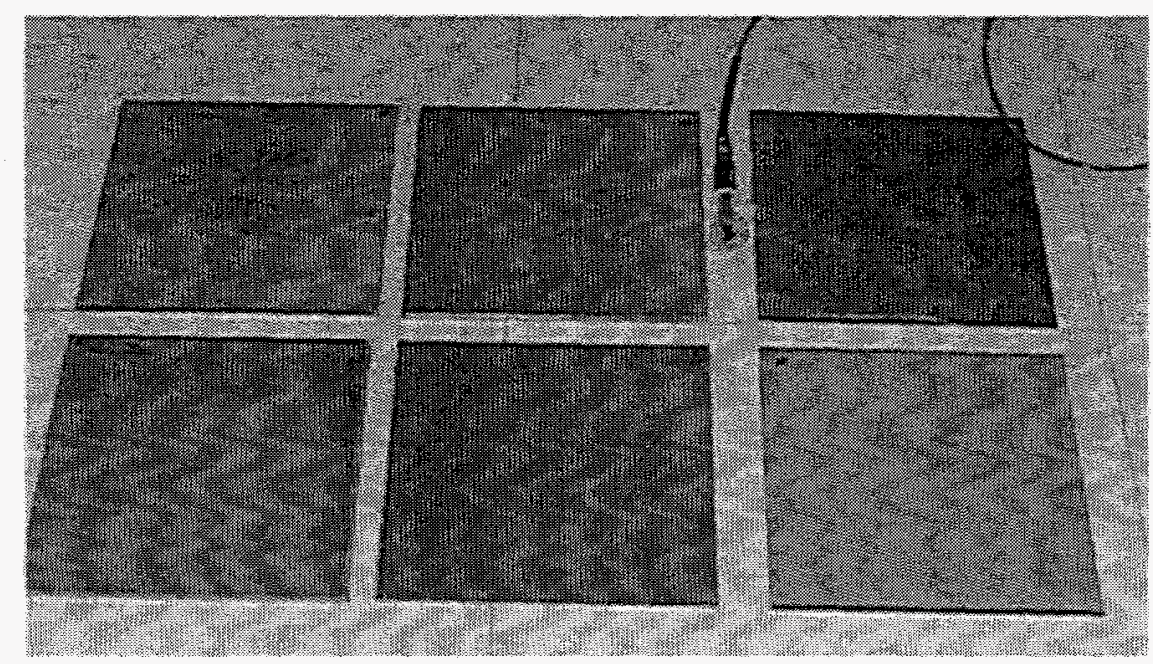

Figure 15. Material standards used to obtain conductivity readings. 


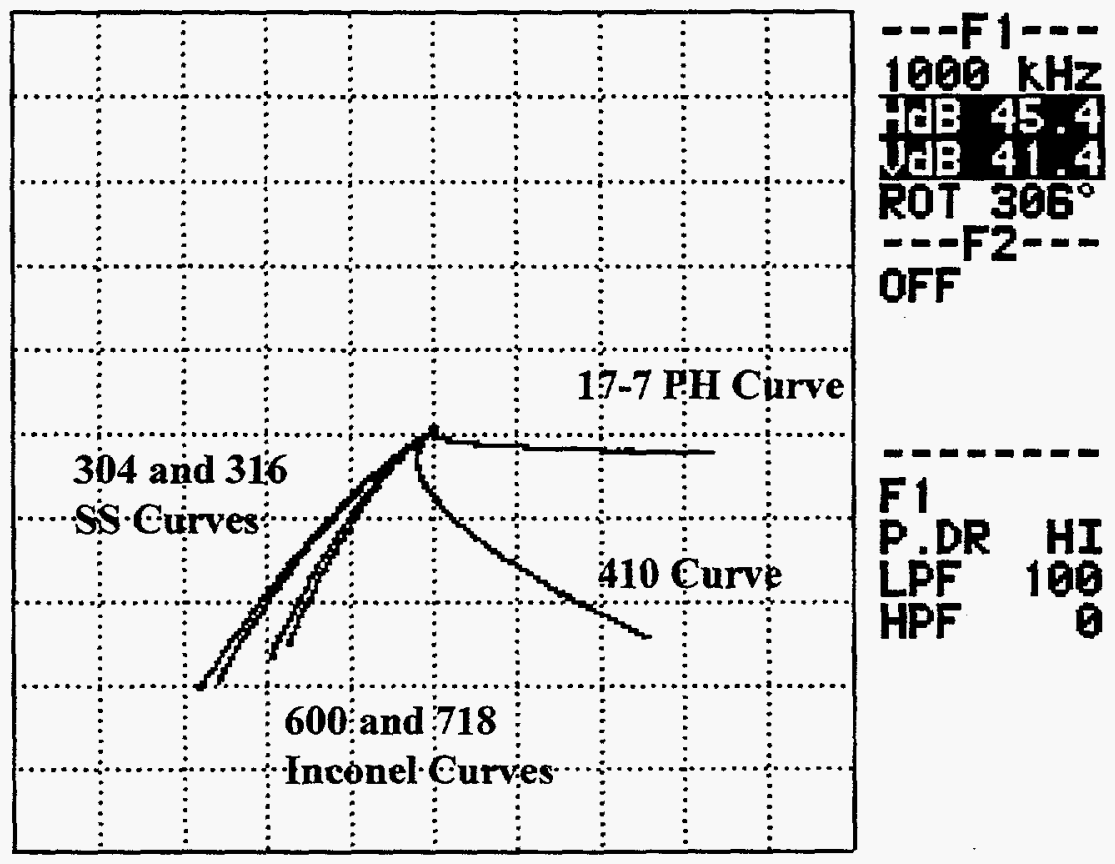

Figure 16. Conductivity curve for stainless steel and inconel alloys using a $1 \mathrm{MHz}$ absolute shielded 0.125 inch diameter probe.

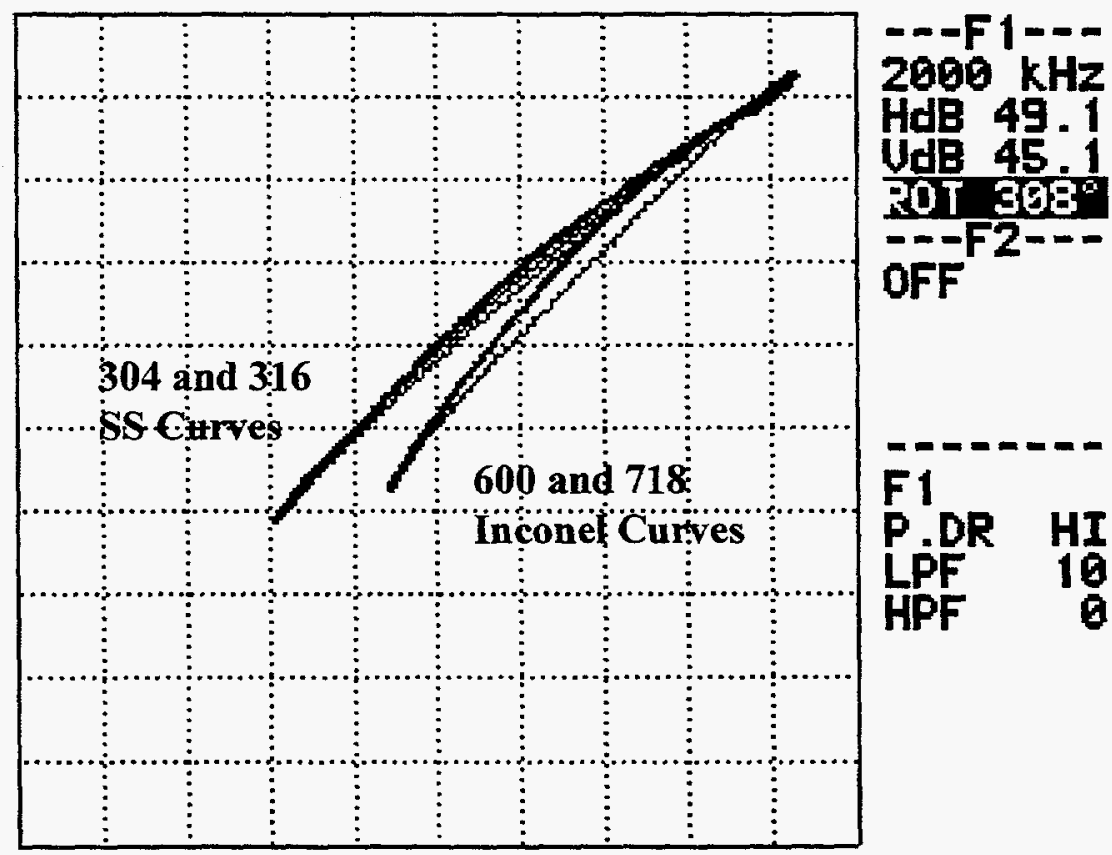

Figure 17. Conductivity curve for stainless steel and inconel alloys using a standard absolute bridge unshielded $2 \mathrm{MHz} 0.750$ inch diameter probe. 


\section{Eddy Current Conductivity Inspection Results}

\section{MHz Absolute Shielded Pencil Probe Compared to the Spot Test}

Conductivity data was collected for each of the fourteen inspection locations on the exhaust components. Following is the conductivity data and material classification for the $1 \mathrm{MHz} 0.125$ inch diameter absolute shielded pencil probe on Samples \#1 and \#2.

\section{Sample \#1 Cessna 400 Series Exhaust Component}

Polymer Pad Cleaning

Inspection sites 1, 4, 7 and 12 on Sample \#1 were mechanically cleaned with a polymer pad.

Figure 18 is the conductivity reading at inspection site \#1. It reveals the difference between a clean surface and a surface with an oxide layer still present. The material is classified as stainless steel with eddy current and the spot test.

Figure 19 is the conductivity reading at inspection site \#12. It reveals the difference between a clean surface and a welded joint. The material is classified as stainless steel with eddy current and the spot test.

Figures 20 and 21 are the conductivity reading at inspection site \#4. It reveals the difference between a clean surface and a surface with an oxide layer still present. The material is classified as stainless steel with the spot test and fell in between stainless steel and inconel with eddy current. This inspection site was cleaned with 320 grit aluminum oxide paper and re-inspected. The material is classified as stainless steel with eddy current after additional cleaning.

Figures 22 through 24 is the conductivity reading at inspection site \#7. It reveals the difference between a clean surface and a surface with an oxide layer still present. The material is classified as stainless steel with the spot test and inconel with eddy current. This inspection site was cleaned with 320 grit aluminum oxide paper and re-inspected. The material is classified as inconel with eddy current after additional cleaning. This site was filed and then cleaned with 320 grit aluminum oxide paper. The material is classified as stainless steel with eddy current after filing and additional cleaning.

600 Grit Silicon Carbide Cleaning

Inspection site 2 on Sample \#1 was mechanically cleaned with 600 grit silicon carbide paper. Figure 25 is the conductivity reading at inspection site \#2. It reveals the difference between a clean surface and a surface with an oxide layer still present. The material is classified as stainless steel with eddy current and the spot test. 


\section{Sample \#1 Cessna 400 Series Exhaust Component (Continued)}

400 Grit Silicon Carbide Cleaning

Inspection location 3 on Sample \#1 were mechanically cleaned with 400 grit silicon carbide paper. Figure 26 is the conductivity reading at inspection site \#3. It reveals the difference between a clean surface and a surface with an oxide layer still present. The material is classified as stainless steel with eddy current and the spot test.

\section{Grit Aluminum Oxide Cloth Cleaning}

Inspection locations 5 and 13 on Sample \#1 were mechanically cleaned with 320 grit aluminum oxide cloth. Figures 27 and 28 are the conductivity reading at inspection site \#5. It reveals the difference between a clean surface and a surface with an oxide layer present. The material is classified as stainless steel with the spot test and fell between stainless steel and inconel with eddy current. This inspection site was cleaned with 320 grit aluminum oxide paper and re-inspected. The material is classified as stainless steel with eddy current after additional cleaning.

Figure 29 is the conductivity reading at inspection site \#13 on Sample \#1. This surface does not have an oxide layer present. The material is classified as stainless steel with eddy current and the spot test.

\section{Grit Aluminum Oxide Paper Cleaning}

Inspection sites 6, and 14 on Sample \#1 were mechanically cleaned with 320 grit aluminum oxide paper. Figure 30 is the conductivity reading at inspection site \#14. This surface does not have an oxide layer present. The material is classified as stainless steel with the spot test and eddy current.

Figures 31 through 34 are the conductivity reading at inspection site \#7 on Sample \#1. Figure 36 reveals the difference between a clean surface and a surface with an oxide layer still present. The material is classified as stainless steel with the spot test and inconel with eddy current. This inspection site was cleaned with 320 grit aluminum oxide paper and re-inspected. This inspection site was cleaned extensively with 320 grit aluminum oxide paper and re-inspected. The material is still classified as inconel with eddy current (Figures 32 - 33). This site was filed and then cleaned with 320 grit aluminum oxide paper. The material is classified as stainless steel with eddy current after filing and additional cleaning (Figure 34). 

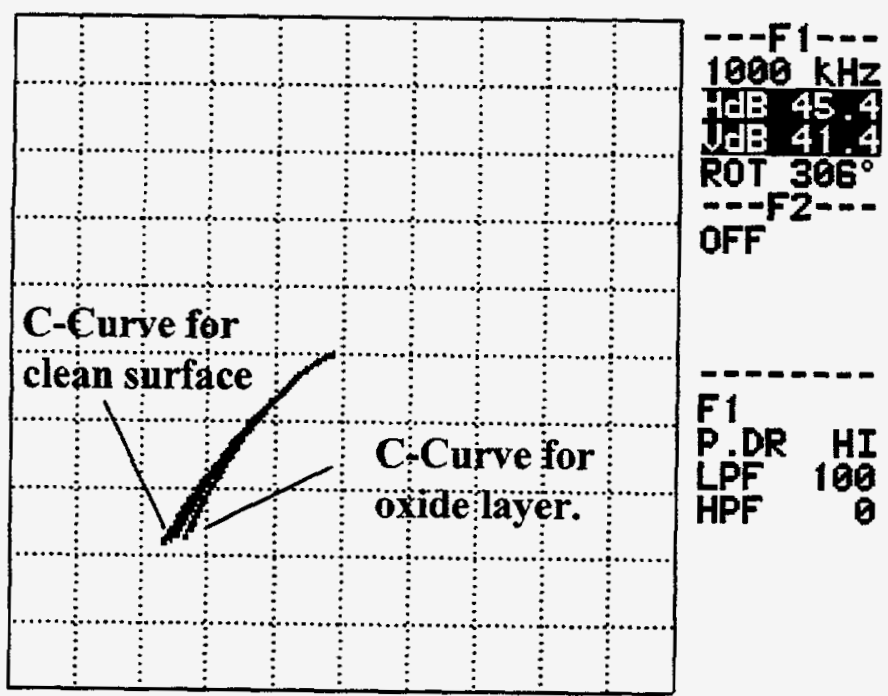

Figure 18. Inspection Site \#1 on Sample \#1 reveals differences between clean surfaceand thermal oxide. The site was cleaned with polymer abrasive pad. The material is classified as stainless steel with eddy current and the spot test.
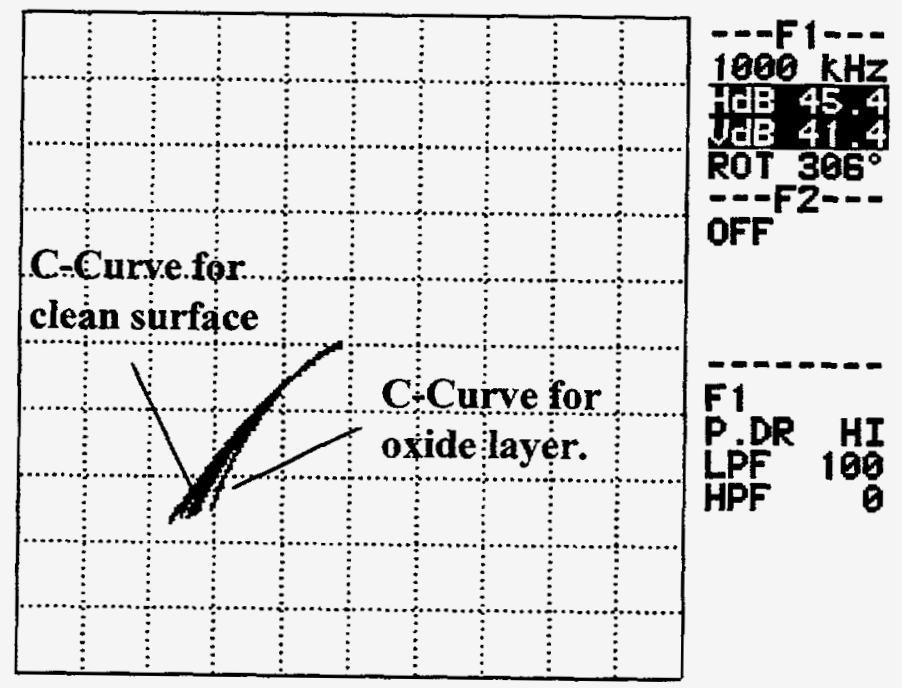

Figure 20. Inspection Site \#4 on Sample \#1 reveals differences between clean surface and thermal oxide. The site was cleaned with polymer abrasive pad. The material is classified as stainless steel with the spot test and fell in between stainless steel and inconel with eddy current.

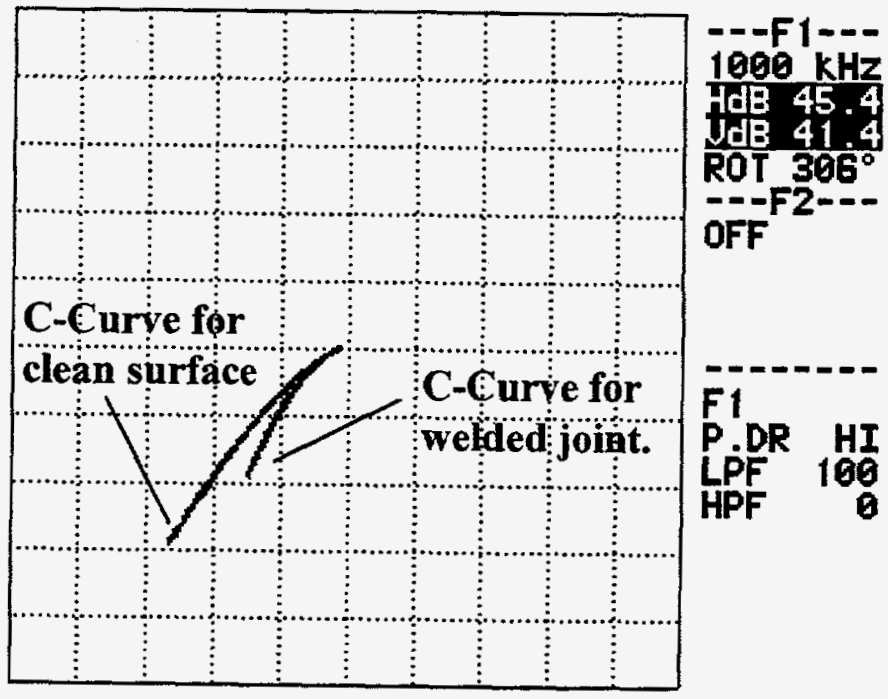

Figure 19. Inspection Site \#12 on Sample \#1 was cleaned with polymer abrasive pad. The material is classified as stainless steel with eddy current and the spot test. A conductivity reading was also taken on the welded joint.

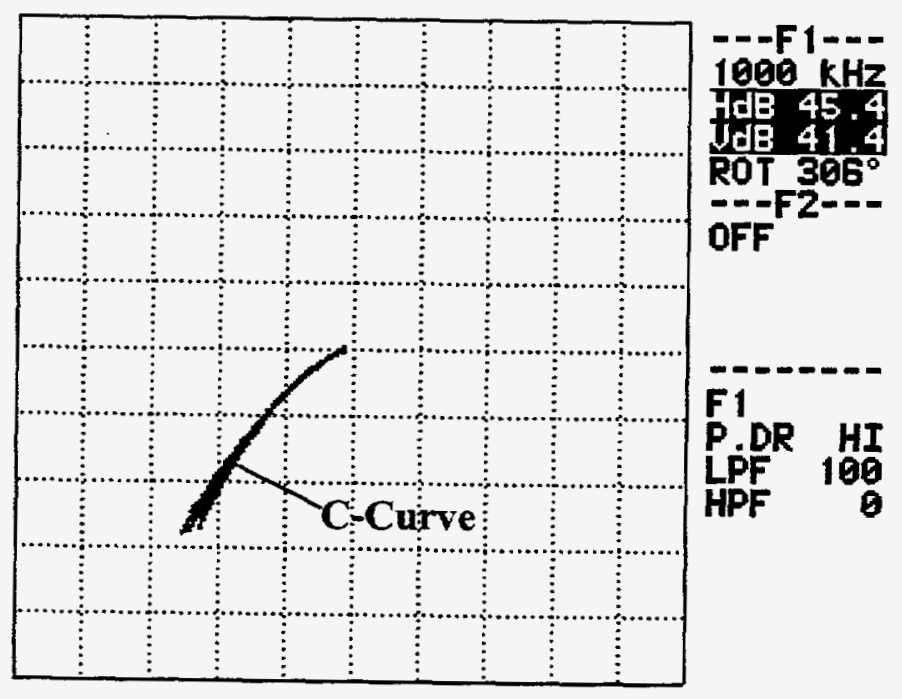

Figure 21. Inspection Site \#4 on Sample \#1 after cleaning with 320 grit aluminum oxide paper. The material is classified as stainless steel with eddy current. 

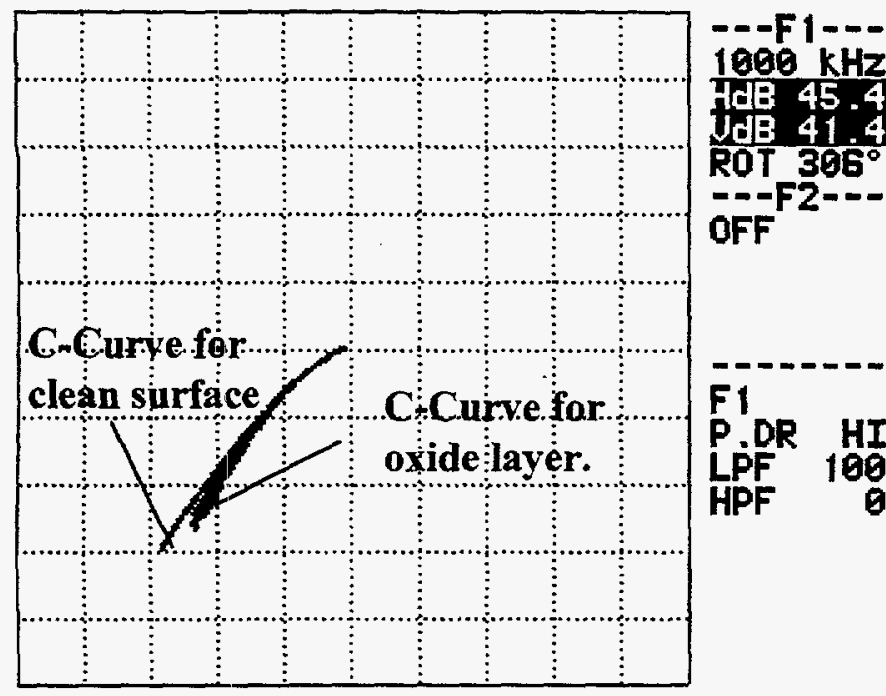

Figure 22. Inspection Site \#7 on Sample \#1 reveals differences between clean surface and thermal oxide. The site was cleaned with polymer abrasive pad. The material is classified as stainless steel with the spot test and inconel with eddy current.

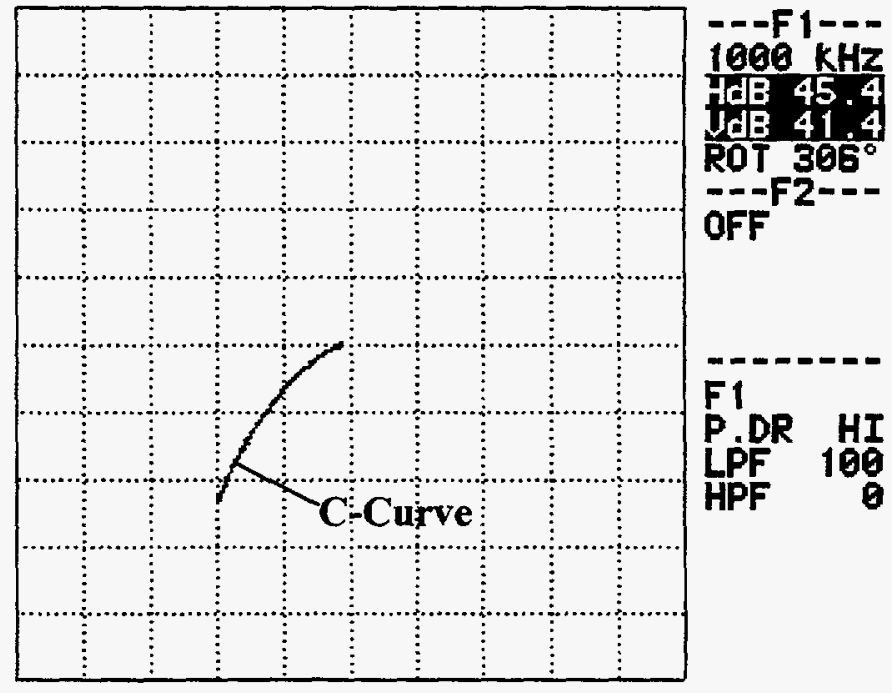

Figure 23. Inspection Site \#7 on Sample \#1 was cleaned with 320 grit aluminum oxide paper. The material is classified as inconel with eddy current.

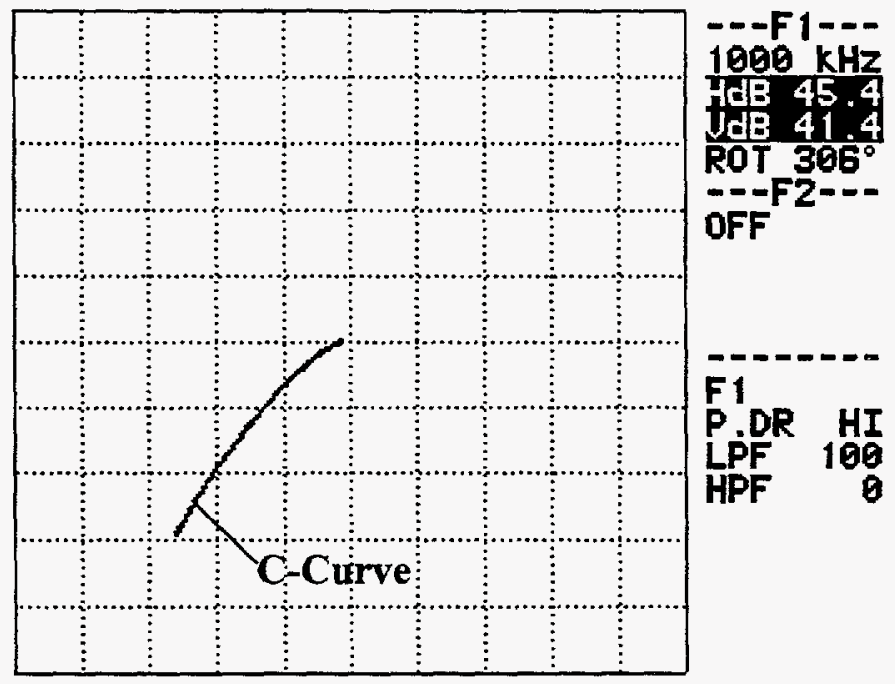

Figure 24. Inspection Site \#7 on Sample \#1 was filed and cleaned with 320 grit aluminum oxide paper. The material is classified as stainless steel with eddy current. 

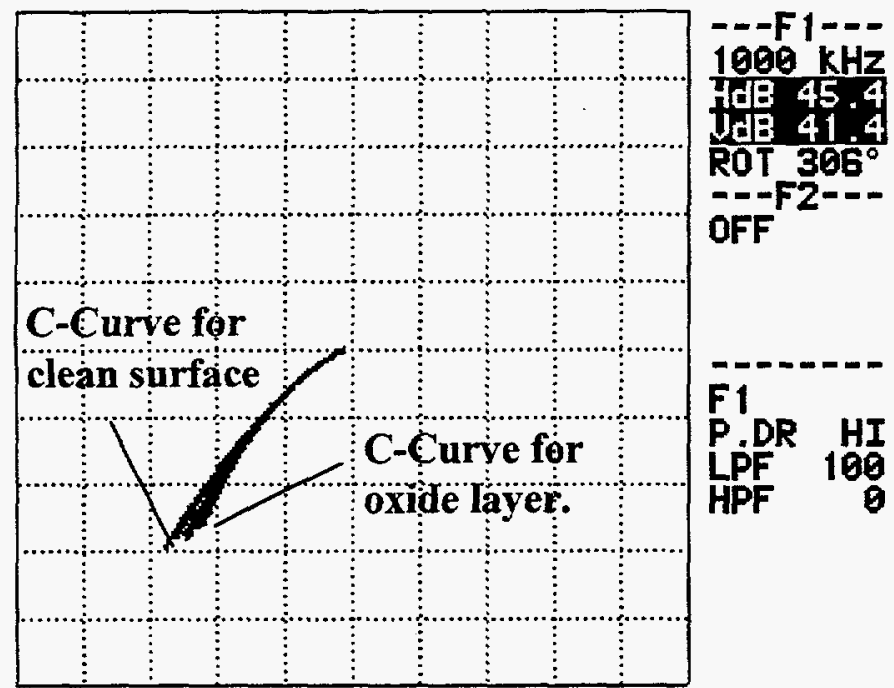

Figure 25. Inspection Site \#2 on Sample \#1 reveals differences between clean surface and thermal oxide. The site was cleaned with 600 grit silicon carbide paper. The material is classified as stainless steel with eddy current and the spot test.
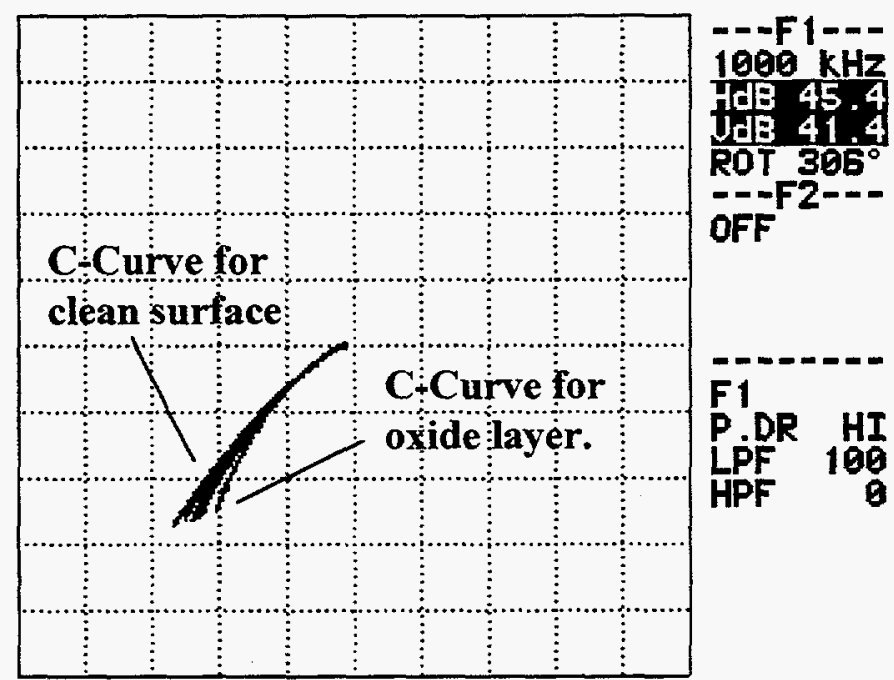

Figure 27. Inspection Site \#5 on Sample \#1 reveals differences between clean surface and thermal oxide. The site was cleaned with 320 grit aluminum oxide cloth. The material is classified as stainless steel with the spot test and fell in between stainless steel and inconel with eddy current.

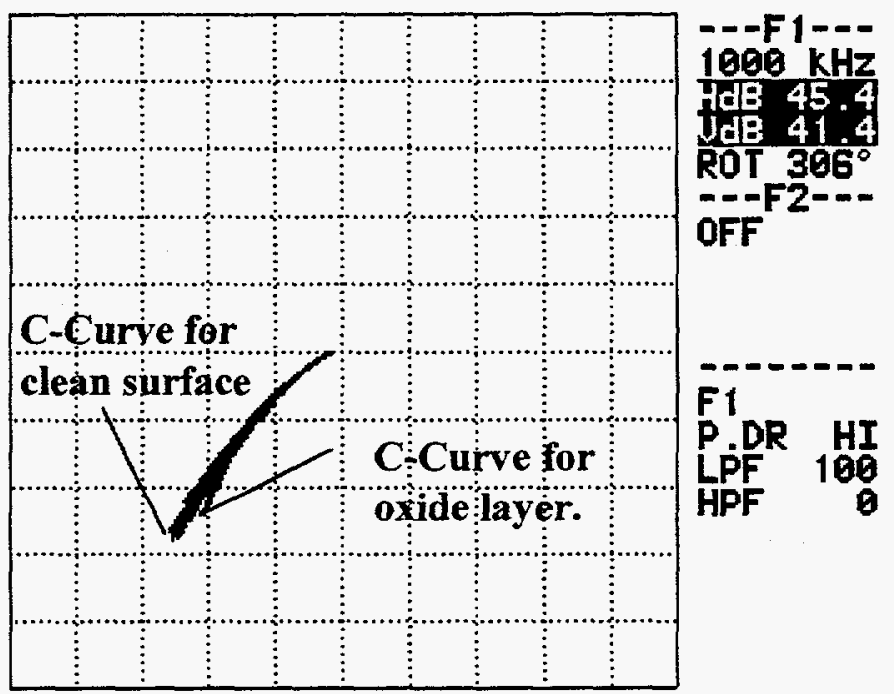

Figure 26. Inspection Site \#3 on Sample \#1 reveals differences between clean surface and thermal oxide. The site was cleaned with 400 grit silicon carbide paper. The material is classified as stainless steel with eddy current and the spot test.

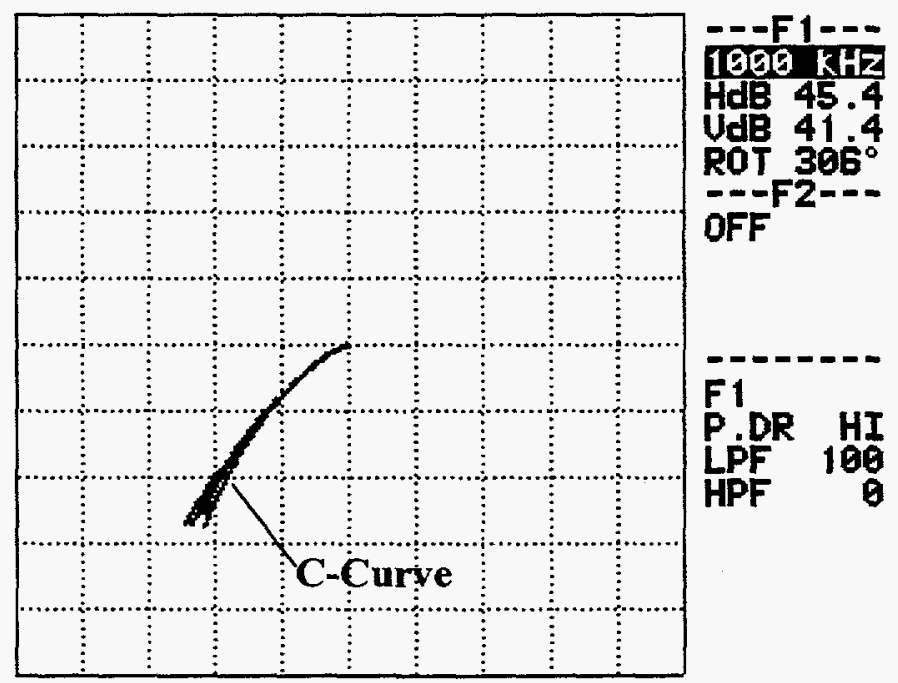

Figure 28. Inspection Site \#5 on Sample \#1 after cleaning with 320 grit aluminum oxide paper. The material is classified as stainless steel with the spot test and eddy current. 


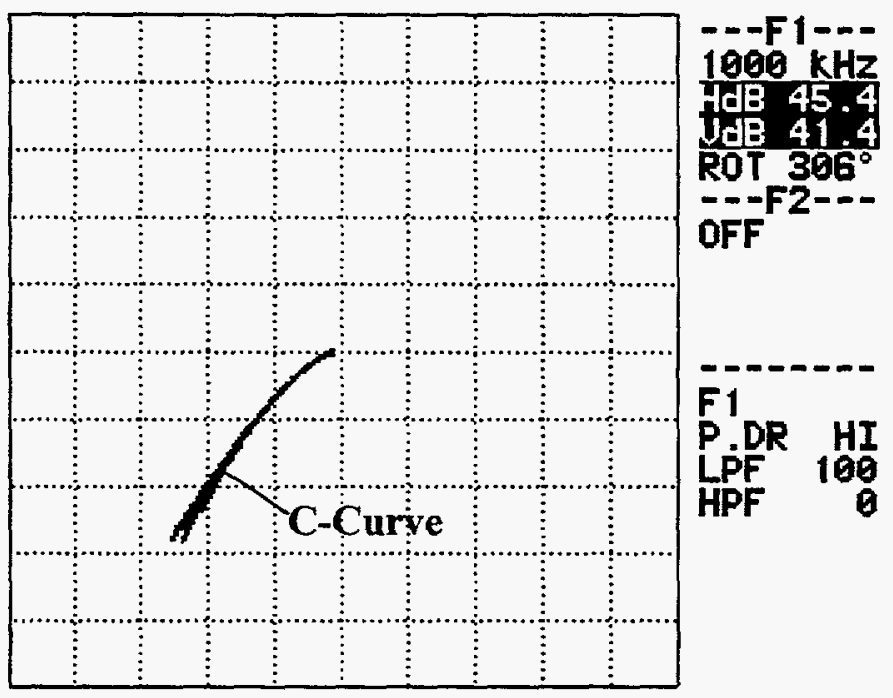

Figure 29. Inspection Site $\# 13$ on Sample \#1 was cleaned with 320 grit aluminum oxide cloth. The material is classified as stainless steel with the spot test and eddy current.

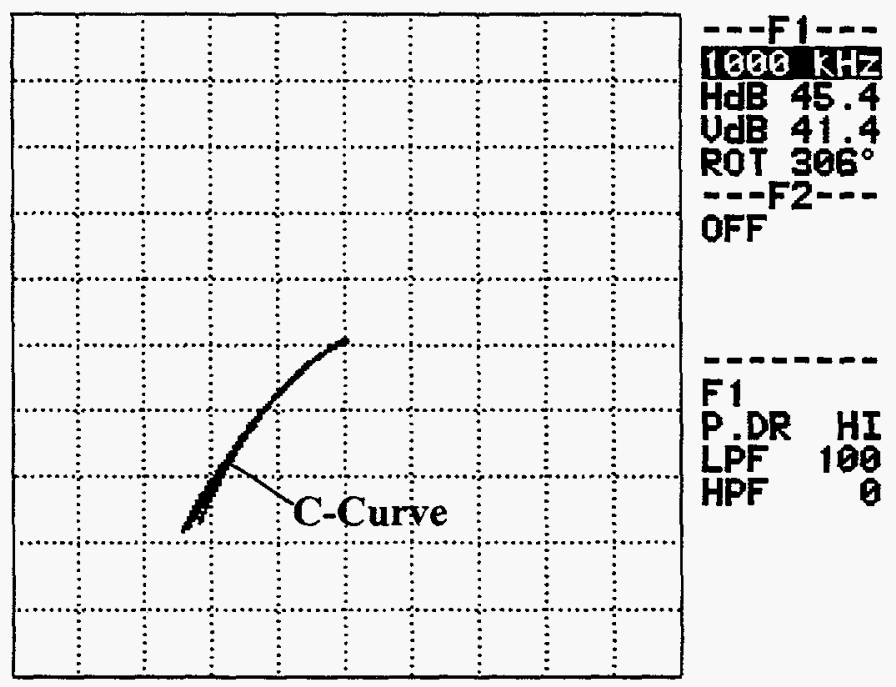

Figure 30. Inspection Site \#14 on Sample \#1was cleaned with 320 grit aluminum oxide paper. The material is classified as stainless steel with eddy current and the spot test. 

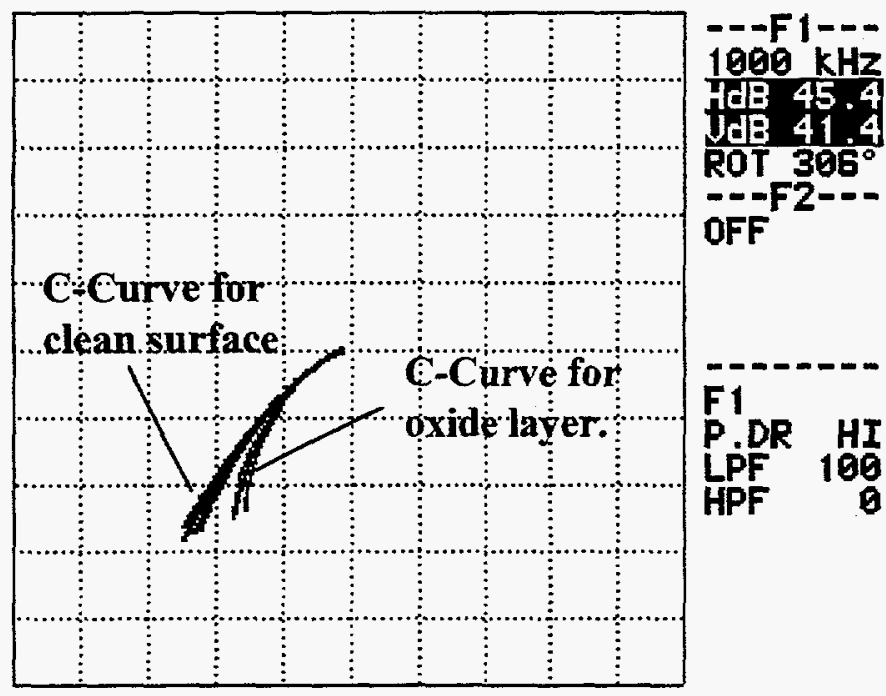

Figure 31. Inspection Site \#6 on Sample \#1 reveals differences between clean surfaceand thermal oxide. The site was cleaned with 320 grit aluminum oxide paper. The material is classified as stainless steel with the spot test and inconel with eddy current.

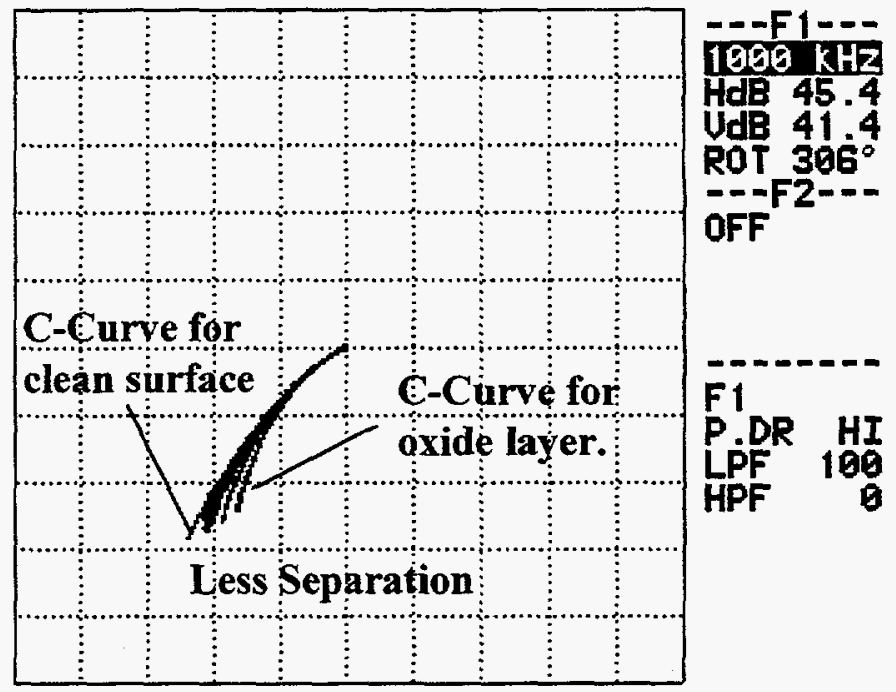

Figure 32. Inspection Site \#6 on Sample \#1 was again cleaned extensively with 320 grit aluminum oxide paper. The material is classified as inconel with eddy current.
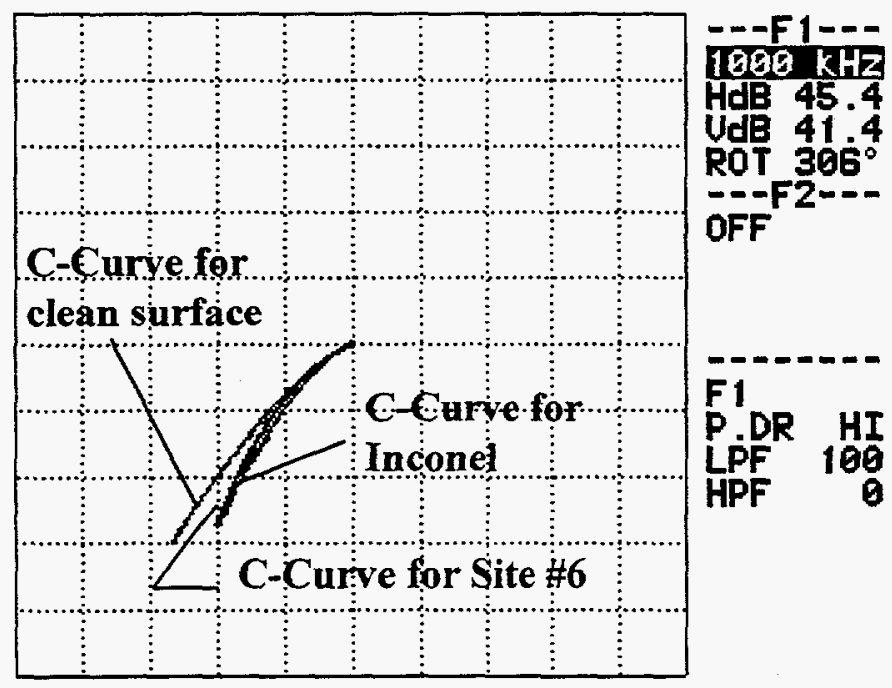

Figure 33. Inspection Site \#6 on Sample \#1 was again cleaned with 320 grit aluminum oxide paper. The stainless steel and inconel calibration curves are added to the impedance plane. This site is still classified as inconel with eddy current.

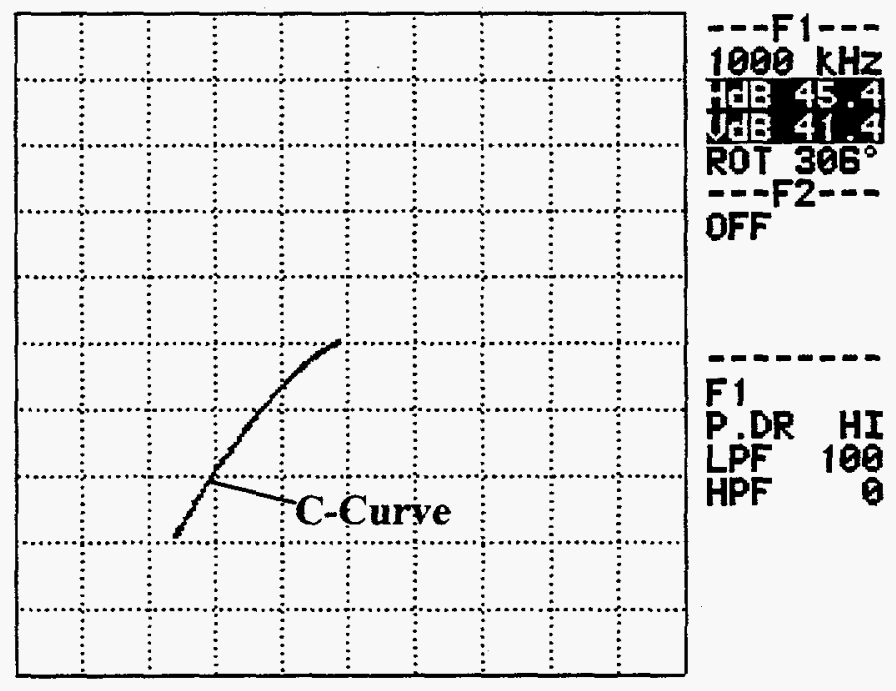

Figure 34. Inspection Site \#6 on Sample \#1 was filed and cleaned with 320 grit aluminum oxide paper. The material is classified as stainless steel with eddy current. 


\section{Sample \#2 Cessna 400 Series Cross Over Pipe}

\section{Grit Aluminum Oxide Cloth Cleaning}

Inspection site 8 on Sample \#2 was mechanically cleaned with 320 grit aluminum oxide cloth. Figure 35 is the conductivity reading at inspection site \#8. It reveals the difference between a clean surface and a surface with a strong magnetic oxide layer present. The material is classified as stainless steel with the spot test and with eddy current. This inspection site was cleaned with 320 grit aluminum oxide paper and re-inspected. Figure 36 displays the eddy current response after the removal of the magnetic oxide layer.

\section{Polymer Pad Cleaning}

Figures 37 and 38 are the conductivity reading at inspection site \#9 on Sample \#2. It reveals the difference between a clean surface and a surface with an oxide layer present. The material is classified as stainless steel with the spot test and fell between stainless steel and inconel with eddy current. This inspection site was cleaned with 320 grit aluminum oxide paper and re-inspected. The material is classified as inconel with eddy current after additional cleaning. This created a false call using eddy current in a section of the exhaust which has a heavy oxide layer.

400 Grit Silicon Carbide Cleaning

Inspection site 10 on Sample \#2 was mechanically cleaned with 400 grit silicon carbide paper. Figure 39 is the conductivity reading at inspection site \#10. It reveals the difference between a clean surface and a surface with an oxide layer still present. The material is classified as stainless steel with the spot test and inconel with eddy current. This inspection site was cleaned with 320 grit aluminum oxide paper and re-inspected. The material is classified as inconel with eddy current after additional cleaning. Figure 40 reveals a false call using eddy current in a section of the exhaust which has a thick oxide layer.

\section{Grit Silicon Carbide Cleaning}

Inspection site 11 on Sample \#2 was mechanically cleaned with 600 grit silicon carbide paper. Figure 41 is the conductivity reading at inspection site \#11. It reveals the difference between a clean surface and a surface with an oxide layer still present. The material is classified as stainless steel with the spot test and between stainless steel and inconel with eddy current. This inspection site was cleaned with 320 grit aluminum oxide paper and re-inspected. The material is classified as stainless steel with eddy current after additional cleaning. Figure 42 displays the eddy current signal after the oxide layer has been removed. 


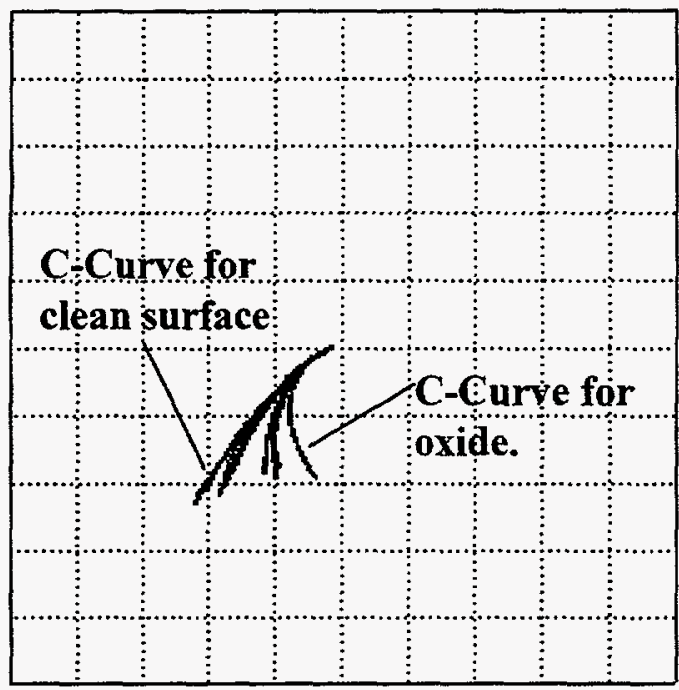

Figure 35. Inspection Site \#8 on Sample \#2 was cleaned with 320 grit aluminum oxide cloth. The material is classified as stainless steel with the spot test and eddy current. This sample has a strong magnetic oxide and could be called as inconel.
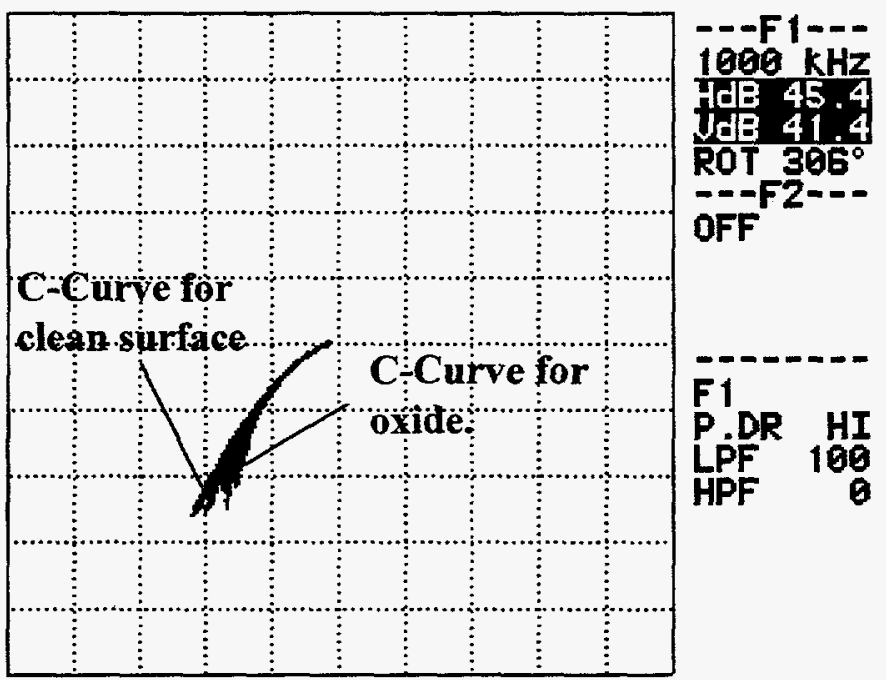

Figure 37. Inspection Site \#9 on Sample \#2 reveals differences between clean surface and thermal oxide. The site was cleaned with polymer abrasive pad. The material is classified as stainless steel with the spot test and is in between stainless steel and inconel with eddy current.

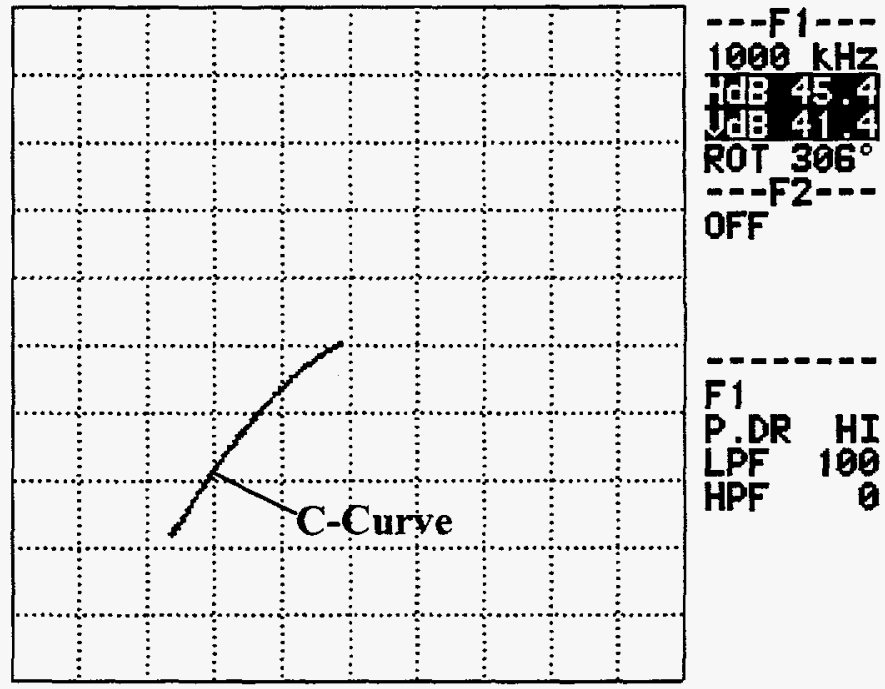

Figure 36. Inspection Site \#8 on Sample \#2 was cleaned was extensive cleaned with 320 grit aluminum oxide paper. The material is classified as stainless steel with the spot test and eddy current.

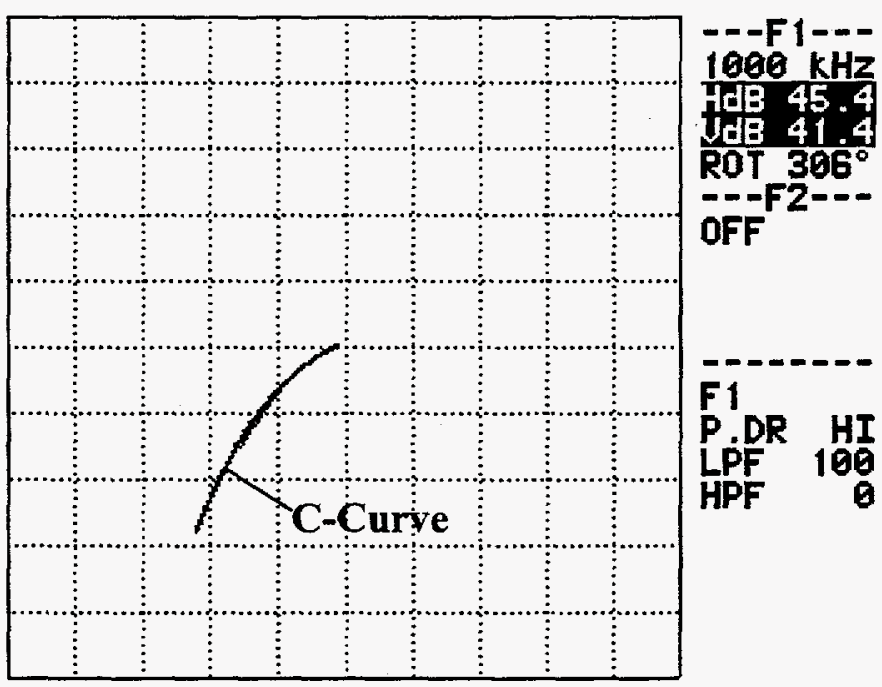

Figure 38. Inspection Site \#9 on Sample \#2 was cleaned with 320 grit aluminum oxide paper. The material is classified as inconel with eddy current. 


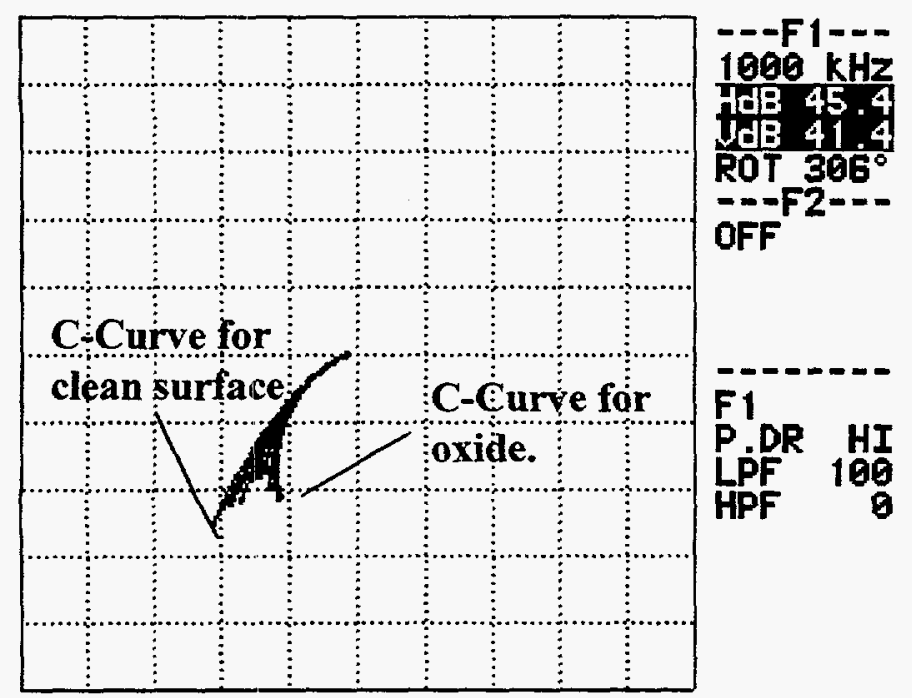

Figure 39. Inspection Site \#10 on Sample \#2 reveals differences between clean surface and thermal oxide. The site was cleaned with 400 grit silicon carbide paper. The material is classified as stainless steel with the spot test and inconel with eddy current.
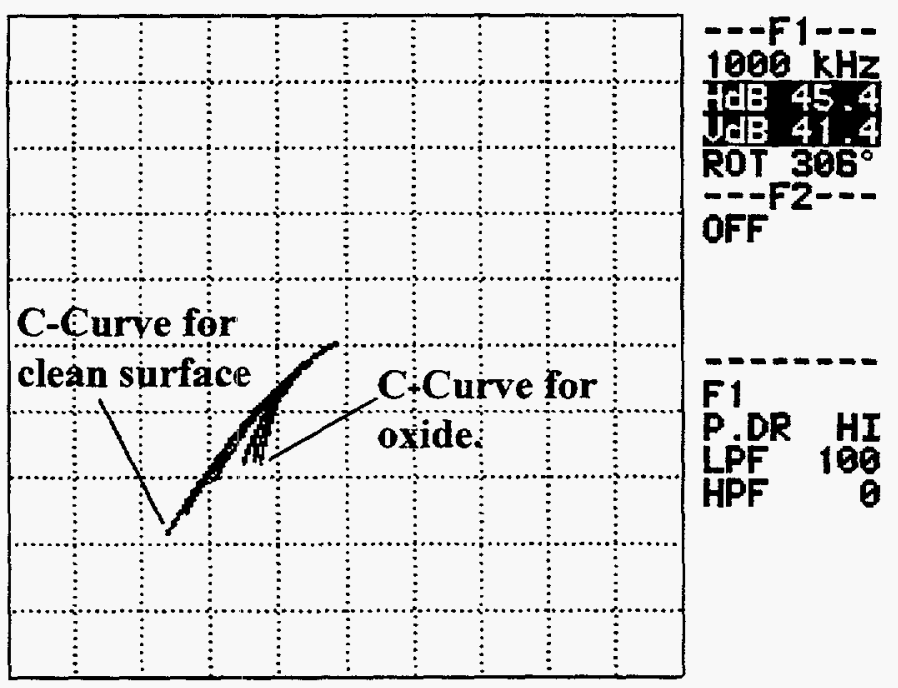

Figure 41. Inspection Site \#11 on Sample \#2 reveals differences between clean surface and thermal oxide. The site was cleaned with 600 grit silicon carbide paper. The material is classified as stainless steel with the spot test and is in between inconel and stainless steel with eddy current.

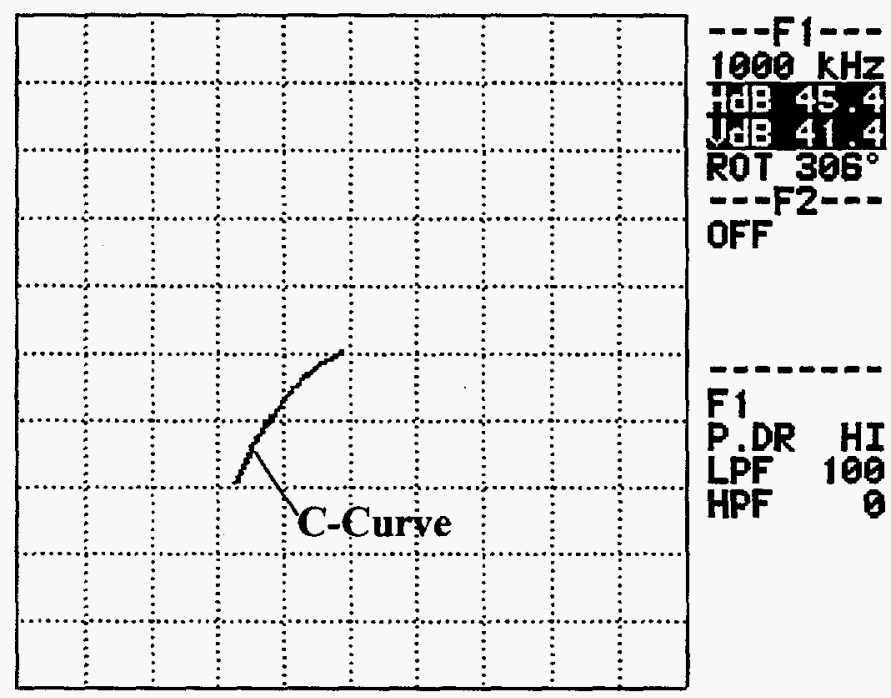

Figure 40. Inspection Site \#10 on Sample \#2 was cleaned with 320 grit aluminum oxide paper. The material is classified as inconel with eddy current.

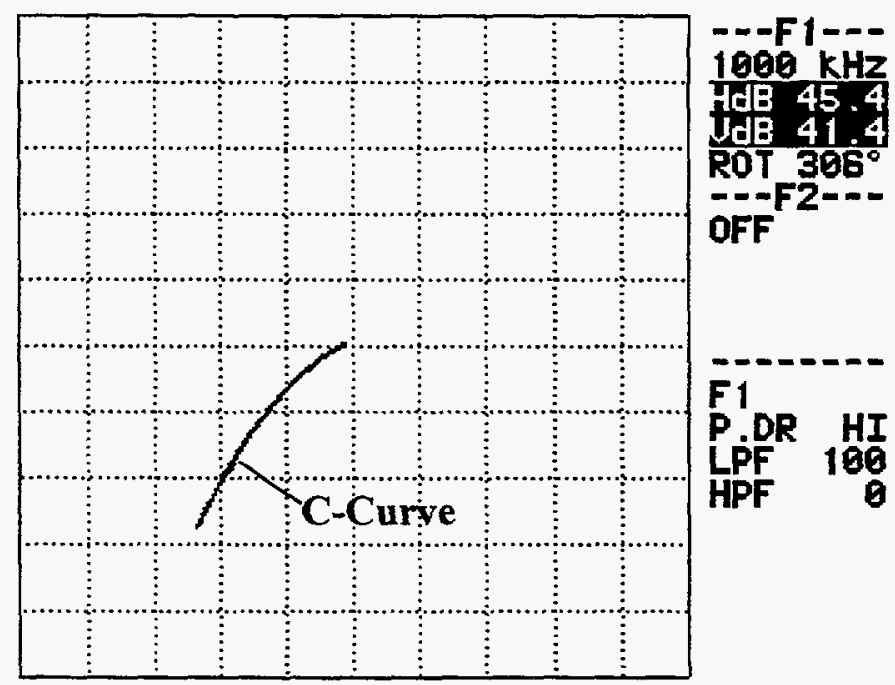

Figure 42. Inspection Site \#11 on Sample \#2 was cleaned with 320 grit aluminum oxide paper. The material is classified as stainless steel with eddy current. 


\section{Inspection Results Comparing the Spot Test and Eddy Current Instrument With the $1 \mathrm{MHz}$, Absolute Shielded Pencil Probe}

Each site was inspected with eddy current and the spot test. The material was classified as either stainless steel or inconel. The criteria for classifying the material using eddy current depends on the location of the curve with respect to the material standards. The criteria for classifying the material using the spot test depends on the color present on the filter paper.

Table 6. Test results for eddy current pencil probe and the spot test.

\begin{tabular}{|c|c|c|c|c|}
\hline \multicolumn{2}{|c|}{$\begin{array}{l}\text { Inspection } \\
\text { Site }\end{array}$} & $\begin{array}{l}\text { Eddy Current } \\
\text { Call }\end{array}$ & $\begin{array}{l}\text { Spot Test } \\
\text { Call }\end{array}$ & $\begin{array}{l}\text { Eddy Current } \\
\text { Call After } \\
\text { Additional } 320 \\
\text { Paper Cleaning }\end{array}$ \\
\hline 1 & Polymer Pad & Stainless Steel & Stainless Steel & \\
\hline$\overline{2}$ & 600 Grit Silicon Carbide & Stainless Steel & Stainless Steel & \\
\hline 3 & 400 Grit Silicon Carbide & Stainless Steel & Stainless Steel & \\
\hline$\overline{4}$ & Polymer Pad & In Between & Stainless Steel & Stainless Steel \\
\hline 5 & 320 Aluminum Oxide Cloth & In Between & Stainless Steel & Stainless Steel \\
\hline 6 & 320 Aluminum Oxide Paper & Inconel & Stainless Steel & Inconel* \\
\hline 7 & Polymer Pad & Inconel & Stainless Steel & Inconel* ${ }^{*}$ \\
\hline 8 & 320 Aluminum Oxide Cloth & Stainless Steel & Stainless Steel & \\
\hline 9 & Polymer Pad & In Between & Stainless Steel & Inconel@ \\
\hline 10 & 400 Grit Silicon Carbide & Inconel & Stainless Steel & Inconel@ \\
\hline 11 & 600 Grit Silicon Carbide & In Between & Stainless Steel & Stainless Steel \\
\hline 12 & Polymer Pad & Stainless Steel & Stainless Steel & \\
\hline 13 & 320 Aluminum Oxide Cloth & Stainless Steel & Stainless Steel & \\
\hline 14 & 320 Aluminum Oxide Paper & Stainless Steel & Stainless Steel & \\
\hline
\end{tabular}

Note:

* Inspection sites \#6 and \#7 on Sample \#1 were filed and then cleaned with 320 grit paper. Each site was then classified stainless steel.

(a) Inspection sites \#9 and \#10 on Sample \#2 were not cleaned further. Sites \# 8 and \#11 were classified as stainless steel on this single pipe. Both site \#9 and \#10 are false calls using eddy current conductivity sorting. 


\section{MHz Absolute Bridge Unshielded Probe Compared to the Spot Test}

Conductivity data were collect for each of the fourteen inspection locations. Following is the conductivity data and material classification for the absolute bridge unshielded 0.750 inch diameter probe on Samples \#1 and \#2.

\section{Sample \#1 Cessna 400 Series Exhaust Component}

Polymer Pad Cleaning

Inspection locations 1, 4, 7 and 12 on Sample \#1 were mechanically cleaned with a polymer pad. Figure 43 is the conductivity reading at inspection site \#1. This probe is less sensitive to localized surface conditions caused by polymer pad cleaning and does not detect a difference between a clean surface and a surface with an oxide layer. The material is classified as stainless steel with eddy current and the spot test.

Figure 44 is the conductivity reading at inspection site \#4. The material is classified as stainless steel with eddy current and the spot test. Figure 45 is the conductivity reading at inspection site \#7. This inspection site was cleaned with a polymer pad then with a 320

grit aluminum oxide paper. The material is classified as stainless steel with eddy current and the spot test. Figures 46 is the conductivity reading at inspection site \#12. The material is classified as stainless steel with the spot test and eddy current.

\section{Grit Silicon Carbide Cleaning}

Inspection location 2 on Sample \#1 was mechanically cleaned with 600 grit silicon carbide paper. Figure 47 is the conductivity reading at inspection site $\# 2$. This probe is less sensitive to localized surface conditions caused by 600 grit $(\mathrm{SiC})$ mechanical cleaning and does not detect a difference between a clean surface and a surface with an oxide layer. The material is classified as stainless steel with eddy current and the spot test.

\section{Grit Silicon Carbide Cleaning}

Inspection location 3 on Sample \#1 were mechanically cleaned with 400 grit silicon carbide paper. Figure 48 is the conductivity reading at inspection site \#3. This probe is less sensitive to localized surface conditions caused by 400 grit $(\mathrm{SiC})$ mechanical cleaning and does not detect a difference between a clean surface and a surface with an oxide layer. The material is classified as stainless steel with eddy current and the spot test. 


\section{Sample \#1 Cessna 400 Series Exhaust Component (Continued)}

\section{Grit Aluminum Oxide Cloth Cleaning}

Inspection locations 5 and 13 on Sample \#1 were mechanically cleaned with 320 grit aluminum oxide cloth and then 320 grit aluminum oxide paper. Figures 49 is the conductivity reading at inspection site \#5. This probe is less sensitive to localized surface conditions caused by aluminum oxide cloth mechanical cleaning and does not detect a difference between a clean surface and a surface with an oxide layer. The material is classified as stainless steel with the spot test and with eddy current. Figure 50 is the conductivity reading at inspection site \#13. The material is classified as stainless steel with eddy current and the spot test.

\section{Grit Aluminum Oxide Paper Cleaning}

Inspection locations 6 , and 14 on Sample \#1 were mechanically cleaned with 320 grit aluminum oxide paper. Figure 51 is the conductivity reading at inspection site \#14. This surface does not have an oxide layer present. The material is classified as stainless steel with the spot test and eddy current.

Figures 52 is the conductivity reading at inspection site \#7. This inspection site was cleaned extensively with 320 grit aluminum oxide paper, filed and then cleaned with 320 grit aluminum oxide paper again. The material is classified as stainless steel with the spot test and with eddy current. 

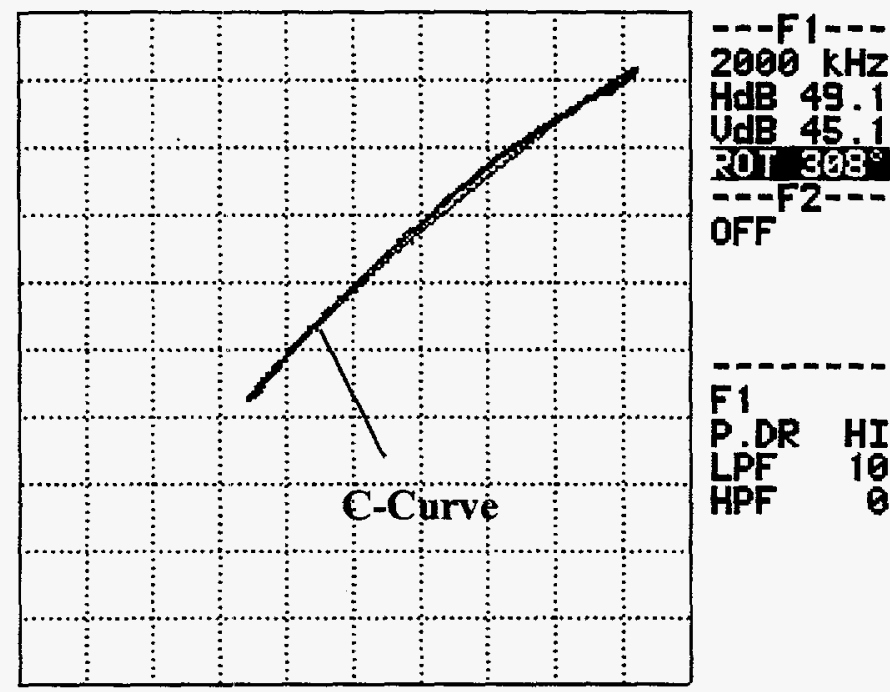

Figure 43. Inspection Site \#1 on Sample \#1 was cleaned with polymer abrasive pad. The material is classified as stainless steel with eddy current and the spot test.

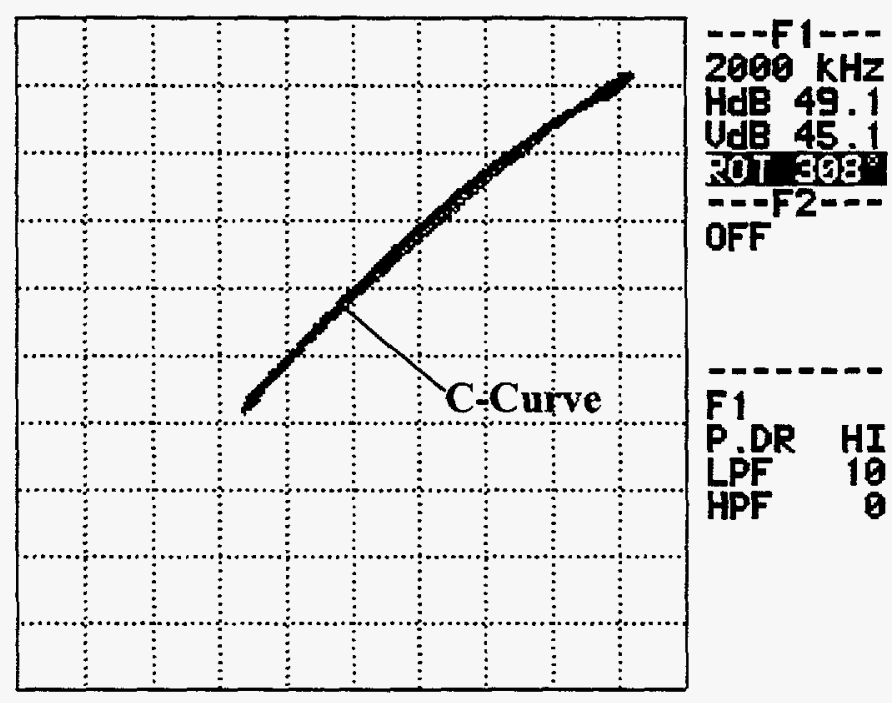

Figure 44. Inspection Site \#4 on Sample \#1 was cleaned with polymer abrasive pad. The material is classified as stainless steel with eddy current and the spot test.

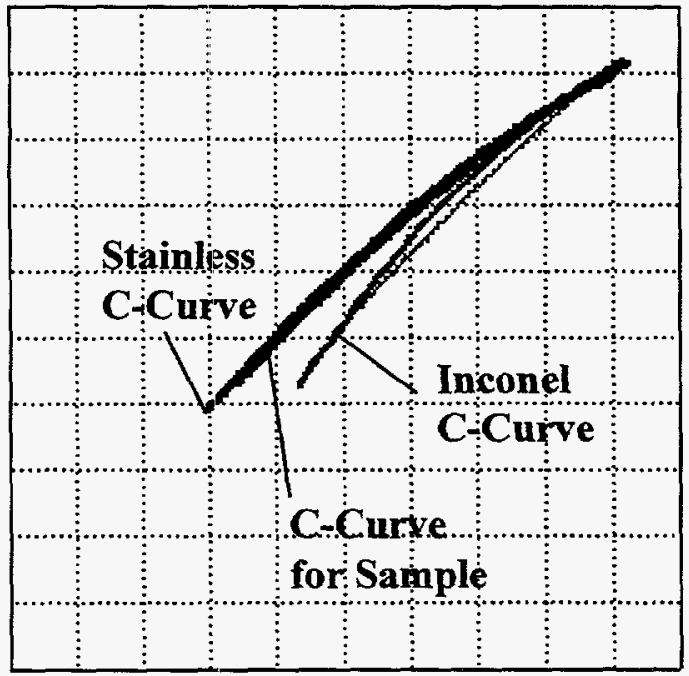

Figure 45. Inspection Site \#7 on Sample \#1 was cleaned with polymer abrasive pad then 320 grit aluminum oxide paper. The material is classified as stainless steel with eddy current and the spot test. Calibration standards are also present as a reference.

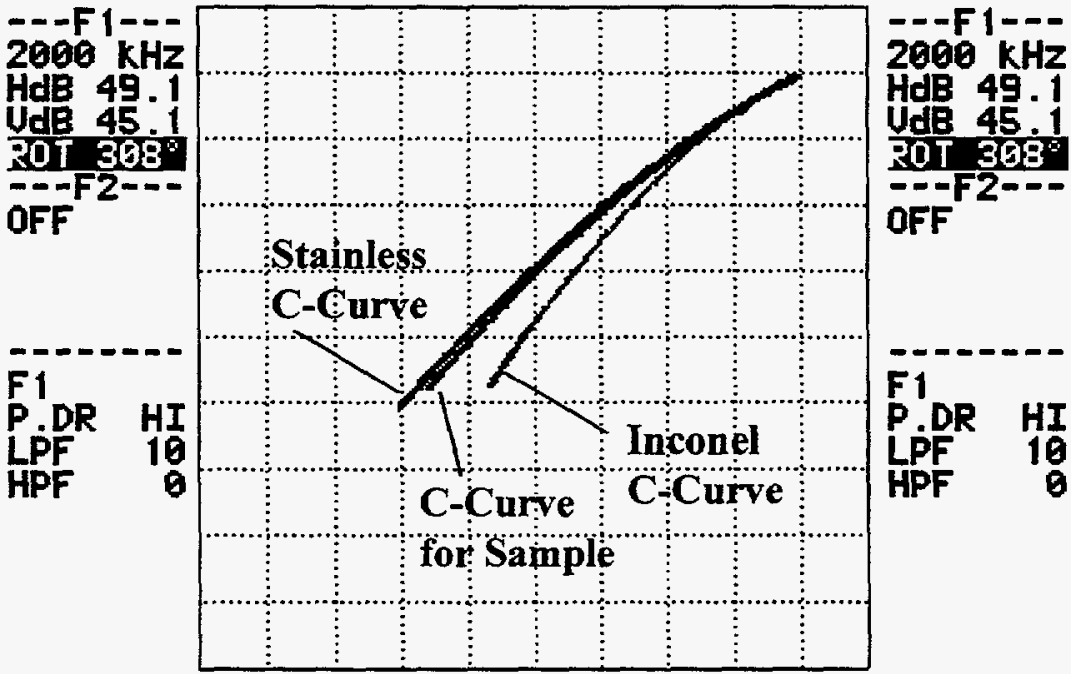

Figure 46. Inspection Site \#12 on Sample \#1 was cleaned with polymer abrasive pad. The material is classified as stainless steel with eddy current and the spot test. Calibration standards are also present as a reference. 


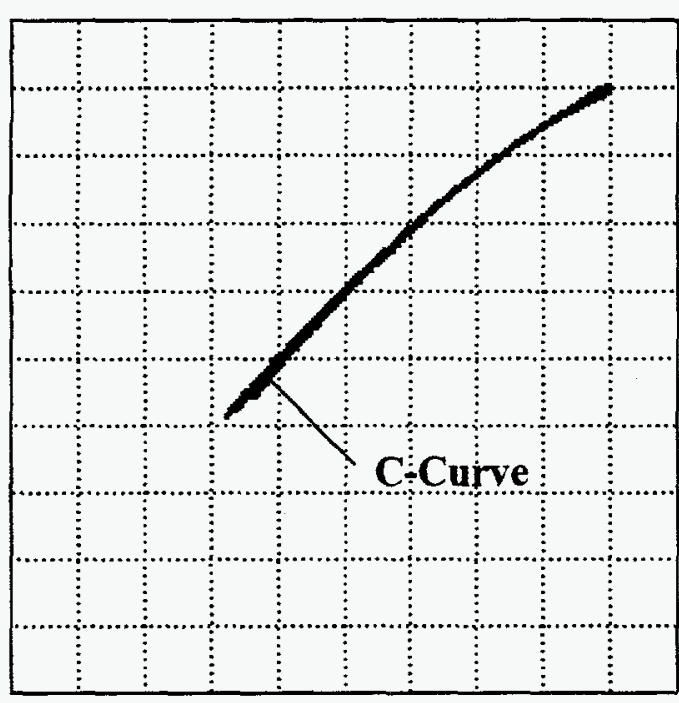

Figure 47. Inspection Site $\# 2$ on Sample \#1 was cleaned with 600 grit silicon carbide paper. The material is classified as stainless steel with eddy current and the spot test.
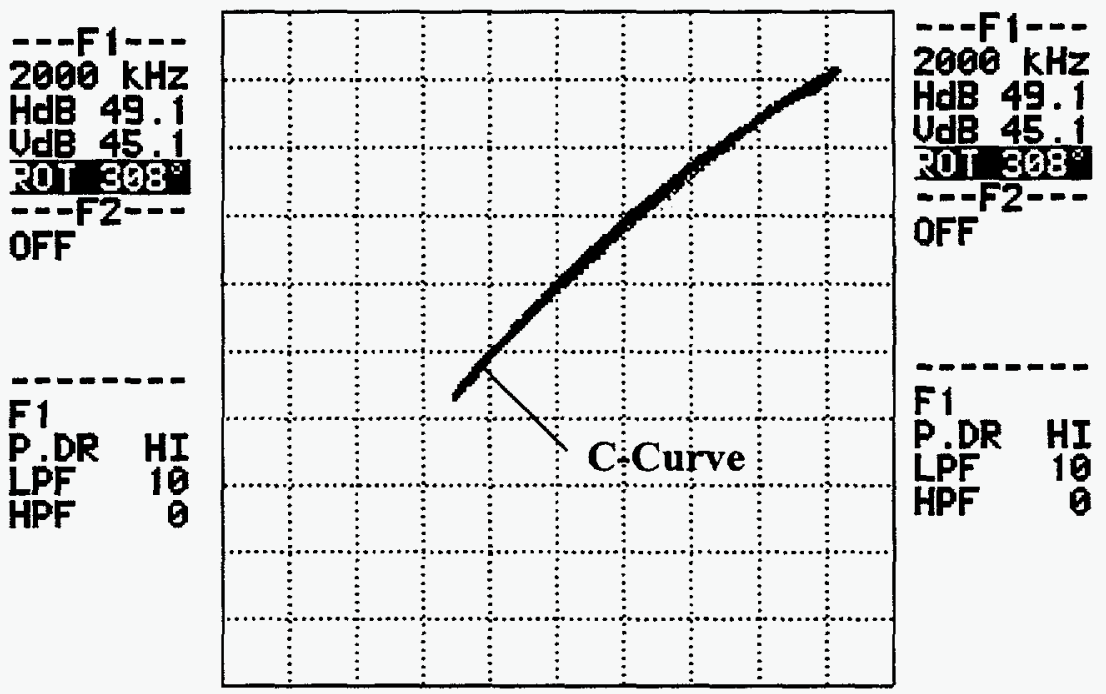

Figure 48. Inspection Site \#3 on Sample \#1 was cleaned with 400 grit silicon carbide paper. The material is classified as stainless steel with eddy current and the spot test.

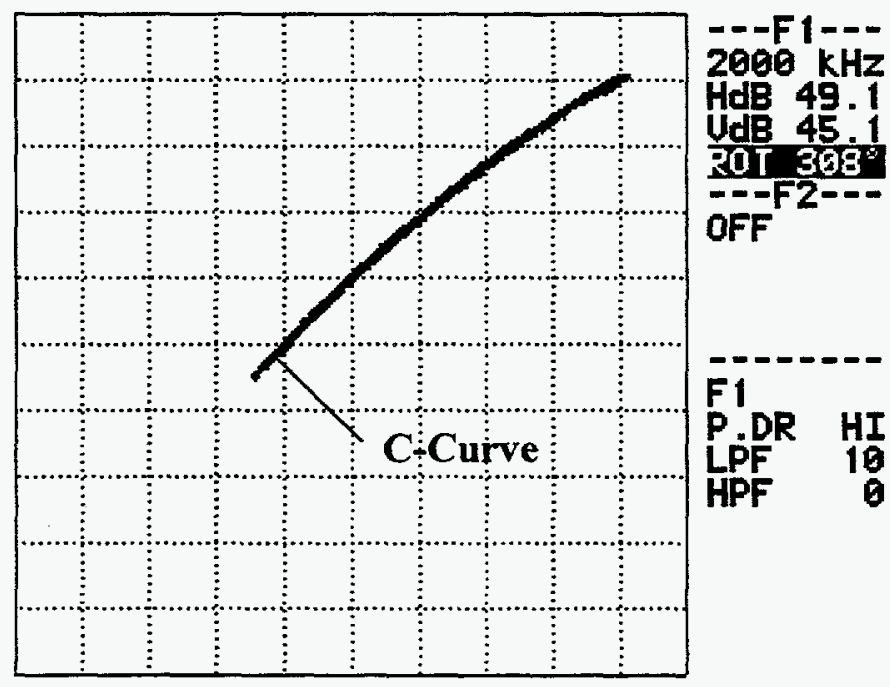

Figure 49. Inspection Site \#5 on Sample \#1 was cleaned with 320 grit aluminum oxide cloth then 320 aluminum oxide paper. The material is classified as stainless steel with eddy current and the spot test. 


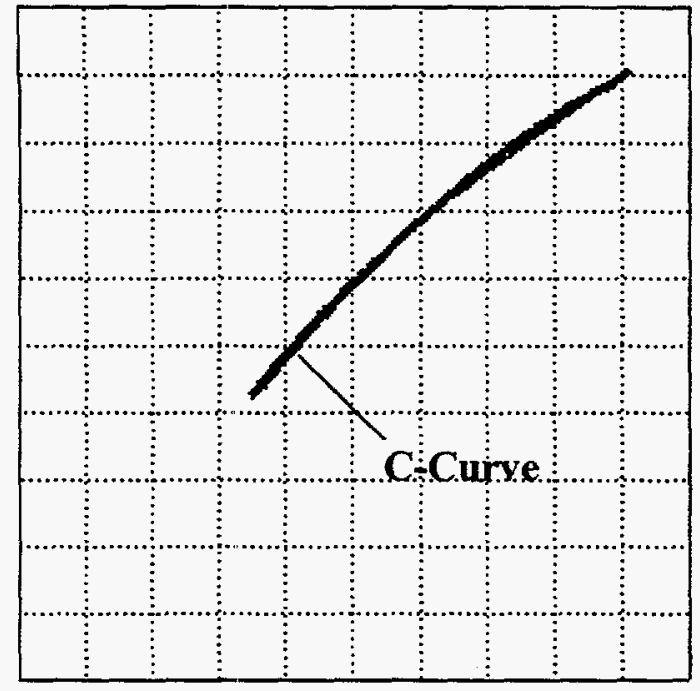

Figure 50. Inspection Site \#13 on Sample \#1 was cleaned with 320 grit aluminum oxide cloth. The material is classified as stainless steel with the spot test and eddy current.

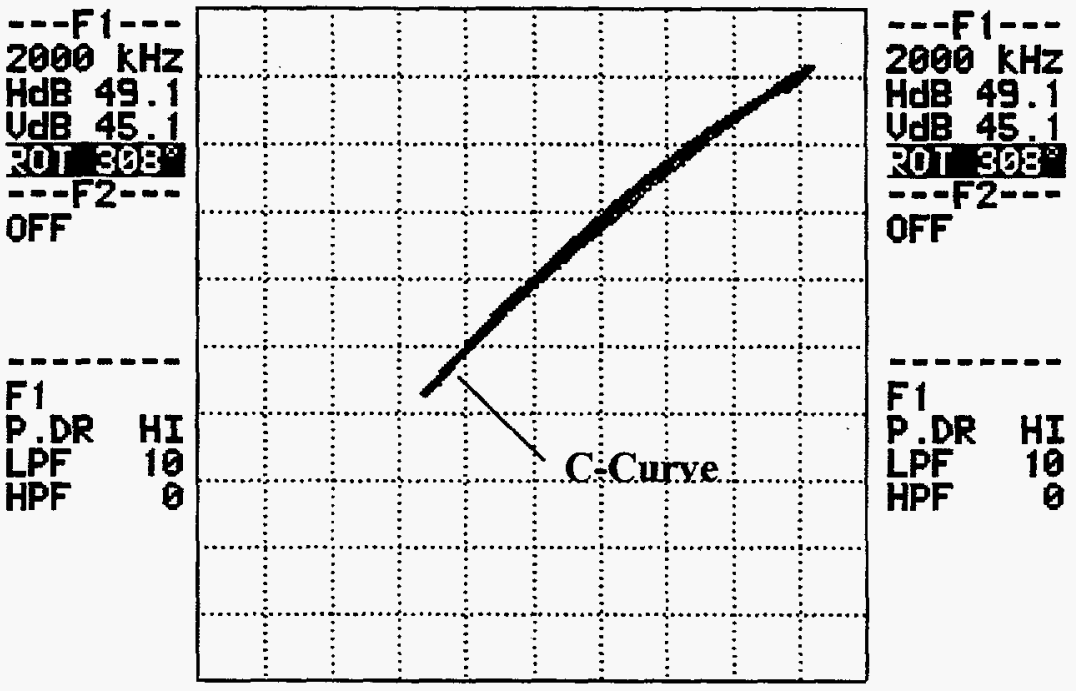

Figure 51. Inspection Site \#14 on Sample \#1 was cleaned with 320 grit aluminum oxide paper. The material is classified as stainless steel with eddy current and the spot test.

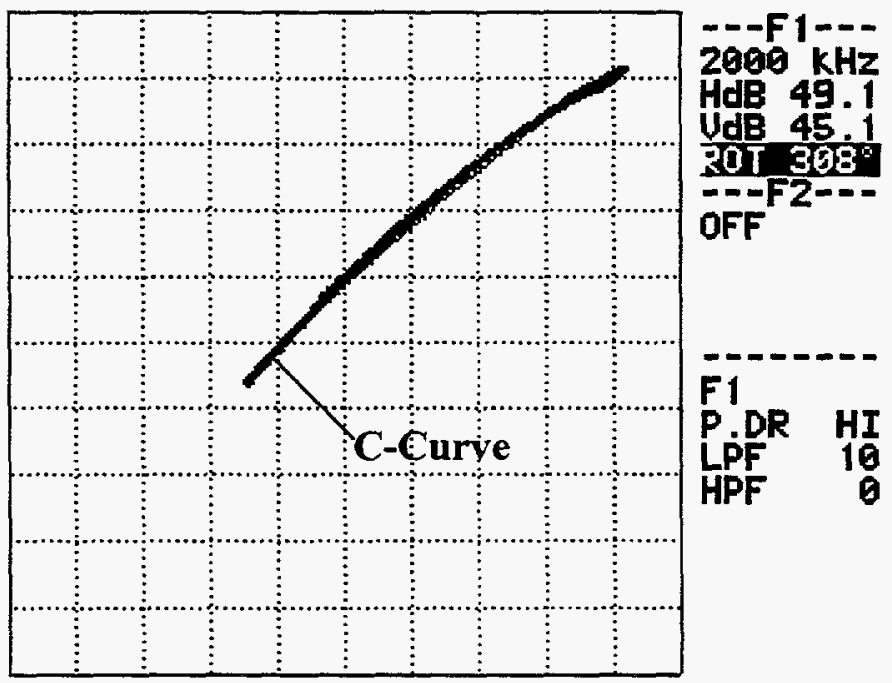

Figure 52. Inspection Site \#6 on Sample \#1 was cleaned with 320 grit aluminum oxide paper. The material is classified as stainless steel with eddy current and the spot test. 


\section{Sample \#2 Cessna 400 Series Cross Over Pipe}

\section{Grit Aluminum Oxide Cloth Cleaning}

Inspection site 8 on Sample \#2 was mechanically cleaned with 320 grit aluminum oxide cloth. Figure 53 is the conductivity reading at inspection site \#8. It reveals the difference between a clean surface and a surface with a strong magnetic oxide layer present and the heat affected zone of a weld repair. This inspection site was also cleaned with 320 grit aluminum oxide paper. The material is classified as stainless steel with the spot test and falls between stainless steel and inconel with eddy current. Figures 54 and 55 displays how the eddy current responds at various points near the repair. It should be noted that inspection points near the weld zone should not be considered valid inspection sites.

\section{Polymer Pad Cleaning}

Figure 56 is the conductivity reading at inspection site \#9 on Sample \#2. This probe is less sensitive to localized surface conditions caused by cleaning and does not detect a difference between a clean surface and a surface with an oxide layer present. This inspection site was cleaned with 320 grit aluminum oxide paper. The material is classified as stainless steel with the spot test and eddy current.

\section{Grit Silicon Carbide Cleaning}

Inspection location 10 on Sample \#2 was mechanically cleaned with 400 grit silicon carbide paper then with 320 grit aluminum oxide paper. Figure 57 is the conductivity reading at inspection site \#10. This probe is less sensitive to localized surface conditions caused by cleaning and does not detect a difference between a clean surface and a surface with an oxide layer. The material is classified as stainless steel with the spot test and eddy current.

\section{Grit Silicon Carbide Cleaning}

Inspection location 11 on Sample \#2 was mechanically cleaned with 600 grit silicon carbide paper then with 320 grit aluminum oxide paper. Figure 58 is the conductivity reading at inspection site $\# 11$. This probe is less sensitive to localized surface conditions caused by cleaning and does not detect a difference between a clean surface and a surface with an oxide layer. The material is classified as stainless steel with the spot test and eddy current. 


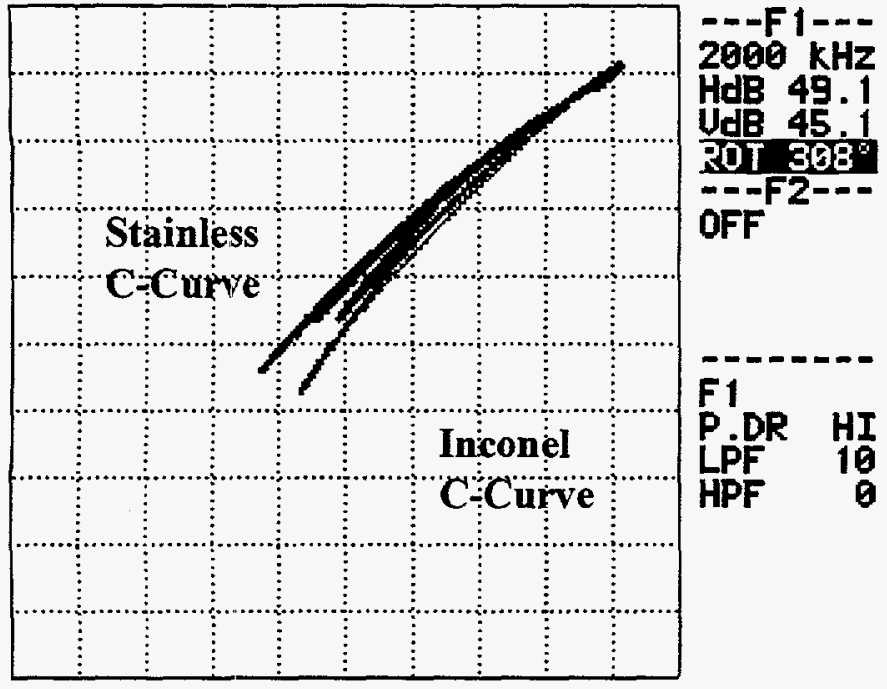

Figure 53. Inspection Site \#8 on Sample \#2 was cleaned with 320 grit aluminum oxide cloth. The material is classified as stainless steel with the spot test and eddy current. Calibration standards are also present as a reference. This site could be called inconel.

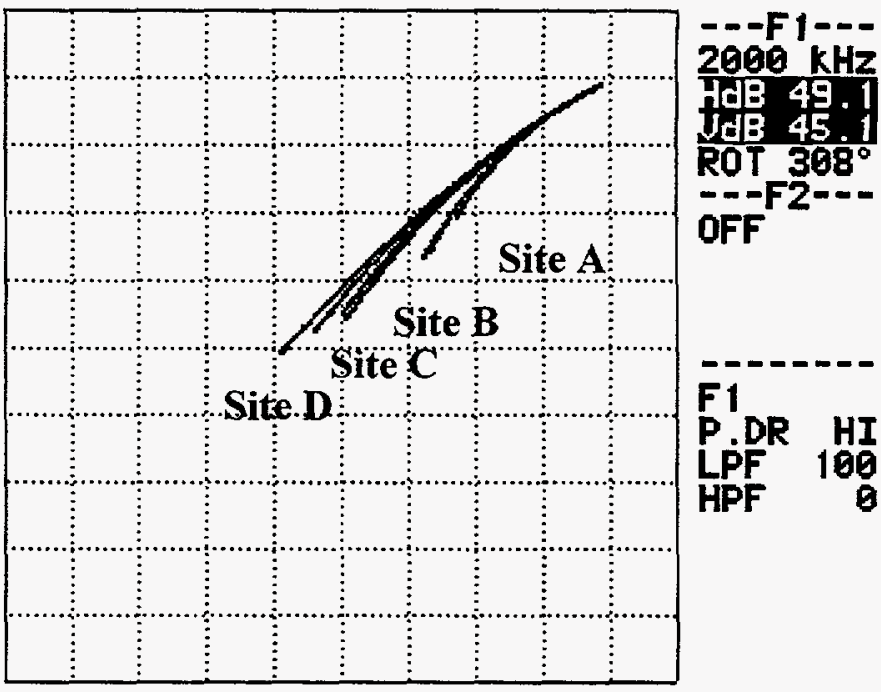

Figure 54. Inspection Site \#8-A on Sample \#2 was not cleaned and the probe was place at various points near the repair. Heat treatment occurred during the weld repair and has changed the material conductivity. Inspection points near the weld should not be considered.

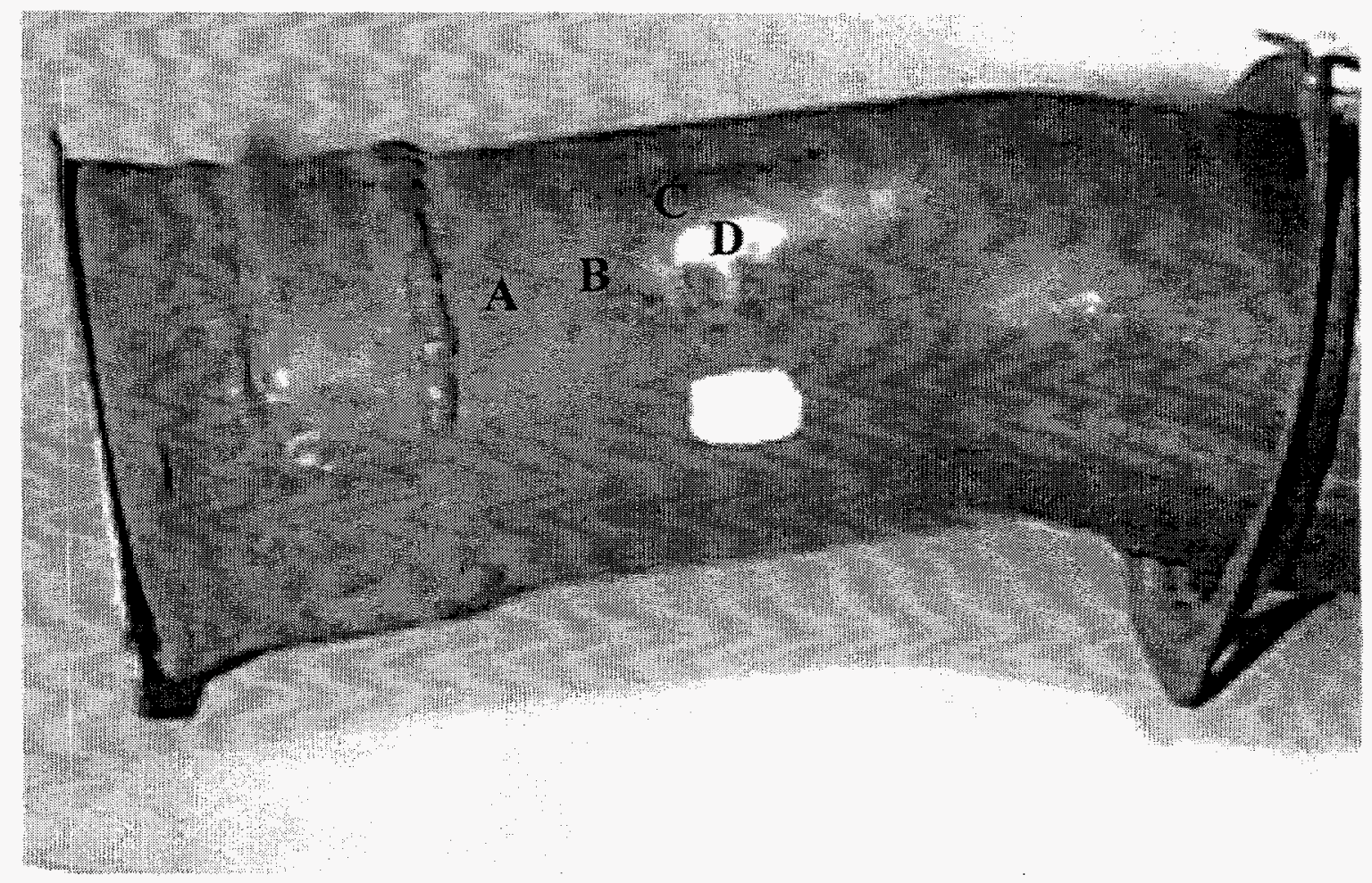

Figure 55. Photo of inspection site \#8 on Sample \#2. As the probe enters the heat affective zone the conductivity moves toward inconel. Site A could be classified as inconel. 


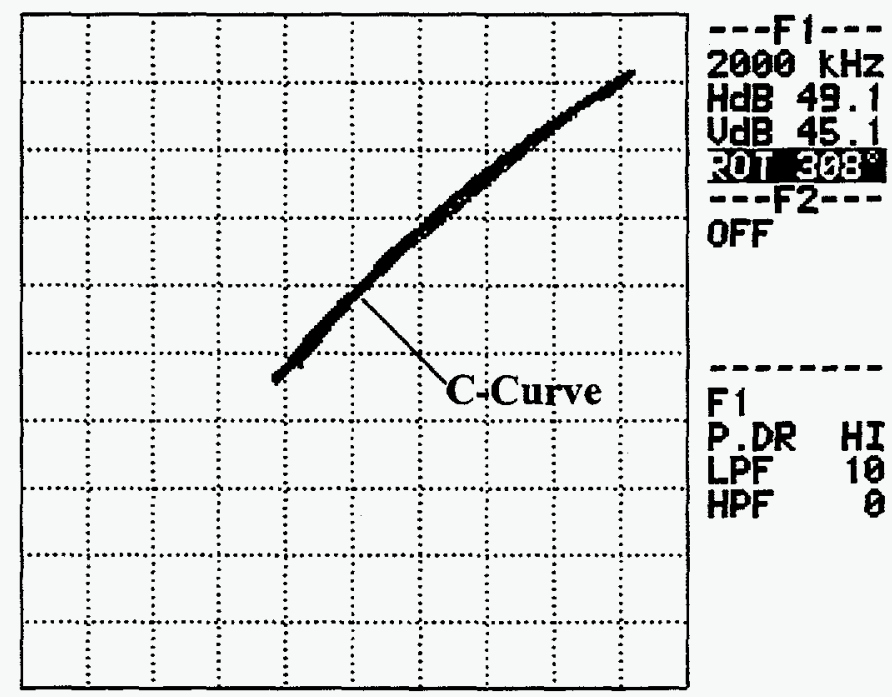

Figure 56. Inspection Site \#9 on Sample \#2 was cleaned with polymer abrasive pad the 320 grit aluminum oxide paper. The material is classified as stainless steel with the spot test and eddy current.

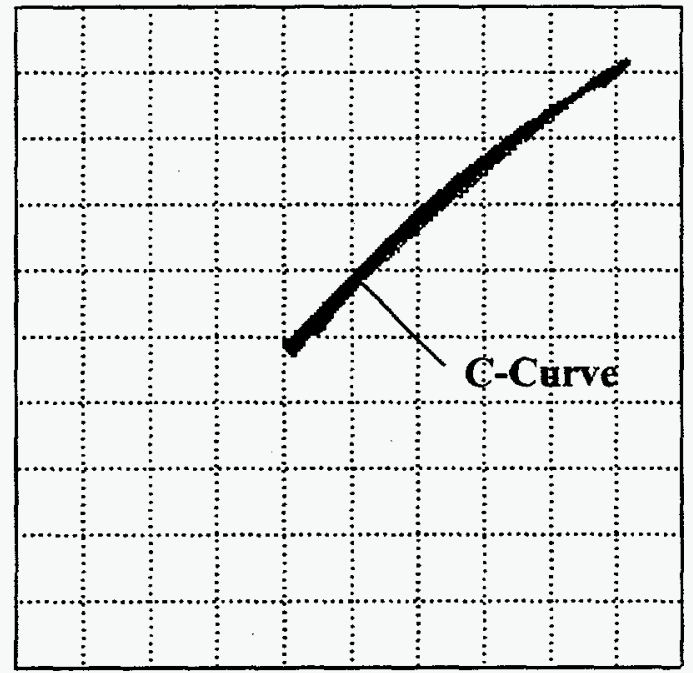

Figure 57. Inspection Site \#10 on Sample \#2 was cleaned with 400 grit silicon carbide paper then with 320 grit aluminum oxide paper. The material is classified as stainless steel with the spot test and eddy current.
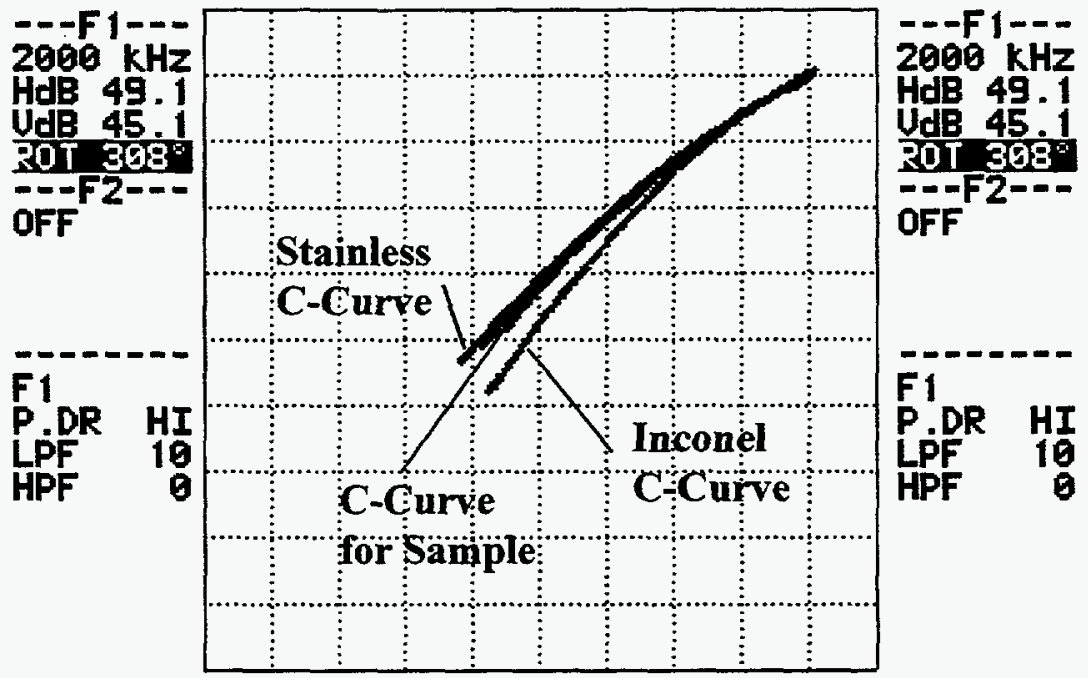

Figure 58. Inspection Site \#11 on Sample \#2 was cleaned with 600 grit silicon carbide paper then 320 grit aluminum paper. The material is classified as stainless steel with the spot test and eddy current. Calibration standards are also present as a reference. 


\section{Inspection Results Comparing the Spot Test and Eddy Current Instrument With SP2000 Absolute Unshielded 2 MHz Probe}

Each site was inspected with eddy current and the spot test. The material was classified as either stainless steel or inconel. The criteria for classifying the material using eddy current depends on the location of the curve with respect to the material standards. The criteria for classifying the material using the spot test depends on the color present on the filter paper.

Table 7. Test results for eddy current SP2000 probe and the spot test.

\begin{tabular}{|l|l|l|l|}
\hline $\begin{array}{l}\text { Inspection } \\
\text { Site }\end{array}$ & \multicolumn{2}{l}{$\begin{array}{l}\text { Cleaning } \\
\text { Technique }\end{array}$} & \multicolumn{2}{l|}{$\begin{array}{l}\text { Eddy Current } \\
\text { Call }\end{array}$} \\
& \multicolumn{2}{l|}{$\begin{array}{l}\text { Spot Test } \\
\text { Call }\end{array}$} \\
\hline 1 & Polymer Pad & Stainless Steel & Stainless Steel \\
\hline 2 & 600 Grit Silicon Carbide & Stainless Steel & Stainless Steel \\
\hline 3 & 400 Grit Silicon Carbide & Stainless Steel & Stainless Steel \\
\hline 4 & Polymer Pad & Stainless Steel & Stainless Steel \\
\hline 5 & 320 Aluminum Oxide Cloth & Stainless Steel & Stainless Steel \\
\hline 6 & 320 Aluminum Oxide Paper & Stainless Steel & Stainless Steel \\
\hline 7 & Polymer Pad & Stainless Steel & Stainless Steel \\
\hline 8 & 320 Aluminum Oxide Cloth & Stainless Steel* & Stainless Steel \\
\hline 9 & Polymer Pad & Stainless Steel & Stainless Steel \\
\hline 10 & 400 Grit Silicon Carbide & Stainless Steel & Stainless Steel \\
\hline 11 & 600 Grit Silicon Carbide & Stainless Steel & Stainless Steel \\
\hline 12 & Polymer Pad & Stainless Steel & Stainless Steel \\
\hline 13 & 320 Aluminum Oxide Cloth & Stainless Steel & Stainless Steel \\
\hline 14 & 3.20 Aluminum Oxide Paper & Stainless Steel & Stainless Steel \\
\hline
\end{tabular}

Note:

* Inspection site \#8 on Sample \#2 is classified as stainless steel however, the weld repair heat effective zone can lead an inspector to assume it is inconel. A statement in the inspection procedure must clearly note this inspection condition. 


\section{Field Survey at Heliarc Welding}

To verify that both the eddy current and spot test techniques could be used to inspect inconel exhaust parts in the field, a trip was taken to Heliarc Welding Company, Denver Colorado. Heliarc Welding refurbishes exhaust systems for general aviation. Mike Fisher was the point of contact. Mr. Fisher supplied AANC with several samples to evaluate. Both an eddy current instrument and a spot test kit were used during the field evaluation. Figure 59 displays the spot test results on the stainless steel (a) and inconel (b) coupons supplied with the test kit. Each sample was inspected with the SP2000 absolute unshielded probe operating at $2 \mathrm{MHz}$. The first exhaust component tested was a Cessna 421 forward and aft riser. The pink color indicates the presence of high nickel content found in inconel alloys. Figure 60 displays the spot test results. Both eddy current and the spot test classified the part as inconel.

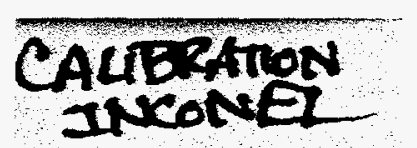

(a)

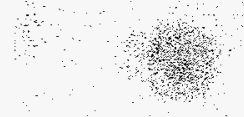

\section{CACIBRA TION
SS.}

Figure 59. Spot test results on the two test coupons from the kit. The pink color indicates the presence of high nickel content in the inconel and is used to distinguish between the two types of alloys.

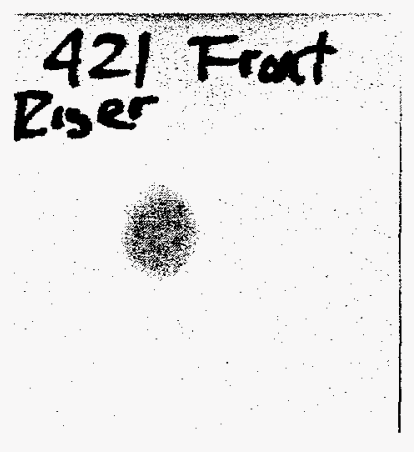

(a)

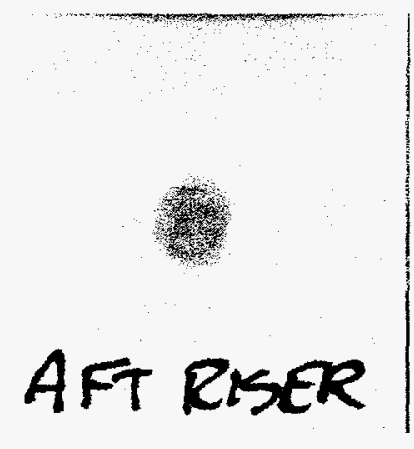

(b)

Figure 60. Spot test results on a 421 front and aft riser. The pink color indicates the presence of high nickel content in the material. Both eddy current and the spot test classified this sample as inconel. 
The second exhaust component provided by Heliarc Welding was from a Cessna 400 series aircraft. The brown color indicates the presence of low nickel content in the material. Figure 61 displays the spot test results. Both eddy current and the spot test classified the part as stainless steel. The third exhaust component was from a Cessna 421 $\mathrm{C}$ series aircraft. This sample was heavily stained on the outside of the pipe. The pink color indicates the presence of high nickel content in the material. The pink color on the filter paper is very faint by it still can be seen. Both eddy current and the spot test classified the sample as inconel. Figure 62 displays the spot test results for the heavy stain on the exhaust component. Mechanical cleaning was not conducted on this sample. If the sample were mechanically cleaned the faint pink color would appear brighter.

$$
5.5-321
$$

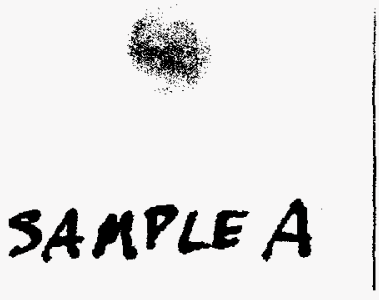

(a)

\section{SAMPLE}

(b)

Figure 61. Spot test results on a sample provided from Heliarc Welding. The brown color indicates the presence of low nickel content in the material. Both eddy current and the spot test classified this sample as stainless steel.

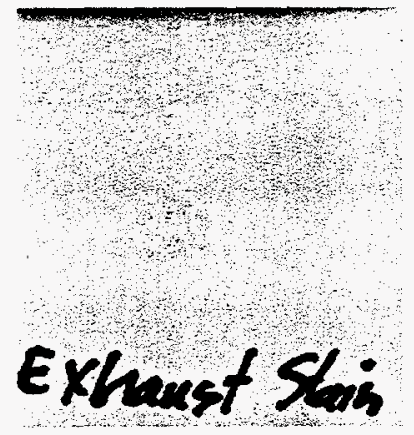

Figure 62. Spot test results on an inconel exhaust component with a stain on the outside of the pipe. The faint pink color indicates a high nickel content in the material. Both eddy current and the spot test classified the sample as inconel. 
The fourth sample was an exhaust component made of stainless steel coated with nickel. The spot test and eddy current probe were place at three different locations on the exhaust pipe. The spot test color ranged from light brown to pink/brown. Both eddy current and the spot classified the part as inconel. Since eddy current and the spot test rely on the material constituent close to the surface to take a measurement it is important to know the material history. In the case of nickel plating on stainless steel, both inspection techniques can give false calls when classifying the material. Figure 63 displays the spot test results on the fourth sample.

The vendor that produced these refurbished exhaust components no longer coats the entire surface with nickel however, all exhaust systems returned from the field should be thoroughly cleaned prior to running the eddy current sorting or electrochemical spot test to determine the alloy.

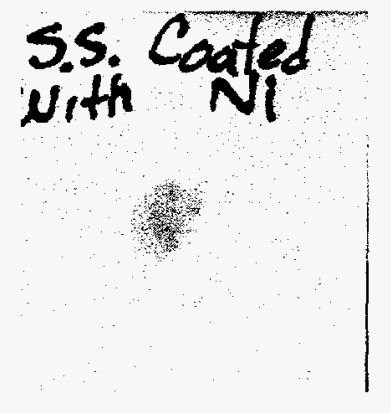

(a)
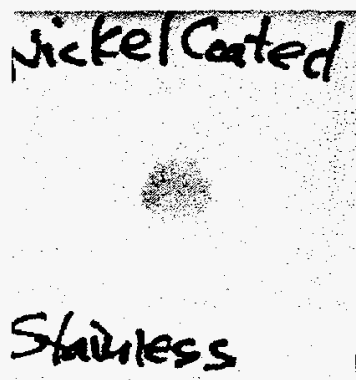

(b)

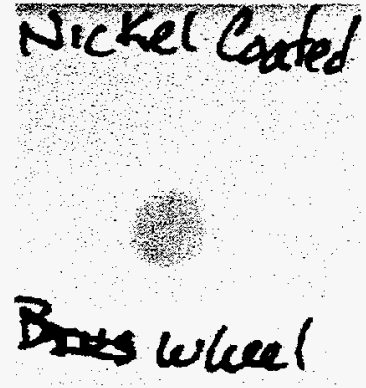

(c)

Figure 63. Spot test results on a nickel coated stainless steel exhaust component. The light brown color (a) indicates the presence of low nickel in the material. Both eddy current and the spot test classified this "clean" location as stainless steel. The pink color (b) and (c) indicates the presence of high nickel content in the material. Both eddy current and the spot test classified these locations as inconel without prior mechanical cleaning. This false call is due to the spot test sampling only on the surface of the part.

The fifth and final sample was from an internal component that directs the air into the turbo charger (Figure 64). This component was cut out of the exhaust system. The surface of the sample had some of the material removed by mechanical sand blast cleaning. Location " $A$ " represents the mechanically cleaned surface. Location " $B$ " represents a surface that is partially cleaned. Location " $C$ " represents the 'as is' surface. Heavy oxide layers still exist on the sample at locations " $B$ " and " $C$ ". The spot test and eddy current sorting was conducted at all three locations. 


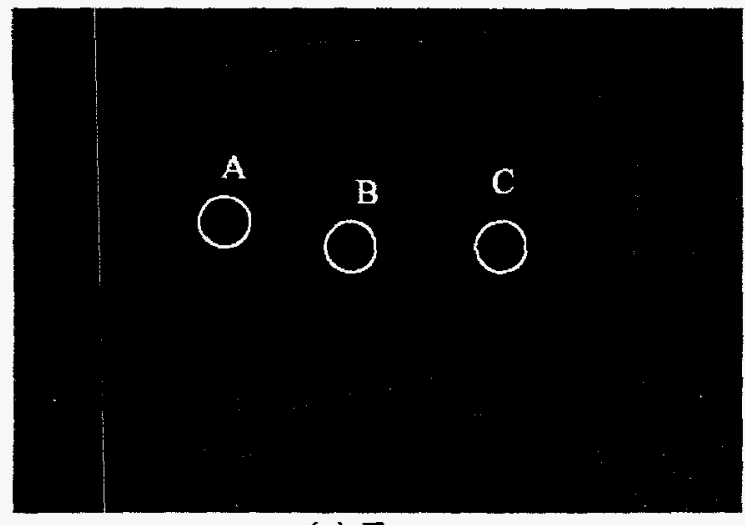

(a) Front

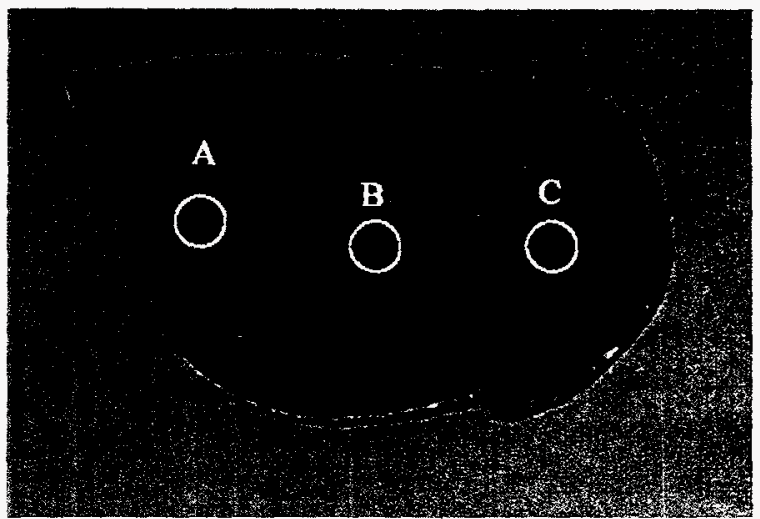

(b) Back

Figure 64. Internal exhaust component taken from the pipe which feeds air into the turbo charger. The three locations (A, B, and C) were inspected with eddy current and the spot test.

Figure 65 displays the test results for the front surface of the sample at position " $\mathrm{A}$ ". The brown color from the spot indicates the presence of low nickel content in the material and classifies the part as stainless steel. The eddy current signal displays a strong magnetic presence on the surface which skews the conductivity curve away from the stainless steel and inconel conductivity curves. Eddy current can not classify the part at this location.
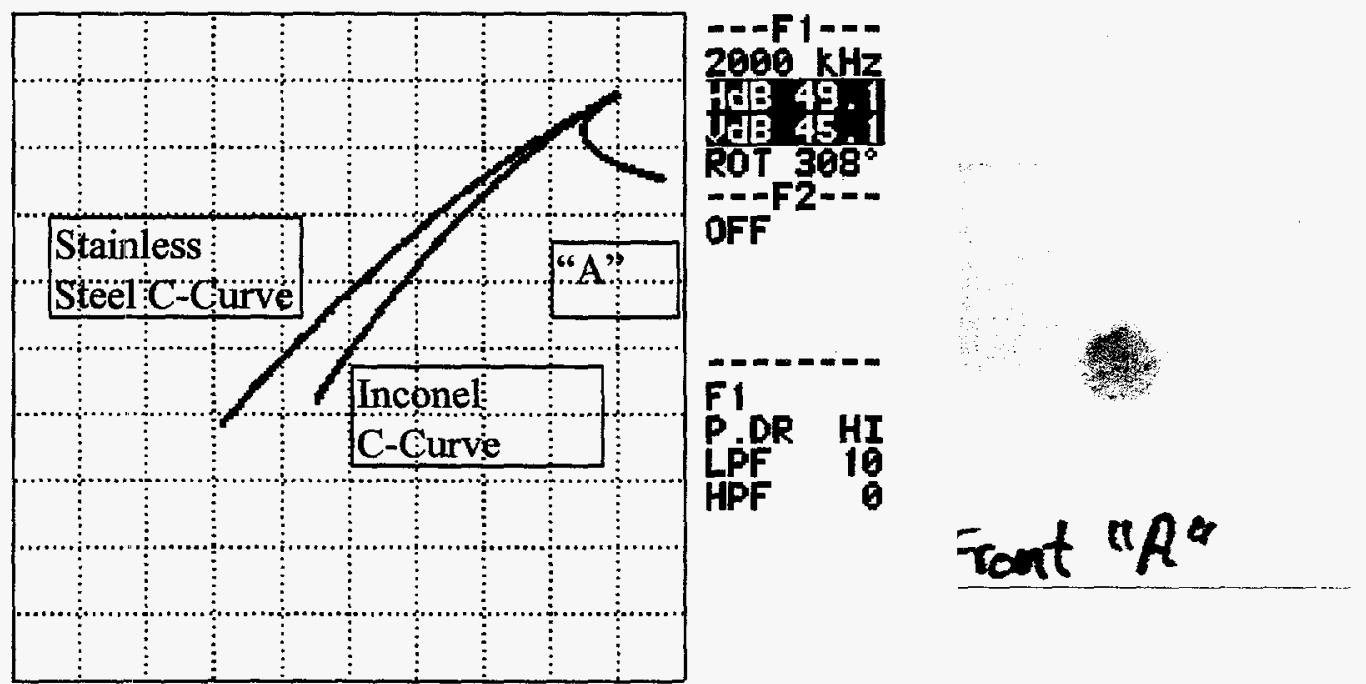

Figure 65. Displays the eddy current and spot test results on the front surface at position " $A$ ". 
Figure 66 displays the test results for the front surface of the sample at position "B". The light brown and pink color from the spot indicates the presence of medium nickel content in the material and classifies the part as inconel. The eddy current signal displays a strong presence on the surface which skews the conductivity curve away from the stainless steel and inconel conductivity curves. Eddy current can not classify the part at this location.
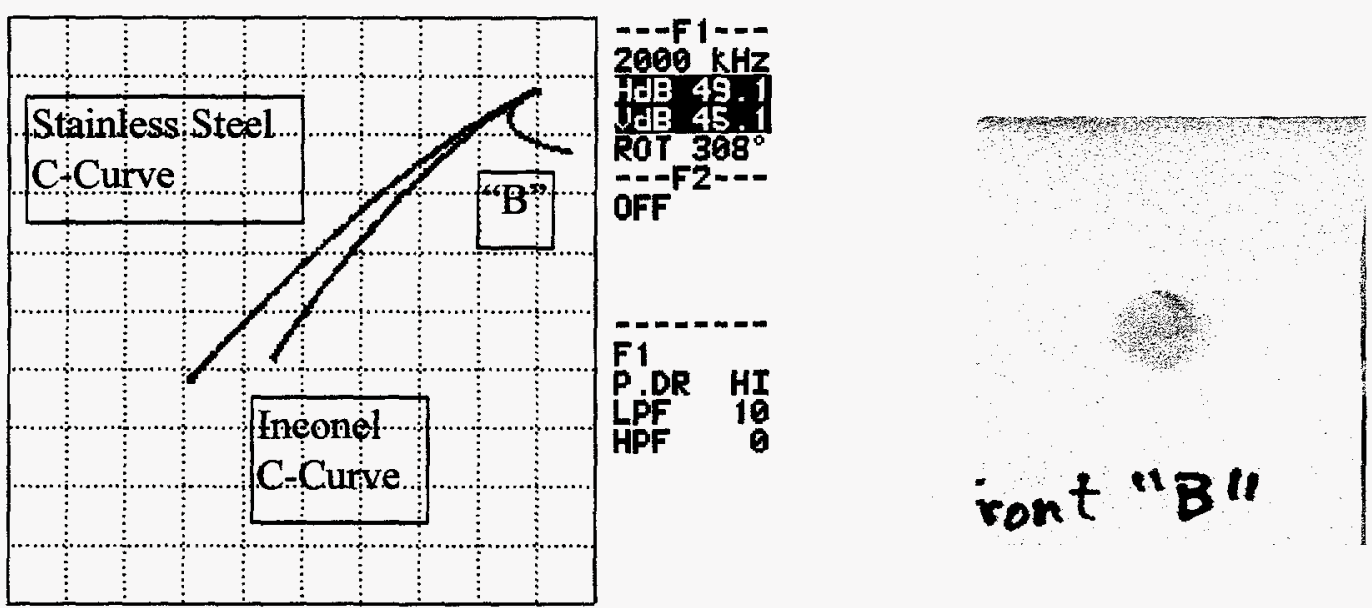

Figure 66. Displays the eddy current and spot test results on the front surface at position " $B$ ".

Figure 67 displays the test results for the front surface of the sample at position "C". The pink color from the spot indicates the presence of high nickel content in the material and classifies the part as inconel. The eddy current signal displays a strong presence on the surface which skews the conductivity curve away from the stainless steel and inconel conductivity curves. Eddy current can not classify the part at this location.
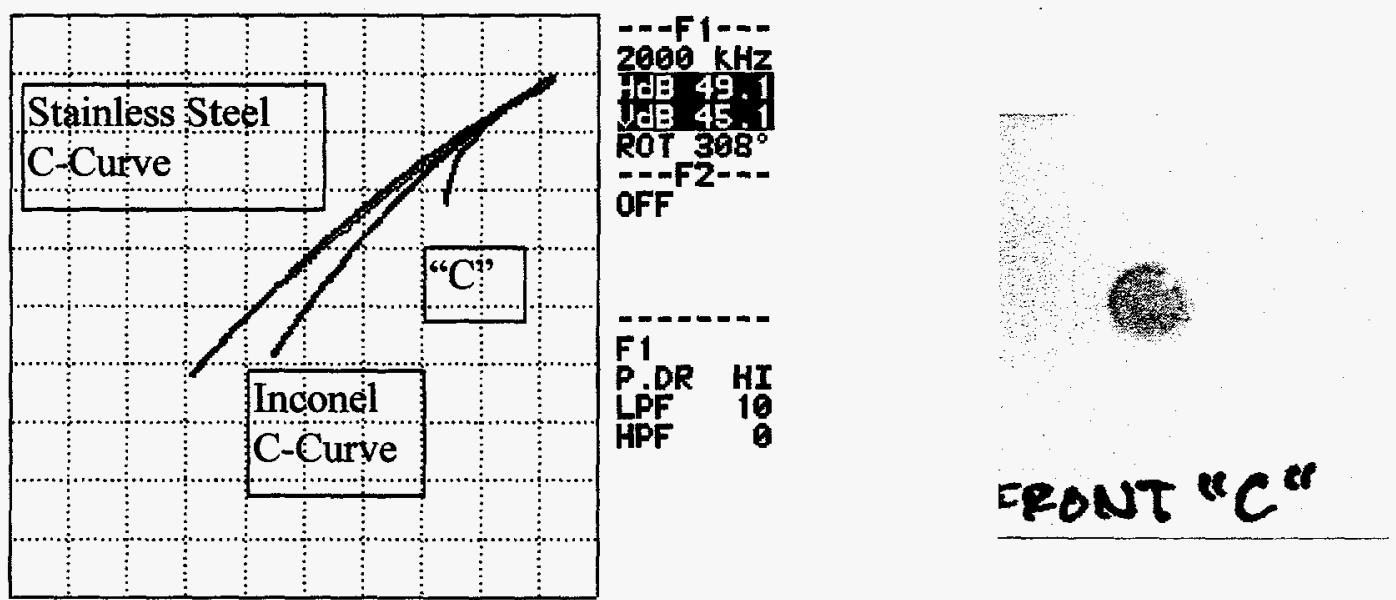

Figure 67. Displays the eddy current and spot test results on the front surface at position " $\mathrm{C}$ ". 
Figure 68 displays the test results for the back surface of the sample at position " $\mathrm{A}$ ". The brown color from the spot indicates the presence of low nickel content in the material and classifies the part as stainless steel. Eddy current classified the material as stainless steel.
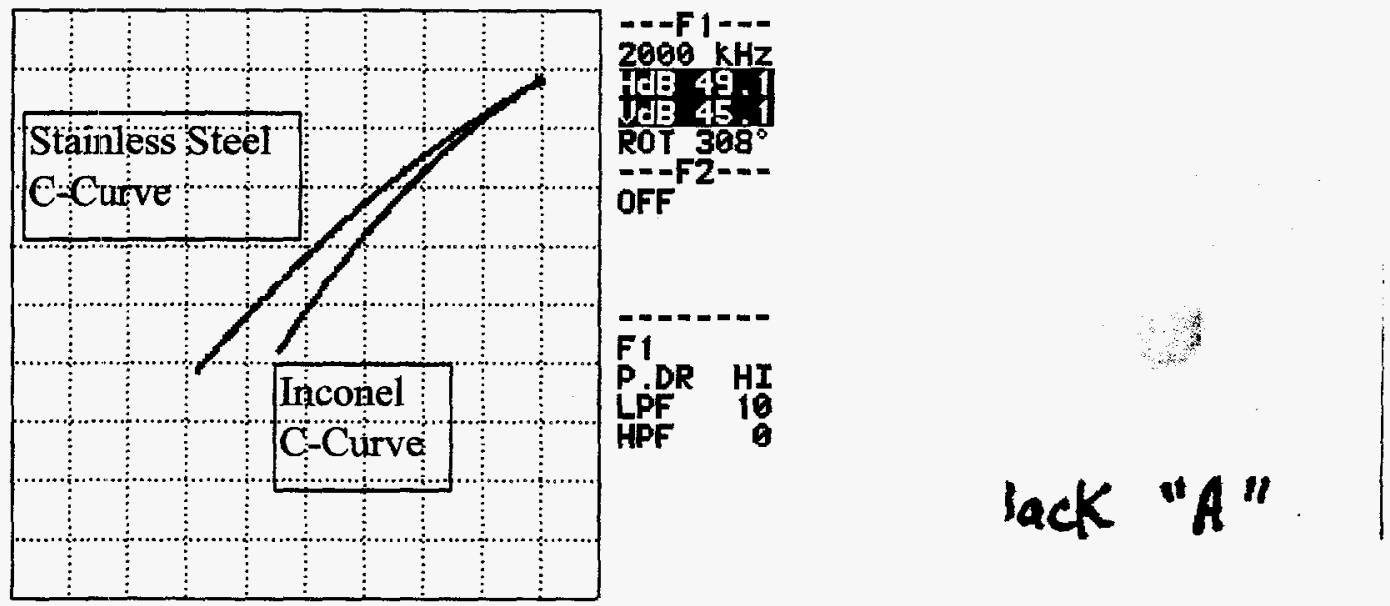

Figure 68. Displays the eddy current and spot test results on the back surface at position "A".

Figure 69 displays the test results for the back surface of the sample at position "B". The light brown and pink color from the spot indicates the presence of medium nickel content in the material and classifies the part as inconel. The eddy current signal is between the stainless steel and inconel conductivity curve. This would require an inspector to classify the material as inconel.
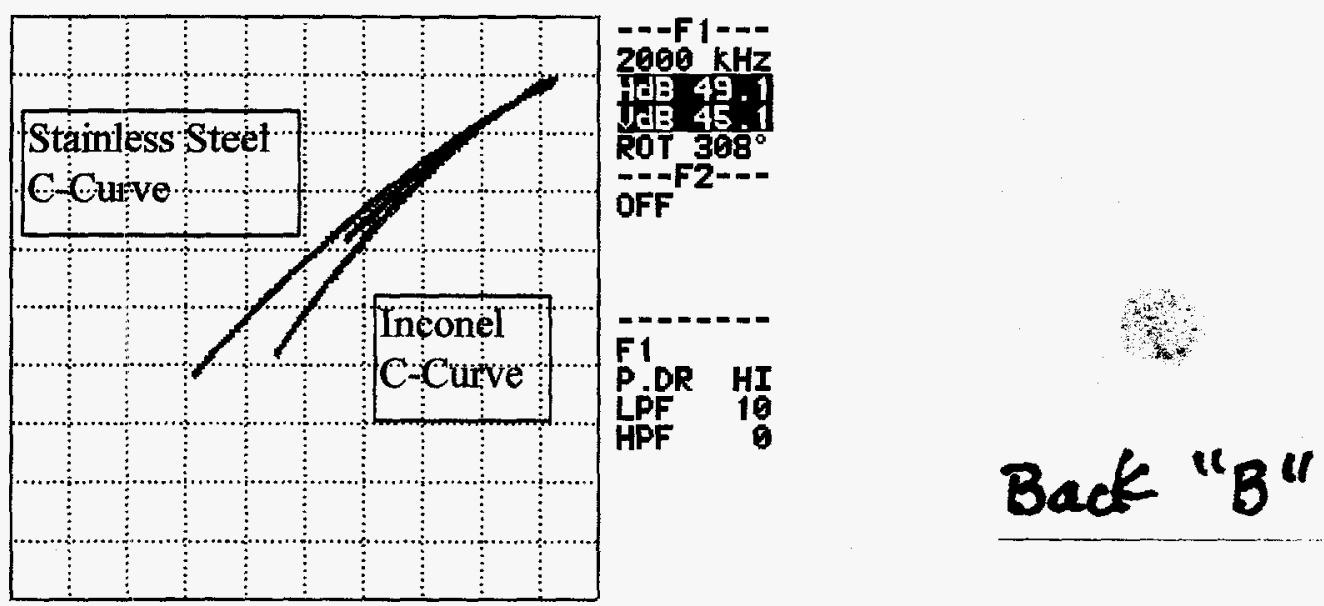

Figure 69. Displays the eddy current and spot test results on the back surface at position "A". 
Figure 70 displays the test results for the back surface of the sample at position " $\mathrm{C}$ ". The pink color from the spot indicates the presence of high nickel content in the material and classifies the part as inconel. The eddy current signal is in on the inconel conductivity curve. This would require an inspector to classify the material as inconel.
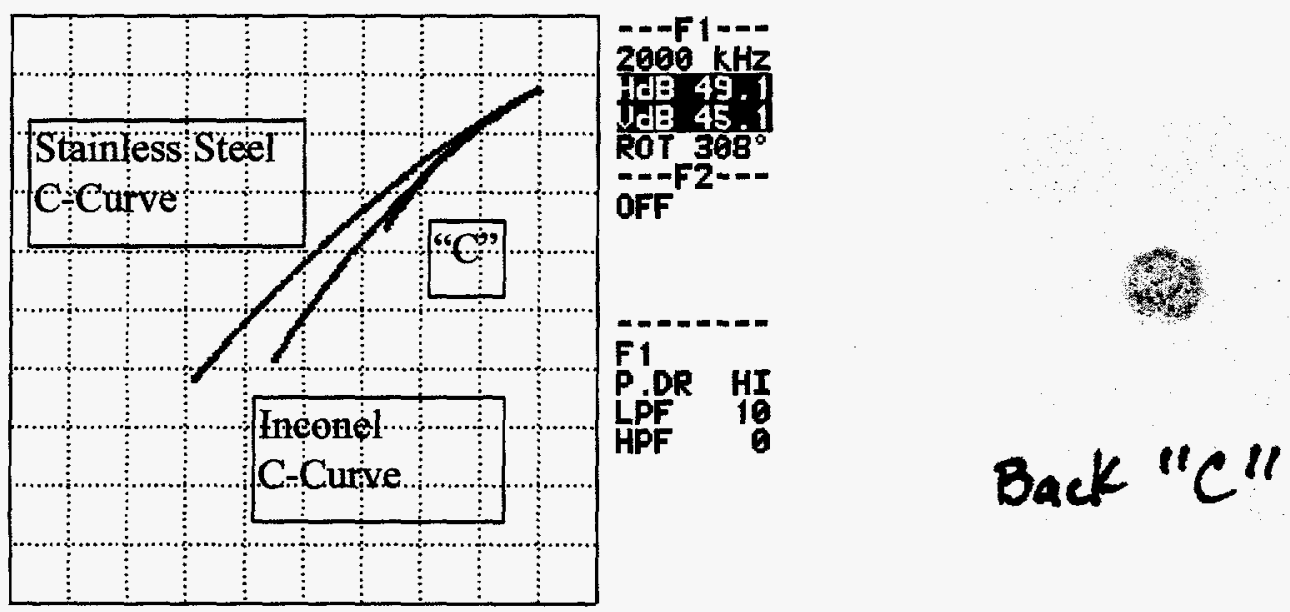

Figure 70. Displays the eddy current and spot test results on the back surface at position " $\mathrm{C}$ ". 
Thermal oxides form on both inconel and stainless steel alloys due to elevated operating temperatures. For maximum inspection effectiveness the inspection should be performed on clean, scale free metal surface. Two types of cleaning methods were attempted on the exhaust components. The first method was chemical cleaning and the second was mechanical cleaning. Following is a summary of the two cleaning techniques.

\section{Summary of Chemical Cleaning}

- Chemical cleaning was ineffective in removing the thermal oxide from any exhaust components.

- The high temperature oxide was not removed using hydrochloric, nitric and sulfuric acids.

- The high temperature oxide is very hard and durable, and is chemically resistant to the range of acids and concentration applied in the experiments.

- Oxide hardness varies from location to location and sample to sample. The oxide hardness may be a function of oxide thickness.

\section{Summary of Mechanical Cleaning}

- Mechanical cleaning can produce a bare metal surface under the appropriate conditions.

- Aluminum oxide is the most effective method of removing the high temperature oxide without damaging the underlying metal surface.

- The abrasive must be at least 320 grit to remove the thermal oxide. A 320 grit cloth did remove the oxide, however significant effort was required.

- When thick oxides are encountered, considerate pressure must be applied to remove the oxide. It did not appear to damage the metal nor were large amounts of oxide removed.

- The polymer pad was able to remove the oxide with significant effort. However, these pads are not classified as extensively as the abrasive papers, so the actual roughness (grit size) of these pads is unknown.

- The 400 and 600 grit silicon carbide paper only burnished the exhaust component surface and did not remove the oxide layer. If significant pressure was used, the silicon carbide had a better change of removing the oxide layer. Additional cleaning at 400 and 600 grit silicon carbide paper sites with 320 grit aluminum oxide paper helped remove the oxide layer and produced correct results. 
Each fourteen inspection sites on the exhaust components were inspected by placing an eddy current probe and aluminum electrode on the surface. Following is a summary of the two inspection of the two inspection techniques.

\section{Summary of the Spot Test}

- The spot test is simple to run and appears to be effective in distinguishing stainless steel from inconel.

- The LED provides positive indication that the circuit is functioning correctly.

- The solutions used are quite benign and pose no threat to personnel or equipment.

- If nickel plated stainless steel parts are encountered, the spot test and eddy current will give a false call as it samples only the surface of the part.

\section{Summary of Eddy Current Conductivity Sorting}

- Eddy current measurements are influenced by heat treatment of the metal. Heat affect zones caused by welding give inaccurate test results.

- The thermal oxide layer at two locations caused the $1 \mathrm{Mhz}$ absolute shielded pencil probe to skew away from the stainless steel and toward the inconel conductivity curve thus creating a false call.

- When using the absolute unshielded $2 \mathrm{Mhz} 0.750$ inch diameter probe did not have trouble separating stainless steel and inconel alloys.

- The small diameter absolute shielded pencil probe eddy current measurements can be influenced by the curved surface of the part.

- Variation in conductivity readings were observed when the surface had heavily deposited thermal oxide layers.

- Conductivity readings should be taken at room temperature and not while the exhaust components are hot.

- The operation frequency to get constant reliable results is above $1 \mathrm{MHz}$. The separation angle for stainless steel is large and allows lift off suppression and good sensitivity to conductivity readings between stainless steel and inconel.

- The large diameter unshielded eddy current probe is less sensitive to localized surface conditions caused by mechanical cleaning and does not detect a difference between a clean surface and a surface with an oxide layer. 


\section{Comparison Between Spot Test and Eddy Current}

- Both eddy current and the spot test classified the exhaust sections as stainless steel when cleaned with a polymer pad. If an oxide layer is present the pencil probe is sensitive to small variations and skews the conductivity curve towards inconel.

- Eddy current readings should not be taken near welded joints or the heat affected zone of a weld repair.

- Thick oxide layers that were not removed using the polymer abrasive pad produced a false call with eddy current but not with the spot test.

- The small diameter eddy current probe is not adequate to use on inspection sites that have not been cleaned thoroughly. Oxide layers still present on the sample create false calls with eddy current.

- The large diameter eddy current probe is not affected by inspection sites that have oxide layer and do not detect a difference between the two.

\section{Summary of Field Survey at Heliarc Welding}

- The spot test was able to detect the presence of high nickel content in the inconel exhaust components and therefore, identifying correctly. The spot test was able to detect the presence of low nickel content in the stainless steel exhaust components and therefore, identifying the correctly.

- The spot test and eddy current ( $2 \mathrm{MHz}, 0.750$ inch diameter probe) were able to identify an inconel exhaust component through a stain on the outside surface. If the exhaust component were mechanically cleaned, the faint pink color on the filter would be a bright pink .

- The spot test and eddy current was not able to identify a stainless steel exhaust component coated with nickel correctly. Since both eddy current and the spot test rely on the material constituent close to the surface to take a measurement, nickel plating stainless steel can give false calls.

- Eddy current could not correctly identify a material through a thick oxide coating. 


\section{Conclusions}

Based on the experiments conducted, the electrochemical spot test was the optimum inspection method for distinguishing inconel and stainless steel alloys. The method can be employed in the field with little or no interruption to normal daily operations. The key to implementing this electrochemical spot test is to overcome the thermal oxide surface contamination due to exhaust gases. This is accomplished by thoroughly cleaning the surface of the part with 320 grit aluminum oxide abrasive paper. 


\section{References}

1. 1990 Annual Book of American Society for Metals, Volume 03.02, American Society for Metals, 1990.

2. Metals Handbook, Ninth Edition, Volume 5, Surface Cleaning Finishing, and Coating, American Society for Metals, 1982, p. 73.

3. Nondestructive Testing Handbook, Second Edition, Volume 4, Electromagnetic Testing, American Society for Nondestructive Testing, 1986, pp. 26 - 88. 
Appendix A

AC 65-9A Draft Revision 


\section{DRAFT}

Subject: AIRFRAME \& POWERPLANT MECHANICS - General Handbook Date: $10 / 7 / 97$

AC No. $65-9$ A Change: 1

1. PURPOSE. This change deletes the "spot test" procedure for distinguishing between Inconel and stainless steel and replaces it with an "electrochemical" procedure.

2. PRINCIPAL CHANGE. Delete the "spot test" procedure using cupric chloride and hydrochloric acid to distinguish Inconel from stainless steel (lines 6 through 22 in the left column of page 197). In its place, substitute the following:

Inconel is a nickel-chromium-iron alloy closely resembling stainless steel (corrosion resistant steel, CRES) in appearance. Both alloys are used interchangeably in aircraft exhaust systems. Because the two alloys look very much alike, a distinguishing test is often necessary. One method of identification is to use an electrochemical technique to identify the nickel (Ni) content of the alloy. Inconel has a nickel content greater than 50 $\%$. The electrochemical test is designed to detect $\mathrm{Ni}$.

Prepare a wiring assembly as shown in Figure 1 and prepare the two reagents (ammonium fluoride and dimethylglyoxime solutions) placing them in separate dedicated dropper solution bottles. Before testing, the metal must be thoroughly cleaned in order for the electrolytic deposition to take place. Non-metallic hand scrubbing pads or 320 to 600 grit crocus cloth may be used to remove deposits and corrosion products (thermal oxide).

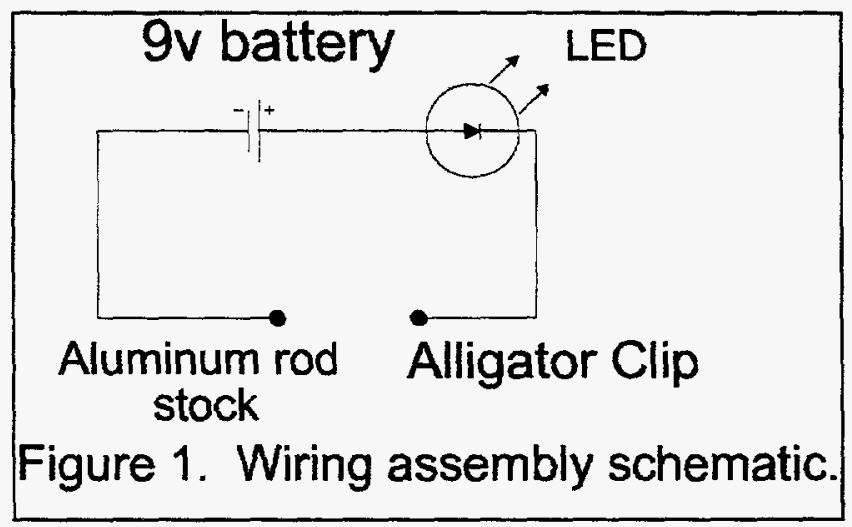

Connect the alligator clip of the wiring assembly to the bare metal being tested. Place one drop of a $0.05 \%$ reagent grade ammonium fluoride solution in deionized water on the center of a (1 inch $\times 1$ inch) sheet of filter paper. Lay the moistened filter paper over the bare metal alloy being tested. Firmly press the end of the aluminum rod over the center of the moist paper. Maintain connection for 10 seconds while rocking the aluminum rod 


\section{DRAFT}

on the filter paper. Ensure that the light emitting diode (LED) remains lit (indicating good electrical contact and current flow) during this period. Disconnect the wiring assembly and set it aside. Remove the filter paper and examine it to determine that a light spot appears where the connection was made.

Deposit one drop of $1.0 \%$ solution of reagent grade dimethylglyoxime in ethyl alcohol on the filter paper (same side that was in contact with the test metal). A bright distinctly pink spot will appear within seconds on the filter paper if the metal being tested is Inconel. A brown spot will appear if the test metal is stainless steel. Some stainless steel alloys may leave a very light pink color. However, the shade and depth of color will be far less than would appear for Inconel. For flat surfaces the test spot will be circular while for curved surfaces, such as the outside of a tube or pipe, the test spot may appear as a streak. See Figure 2 for sample test results. This procedure should not be used in the heat affected zone of weldments and on nickel coated surfaces.

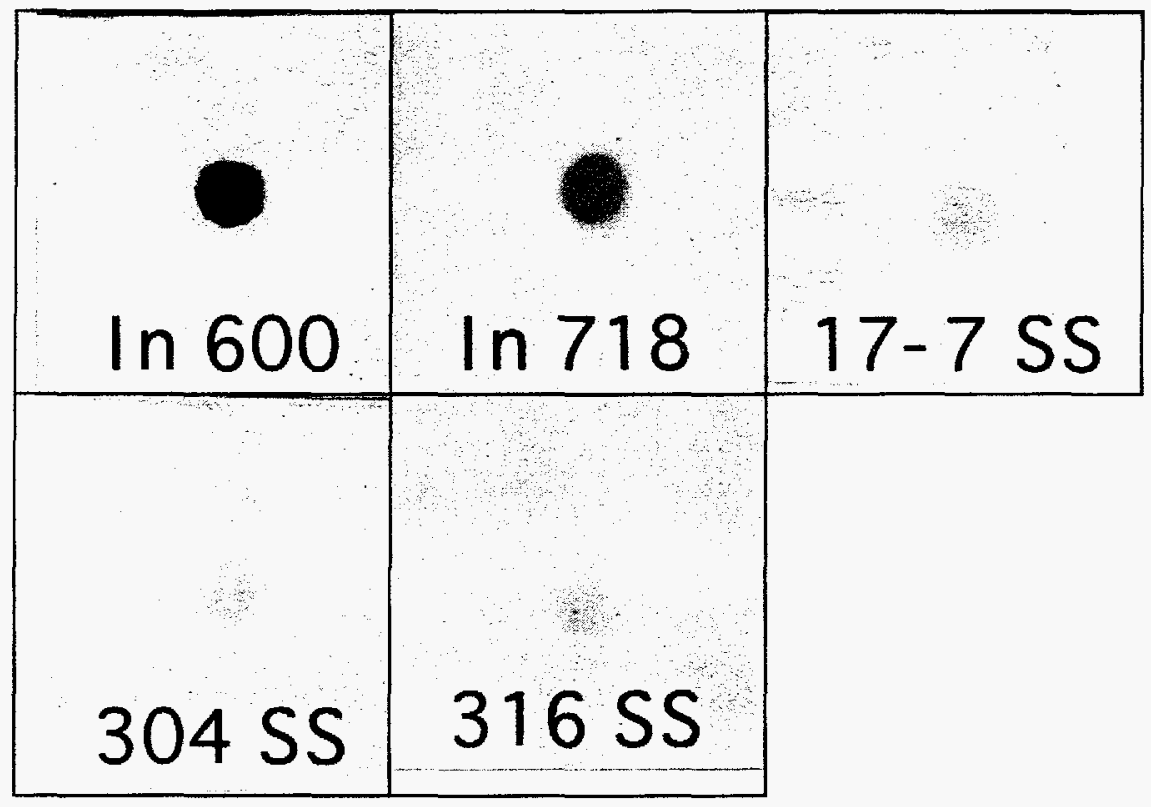

Figure 2. Electrochemical Test Results, Inconel and Stainless Steel Alloys. 
This Page Left Intentionally Blank 
DISTRIBUTION:

1 Nick Anderson

Section Chief, Airworthiness

Cessna Aircraft Company

P. O. Box 7704

Wichita, KS 67277-7704

1 Tom Corsentino

Wall Clomonoy Corp.

4700 S. E. $59^{\text {th }}$ Street

Oklahoma City, OK 73135

3 DOT/FAA

Engine and Propeller Directorate

Attn: A. L. Broz, ANE-105N

12 New England Exec. Pk.

Burlington, MA 01803

1 DOT/FAA

Northwest Mountain Region

Attn: Dorenda Baker ANM-109

1601 Lind Ave. S. W.

Renton, WA 98055-4056

2 FAA Flight Standards

Attn: Fred Sobeck, AFS-330D

Dave Hempe, AIR-100

800 Independence Ave. SW

Washington, DC 20591

10 FAA Hughes Technical Center Aging Aircraft Program

Attn: Dave Galella, AAR-433

Chris Smith, AAR-433

5 FAA Airworthiness Program AFS-610

Attn: Jess Lewis

6500 South MacArthur

Oklahoma City, OK 73169

3 Mike Fischer

Heliarc Welding Service

3965 Newport Street

Denver, CO 80207
1 FAA Central Region

Small Airplane Directorate

Attn: Bob W. Sexton, ACE-102

601 East $12^{\text {th }}$ Street

Kansas City, MO 64106

3 Jim Gilleeny

Systems Scientific Laboratories, Inc.

1295 Boulevard Way

Walnut Creek, CA 94595

3 Iowa State University

FAA Center for Aviation Systems Reliability

Attn: William Shurtleff

Lisa Brasche

Applied Sciences Complex II

1915 Scholl Road

Ames, IA 50011

3 George A. Matzkanin

NDI Testing \& Analysis Center

415 Crystal Creek Drive

Austin, TX 78746

5 Paul O. Penleton

Federal Aviation Administration

Wichita Aircraft Certification

Office ACE-116W

Mid-Continent Airport

1801 Airport Road, Room 100

Wichita, KS 67209

1 David Lotterer

Regional Airline Association

$120019^{\text {th }}$ Street NW Suite 300

Washington, DC 20036

3 Anthony R. Saxton

Manager Technical Support

The Twin Cessna Flyer

c/o TAS Aviation

P. O. Box 860

Defiance, $\mathrm{OH} 43512$ 
1 MS1435 Dan E. Arvizu, 1800

1 MS0340 Wendy R. Cieslak, 1832

20 MS0340 N. Rob Sorensen, 1832

1 MS0469 Kathleen McCaughey, 9700

1 MS0615 Richard Perry, 9752

1 MS0615 Mike Ashbaugh, 9752

1 MS0615 Larry Dorrell, 9752

1 MS0615 John Gieske, 9752

1 MS0615 Ken Harmon, 9752

1 MS0615 Craig Jones, 9752

20 MS0615 David Moore, 9752

1 MS0615 Dennis Roach, 9752

1 MS0829 Floyd Spencer, 12323

1 MS0615 Gerry Stoker, 9752

1 MS0615 Mike Valley, 9752

1 MS0615 Phil Walkington, 9752

1 MS9018 Central Technical Files, 8940-2

2 MS0899 Technical Library, 4916

2 MS0619 Review \& Approval Desk, 12690 For DOE/OTSI 